NBER WORKING PAPER SERIES

\title{
GRANULAR CREDIT RISK
}

\author{
Sigurd Galaasen \\ Rustam Jamilov \\ Ragnar Juelsrud \\ Hélène Rey \\ Working Paper 27994 \\ http://www.nber.org/papers/w27994 \\ NATIONAL BUREAU OF ECONOMIC RESEARCH \\ 1050 Massachusetts Avenue \\ Cambridge, MA 02138 \\ October 2020, Revised December 2021
}

The views expressed are those of the authors and do not necessarily reflect those of Norges Bank, the Haut Conseil de Stabilite Financière, or the National Bureau of Economic Research. We thank our discussants Sebastian Doerr, Ralph Koijen, José-Luis Peydró and Daniel Paravisini as well as Christoph Basten, Svetlana Bryzgalova, Andreas Fagereng, Julian di Giovanni, Francisco Gomes, Refet Gürkaynak, Victoria Ivashina, Joseba Martinez, Atif Mian, Steven Ongena, Elias Papaioannou, Anna Pavlova, Kasper Roszbach, Stephen Schaefer, Vania Stavrakeva, Kjetil Storesletten, Paolo Surico, Anette Vissing-Jorgensen, Gianluca Violante and seminar participants at the NBER SI 2021 Risks of Financial Institutions meeting, CEPR/ERC/LBS Conference on Granularity and Applications, 10th MoFiR Workshop on Banking, AFA 2021, EEA 2020, SNDE 2020, WEAI 2020, LBS, Norges Bank, Nordea Bank, Banco Central De Chile, Oslo Macro Group, Statistics Norway and the University of Zurich for valuable comments and suggestions. We thank Mikkel Riiser for excellent research assistance. Rey is very grateful to the ERC (Advanced Grant 695722). All errors are our own.

NBER working papers are circulated for discussion and comment purposes. They have not been peer-reviewed or been subject to the review by the NBER Board of Directors that accompanies official NBER publications.

(C) 2020 by Sigurd Galaasen, Rustam Jamilov, Ragnar Juelsrud, and Hélène Rey. All rights reserved. Short sections of text, not to exceed two paragraphs, may be quoted without explicit permission provided that full credit, including $\odot$ notice, is given to the source. 
Granular Credit Risk

Sigurd Galaasen, Rustam Jamilov, Ragnar Juelsrud, and Hélène Rey

NBER Working Paper No. 27994

October 2020, Revised December 2021

JEL No. E3,G2

\section{$\underline{\text { ABSTRACT }}$}

What is the impact of granular credit risk on banks and on the economy? We provide the first causal identification of single-name counterparty exposure risk in bank portfolios by applying a new empirical approach on an administrative matched bank-firm dataset from Norway. Exploiting the fat tail properties of the loan share distribution we use a Gabaix and Ko1/4en (2020, 2021) granular instrumental variable strategy to show that idiosyncratic borrower risk survives aggregation in banks portfolios. We also find that this granular credit risk spills over from affected banks to firms, decreases investment, and increases the probability of default of nongranular borrowers, thereby sizably affecting the macroeconomy.

Sigurd Galaasen

Norges Bank

Postboks 1179 Sentrum

0107 Oslo

Norway

sigurd.galaasen@gmail.com

Rustam Jamilov

All Souls College

Oxford University

Oxford OX1 4AL

United Kingdom

jamilovrustam@gmail.com

\author{
Ragnar Juelsrud \\ Norges Bank \\ Postboks 1179 Sentrum \\ 0107 Oslo \\ Norway \\ ragnar@juelsrud.no \\ Hélène Rey \\ London Business School \\ Regents Park \\ London NW1 4SA \\ United Kingdom \\ and CEPR \\ and also NBER \\ hrey@london.edu
}




\section{Introduction}

What is the impact of idiosyncratic borrower risk on banks and the economy? It has been understood for years that if individual loans are small enough relative to the overall size of the portfolio then credit risk pooling should achieve perfect insurability against idiosyncratic shocks (Diamond, 1984). But what if some loans are large? What if the distribution of loan sizes is fat-tailed: can the performance of a single large loan directly affect portfolio-level outcomes and lending? A rapidly growing literature, originating from the seminal contribution by Gabaix (2011), has emphasized the micro - or "granular" - origins of macroeconomic outcomes in a variety of theoretical and applied contexts. According to the granular hypothesis, shocks to large, nonatomistic agents generate non-diversifiable "grains" of economic and financial activity, which can directly affect aggregate fluctuations and, via general equilibrium effects, all other agents.

Curiously, there are few empirical applications of the granular hypothesis to banking. This is puzzling because in practice the hypothesis maps directly into the "large exposure regulation" of the Basel Committee on Banking Supervision (BCBS). The BCBS has been regulating bank credit concentration risk for decades, formally at least since the Basel I Accords. The Core Principles for Effective Banking Supervision emphasize that local country laws should "set prudent limits on large exposures to a single borrower" (BIS, 2013). In practice however, the Principles admit that "material differences in scope of application, the value of large exposure limits, methods for calculating exposure values, and more lenient treatments for certain types of exposures exist". As a result, the document concludes, "although a concentration risk adjustment could be made to mitigate these risks, these adjustments are neither harmonised across jurisdictions, nor designed to control traumatic losses from a single counter-party default".

This paper is the first to provide causal empirical evidence on the importance and implications of "single-name" credit concentration risk". We develop a new empirical approach and apply it to a novel administrative firm-bank matched dataset from Norway ${ }^{2}$. We merge our loan-level administrative database with firm and bank balance sheet data. We cover every single bank loan made to limited liability companies (LLC) in Norway over the 2003-2015 period ${ }^{3}$. This data-rich environment enables us to study the transmission mechanism and heterogeneous treatment effects at many levels of aggregation.

Our empirical strategy consists of five steps. First, we establish that the distribution of loan

\footnotetext{
${ }^{1}$ We follow the BCBS vocabulary where "single-name"refers to the level of an individual borrower or counterparty. This is in contrast, for example, to how BCBS defines and treats sectoral or geographical exposures where the unit of analysis is either a whole industry or region.

${ }^{2}$ Throughout the paper we focus on corporate clients and loans. Our empirical approach however, is general and flexible enough to be applied to other borrower types such as households, state institutions, or other intermediaries.

${ }^{3} \mathrm{LLC}$ is by far the most commonly used organizational structure in Norway. For most years, our firm data accounts for more than $90 \%$ of total employment in the private sector.
} 
shares in our dataset is fat-tailed. Our estimate of the Pareto power implies that $80 \%$ of all credit is concentrated in $20 \%$ of the loans. Interestingly, we provide therefore another example of the famous "80-20" Pareto principle that occurs in a variety of settings in economics as well as more generally in social and physical sciences (Gabaix, 2009).

Second, we construct a measure of idiosyncratic borrower risk. We use data on firm balance sheets and income statements to estimate idiosyncratic value-added shocks for the universe of all LLC firm $\times$ years in Norway over 2003-2015. We extract non-systematic variation in firm valueadded by controlling for a variety of balance sheet items like firm size and costs as well as firm, industry, year, and geographical fixed effects. Our approach follows very closely a large literature in labor economics and macroeconomics (Guiso et al., 2005; Hsieh and Klenow, 2009; Fagereng et al., 2018) ${ }^{4}$. An example of such an idiosyncratic shock in our sample is the closure of the main waste management facility of the company Hera Vekst by the authorities because of "smell far in excess of what the local population should tolerate" (nrk.no, 2011).

Third, we establish the pass-through from these idiosyncratic firm shocks to loan-level returns. ${ }^{5}$ We investigate how such shocks affect returns on loans within the same bank, industry, county, year, and loan type. ${ }^{6}$ Importantly, our specification controls for time-varying confounding bank-side supply factors, potentially specific to a given industry, county, or contractual type. ${ }^{7}$ We find that idiosyncratic firm shocks have a strong effect on loan returns. In our preferred specification with a full set of controls and fixed effects, a one standard deviation negative firm shock causes annual loan-level returns to fall by 36 basis points. We explore numerous dimensions of heterogeneity, including firm characteristics, geographical location, ownership, and sector.

Fourth, we look at the impact of idiosyncratic borrower shocks on banks' portfolio-level outcomes. This is a critical step in our analysis. Once aggregated to the level of a bank, we potentially

${ }^{4}$ We perform a variety of validation and robustness checks to discipline our measure. First, we run a series of factor analysis exercises whereby we explicitly extract parametric and nonparametric common factors. Second, we establish that shocks are not cross-sectionally correlated or persistent across time. Third, we run several placebo permutation tests. Fourth, we show that these shocks only have contemporaneous and lead effects on loan and bank outcomes, i.e. that there are no "pre-trends". Finally, we validate our measure with a narrative-based approach by matching realizations in the bottom percentile of the shock distribution to actual news stories from Norwegian media.

${ }^{5}$ This step constitutes one of the key ways in which we differ from the contribution by Amiti and Weinstein (2018). Amiti and Weinstein (2018) provide a decomposition of investment growth in Japan into idiosyncratic bank $\mathrm{x}$ time and firm $x$ time components. They show that the idiosyncratic bank-side factor, driven particularly by granular banks, matters a lot for aggregate investment dynamics. In contrast, we estimate the pass-through of estimated idiosyncratic performance shocks hitting granular borrowers onto loan, bank, and macroeconomic outcomes.

${ }^{6}$ Conceptually, this step can be viewed as a "reverse Khwaja and Mian (2008)" approach. In Khwaja and Mian (2008), authors trace out the impact of bank supply shocks for the same firm borrowing from different banks. This way, they are able to control for any confounding firm-side factors. Our strategy is to compare loan outcomes within the same bank in order to control for supply-side factors. Our approach is very "granular" since we zoom in on firms not only within the same bank but also within the same industry and county.

${ }^{7}$ Our saturation of specifications with time $\times$ bank and other fixed effects is similar to Jimenez et al. (2014) who study monetary policy and loan applications of the same firm to different banks in the same period of time. 
lose the appealing properties of loan-level analysis: the loan share-weighted firm shock series could be contaminated by bank $\times$ year confounding factors which we no longer have the power to deal with ${ }^{8}$. For this stage, we adopt the "Granular Instrumental Variable" (GIV) approach, newly developed in a series of papers by Gabaix and Koijen (2020, 2021). Intuitively, the GIV extracts variation in the share-weighted aggregated firm shock series that can be attributed to "granular" borrowers. Specifically, the instrument in its simplest form is the difference between size-weighted and unweighted aggregated firm shocks. The GIV thus purges away any bank $\times$ year factor. Conditional on the distribution of credit shares being fat-tailed, idiosyncratic shocks to large borrowers allow us to achieve identification. Our various parameteric and non-parameteric specifications allow for a flexible number of bank factors and, importantly, for loadings on bank factors to be either homogenous or heterogeneous across firms within any bank's portfolio.

One important result of our paper is that idiosyncratic firm shocks, instrumented by the GIV, have a large and significant effect on portfolio-level return on loans (RoA). A one-standard-deviation granular credit shock causes portfolio RoA to move by 11.6 basis points on average. Given that in the estimation sample the standard deviation of RoA is 1.35 , our estimate can explain $8.6 \%$ of the total dispersion of bank returns. We also find that the relationship is strongly concave, driven mainly by negative shocks. In particular, if we condition on positive share-weighted shocks, the estimated coefficient becomes a noisy zero. In contrast, when conditioning on negative share-weighted shocks, the estimate jumps to as high as 19.4 basis points, which is $15 \%$ of the sample standard deviation of RoA - an increase of $74 \%$ over the average estimate ${ }^{9}$. We investigate heterogeneity at the bank level and find that the pass-through of granular credit shocks is stronger for banks with high portfolio risk weights, low assets, high loan portfolio concentration, and high profitability. We also find that the number of loans in credit portfolios does not affect the transmission mechanism, indicating that granular credit risk is not merely a "small-N" problem.

Fifth, having established that shocks to granular borrowers have a direct effect on portfolio-level returns, we ask whether banks pass on these shocks to the real economy. In other words, are there macroeconomic spillovers from granular credit risk? ${ }^{10}$ We start by examining credit supply effects, by comparing bank loan quantity and rate changes in response to granular credit shocks. We restrict the sample to firms with multiple bank relationships and ask if banks that experience bad

${ }^{8}$ In recent work, Jimenez et al. (2020) extend the Khwaja and Mian (2008) loan-level estimator to firm-level, thus offering a way to achieve identification despite aggregation. We pursue a novel and complementary approach that exploits fat tail of the loan share distribution.

${ }^{9}$ The concave relationship is reassuring to us for the simple reason that it reflects the basic payoff structure of the debt contract. While there is no upside for the lender from borrowers experiencing positive value-added shocks, the downside is capped only by the principal of the loan, not counting default-related costs, be they pecuniary or not. Apart from the intuitive economic interpretation, we also view our finding of strong asymmetric effects as an important sign of validation that our measure of idiosyncratic shocks is indeed economically informative.

${ }^{10}$ For example, negative granular credit shocks could be perceived as sudden and detrimental changes to the banks' financial positions, which in turn translate into adverse lending and pricing decisions (Paravisini, 2008). 
granular credit outcomes reduce credit supply or increase prices. Within-firm analysis allows us to control for demand-side effects using time-varying firm fixed effects, thus isolating the supply side. We find strong evidence, both in terms of quantity and price effects, that banks pass on granular credit shocks to their non-granular clients, i.e. firms with a loan share that is less than a certain threshold (such as the median) in the pooled distribution of all credit shares ${ }^{11}$. We show that a one-standard-deviation bank-level negative granular credit shock reduces loan supply and increases interest rates by as much as 71.7 and 63.4 basis points, respectively. This identifies a leftward shift of the credit supply curve: quantities fall while prices rise. There are "granular credit risk spillovers": idiosyncratic borrower shocks spill over to other firms that borrow from the same bank. ${ }^{12}$

We then ask whether affected non-granular firms experience negative real economic outcomes. We find that affected non-granular firms cut investment. Moreover, these firms experience elevated bankruptcy rates for up to 3 years after the initial shock. A one-standard deviation negative granular credit supply shock increases the likelihood of bankruptcy by roughly 32-60 basis points for all firms, and 68-101 basis points for non-granular borrowers. Granular credit risk has therefore sizable implications for the aggregate economy.

An important question is whether banks hedge granular risk with alternative sources of income. For example, in states of the world where credit income is low derivative income could be high. We collect detailed bank-level data on non-interest income and find that none of the measures we have correlate with GIV-instrumented firm shocks. We see no correlation between our shock measures and fees income, equity and bond appreciations, dividend income, or derivatives income. Another issue is that banks could potentially pre-insure against granular borrower shocks by charging higher markups for risky clients. But when extracting value-added shocks we control for firm size, liquidity, credit ratings, leverage and time-invariant factors. From the bank's perspective, unless markups are stochastic for some very unique reason, any firm shock comes therefore as a surprise relative to the firm's average performance and its creditworthiness, both of which would in turn be very highly correlated with the loan contract's price.

${ }^{11}$ The tendency to pass along adverse economic shocks to their clients, especially small firms, is not uncommon for banks. In their classic paper, Peek and Rosengren (2000) find that the 1990s Japanese banking crisis had a negative effect on commercial real estate activity in the U.S. through the network of banks exposed to both markets. Klein et al. (2002) further document that unequal access to credit by Japanese firms during the 1990s led to the decline in the number of FDI projects by the same firms into the United States. Lin and Paravisini (2012) trace out the pass-through of the collapse of WorldCom on firms that shared the same lender. In a recent paper, Greenwald et al. (2020) show that banks that experience larger credit line drawdowns restrict lending to firms that borrow through term loans - a negative spillover effect on smaller borrowers.

${ }^{12}$ It is possible that our spillover result is in part driven by production network linkages, i.e. granular and nongranular borrowers are linked not only via the balance sheet of their common lender but through some other channel as well. In Section 5.3 we account for these production network effects with the use of the Norwegian input-output table and find that our results do not change. 
How valid are our methodology and results externally? In other words, to what extent is credit portfolio concentration a uniquely Norwegian phenomenon or a ubiquitous feature of financial markets? In Section 5.3 we discuss how portfolio concentration appears to be indeed very common across various countries and asset classes. We also ourselves document the degree of portfolio concentration for a completely different but important setting: equity holdings of US institutional investors. We find that concentration in the Norwegian corporate credit sector is quantitatively very similar to the universe of U.S. equity investors. Our analysis concludes that both the methodology and results are applicable to many other settings and environments.

Finally, we supplement our empirical analysis by providing a theoretical motivation. We introduce parsimoniously bank credit into the canonical framework of Gabaix (2011). We model firm borrowing needs as a power function of firm size, which in turn is drawn from a power law density. Under this assumption, the distribution of bank loans (or, equivalently, firm borrowing) follows the Singh-Maddala (SM) family of densities (Singh and Maddala, 1976). The SM distribution has been used extensively to model wealth and income inequality. Our main contribution here is the derivation of sufficient statistics-based parameter restrictions under which the bank loan distribution also has a fat tail. If that is the case, then shocks to large borrowers may survive aggregation and impact bank-level portfolio outcomes. Using our dataset, we provide maximum likelihood estimates of the sufficient statistics and confirm that all the restrictions are satisfied on average.

Literature Review Our paper relates to several literatures. First, it builds on the rapidly growing literature on the "granular hypothesis" and its applications. Some of the more salient contributions across fields range from papers on business cycles (Carvalho and Gabaix, 2013), to trade (Gaubert and Itskhoki, 2021), international finance (di Giovanni et al., 2018), asset management (Choi et al., 2017), life insurance (Chodorow-Reich et al., 2021), exchange rates (Camanho et al., 2020), banking (Bremus et al., 2018; Kundu and Vats, 2021). In important work, Amiti and Weinstein (2018) develop a methodology that decomposes loan growth into time-varying bank supply and firm demand components and find that idiosyncratic bank supply fluctuations, particularly those of granular lenders, have a large impact on aggregate lending and investment in Japan. In contrast to Amiti and Weinstein (2018), we estimate idiosyncratic firm performance shocks and study how these shocks transmit to bank outcomes and the real economy. We contribute to the "granular hypothesis" literature by first showing that, when the loan distribution is fat tailed, idiosyncratic performance shocks to granular borrowers do not wash out at the lender's portfolio level. Second, we study spillovers of granular credit shocks on the rest of the economy by tracing out how affected banks pass on granular credit risk to other firms.

Second, we relate to the literature studying the trade-off between credit concentration and diversification. On the one hand, diversification enhances credit monitoring and information provision 
capacity (Diamond, 1984; Boyd and Prescott, 1986). Recently, Doerr and Schaz (2021) have shown that geographically diversified banks not only lend more during local crises in their borrower countries, but also mitigate the transmission of such shocks to borrowers in other countries. On the other hand, some empirical studies found a positive correlation between portfolio concentration, returns, and monitoring efficiency (Acharya et al., 2006). Beck et al. (2017) have shown that bank specialization and concentration potentially have positive implications for systemic financial stability. Our paper contributes to this debate. We argue that as long as the distribution of credit shares features a fat tail, banks remain exposed to idiosyncratic shocks to their (granular) borrowers. Everything else equal, this is detrimental for financial stability. Because we find that banks pass on granular credit shocks to the real economy, credit concentration induces negative economic outcomes on average, ceteris paribus. But a normative interpretation of our results depends on the precise theories generating loan concentrations in the first place, an issue we discuss further in Section 6.

There is an emerging new literature on credit concentration that, like us, takes advantage of detailed microeconomic data. In a recent study, Agarwal et al. (2020) find that Mexican banks that specialized in energy lending around the 2014 collapse of energy prices amplified the sectoral shock to the rest of the real economy. Paravisini et al. (2020) find that persistent bank market-specific specialization can explain a significantly larger fraction of within-firm variation in credit than actual bank supply shocks. Goetz et al. (2016) show that geographic diversification by banks has no impact on average loan quality and is associated with a reduction of exposure to local idiosyncratic risks. Finally, Huremovic et al. (2020) and Dewachter et al. (2020) study the role of production networks in Spain and Belgium, respectively, for the propagation of bank shocks. Our paper differs from this literature because we work explicitly with single-name concentration risk, while most of the literature deals with either sectoral or geographical specialization. In addition, we emphasize both empirically and theoretically the importance of granularity of the loan share distribution for the pass-through of idiosyncratic shocks to the aggregate bank portfolio. Thus our paper provides an empirical basis for the work of Mendicino et al. (2020) who show in a quantitative model that if banks are not perfectly diversified, the interaction between borrowers' and banks' solvency has important effects on the probability and severity of crises.

The remainder of the paper is structured as follows. Section 2 provides a description of our data. Section 3 describes the different stages of our empirical approach. Section 4 reports the main empirical results. Section 5 explores heterogeneity at different levels of aggregation and reports results from various robustness checks. Section 6 discusses the assumptions we make in our empirical approach and the implications of our findings. Section 7 lays out our theoretical motivation. Finally, section 8 concludes. 


\section{Data}

Our empirical investigation is based on a unique dataset assembled from three major sources: administrative data from the Norwegian Tax Authority, credit rating agency data from Bisnode and supervisory data from ORBOF. They were merged using the unique identifiers for banks and firms. The Norwegian Tax Authority data is a high-quality matched firm-bank administrative register. The unit of observation in this database is an individual loan and the frequency is annual. For every loan, we observe the firm-bank identifiers as well as the flow of interest paid during the year and the end-of-year stock of debt. Because the data is collected and maintained by the tax authority as a basis for corporate taxation, the variables are essentially measurement error-free. ${ }^{13}$ The data set covers all limited liability companies for the time period of 2003-2015, which accounts for roughly $90 \%$ of private sector employment for most years. We aggregate all loans into a single annual firm-bank "relationship" unit. The terms loan and relationship are used interchangeably, and refer to the sum of loans and interests paid across all individual loans between a bank and a firm.

A key measure in our analysis is the return on a loan, or a credit relationship (RoL). This is not directly observed, and hence we impute it. Specifically, we observe interest collected throughout year $t\left(R_{t}\right)$ and the end-of-year stock of outstanding debt $\left(D_{t}\right)$. We then define the RoL in year $t$ as $R_{t} /\left(0.5 D_{t-1}+0.5 D_{t}\right)$, which is equivalent to interest received relative to the average of debt outstanding at the beginning and end of the calendar year.

We merge the loan-level data with detailed information on Norwegian firms and banks. Our firm data comes from the credit rating agency Bisnode. In addition to information about the firms' credit rating scores and firm characteristics such as age, location and industry, the data set includes annual balance sheet and income statement items on all Norwegian firms for 1999-2019. The bank data is from a supervisory registry (ORBOF) and includes annual balance sheet and income statement information covering all Norwegian banks over 1987-2019. The data set also provides us with confidential information on non-interest income, including income from derivatives, equity and bond investment, dividends, and loan fees.

We perform several cleaning and truncation steps on the raw data. First, we drop observations that are clearly erroneous, such as cases of liquidity ratios being greater than 1 . Second, following Foster et al. (2008) we truncate the distribution of cost-to-total-cost ratios for each cost type at the $10 \%$ and $90 \%$ in each industry and year. Cost types include wage bill, energy, material and other costs. This is important as firms could dump all their operational costs to a particular fiscal year in order to receive tax advantages, and what we would thus pick up are in fact endogenous outcomes rather than unanticipated performance shocks. Third, we truncate the extracted firm

\footnotetext{
${ }^{13}$ Provision of false tax information carries substantial legal, financial and reputational penalties. Additionally, the information about outstanding debt and interest paid is reported to the tax authority by the banks, and not the firms themselves.
} 
shock distribution at the $1 \%$ and $99 \%$ levels. All our main results at the loan and bank levels are quantitatively robust to alternative cleaning rules. Table 1 provides summary statistics for some of the key variables used in our analysis. 
Table 1: Descriptive Statistics

\begin{tabular}{|c|c|c|c|c|c|}
\hline Variable & Observations & Mean & Std. Dev & Min & Max \\
\hline \multicolumn{6}{|c|}{ Loans } \\
\hline Interest Received & 333289 & 196645.31 & 1620919.78 & 1.00 & $2.67 e+08$ \\
\hline Loan Amount Outstanding & 333289 & 4035259.25 & 43884811.59 & 1.00 & $7.00 \mathrm{e}+09$ \\
\hline Return on Loan (\%) & 333289 & 9.01 & 8.92 & 0.00 & 100.00 \\
\hline \multicolumn{6}{|c|}{ Firms } \\
\hline Sales (1000 NOK) & 277707 & 26532.69 & 217768.69 & 0.00 & 33761000.00 \\
\hline Total Assets (1000 NOK) & 277707 & 42361.08 & 1052017.18 & 2.00 & $1.20 \mathrm{e}+08$ \\
\hline Wage Costs (1000 NOK) & 277707 & 6827.88 & 65057.01 & 1.00 & 7098000.00 \\
\hline Material Costs (1000 NOK) & 277707 & 11643.95 & 103640.10 & 0.00 & 15313000.00 \\
\hline Equity / Assets Ratio & 277707 & 0.27 & 0.18 & 0.00 & 1.00 \\
\hline Liquidity Ratio & 277707 & 0.16 & 0.17 & 0.00 & 1.00 \\
\hline Employees & 277707 & 15.81 & 156.66 & 0.00 & 20781.00 \\
\hline Firm Age (years) & 277707 & 12.94 & 11.81 & 0.00 & 159.00 \\
\hline \multicolumn{6}{|c|}{ Banks } \\
\hline Return on Loans (\%) & 1380 & 6.40 & 1.46 & 0.06 & 14.39 \\
\hline Total Assets (1000NOK) & 1377 & 21130037.71 & $1.35 \mathrm{e}+08$ & 92384.00 & $1.96 \mathrm{e}+09$ \\
\hline Total Equity (1000NOK) & 1377 & 1491611.98 & 8512785.73 & 16139.00 & $1.51 \mathrm{e}+08$ \\
\hline Assets / Equity Ratio & 1377 & 10.90 & 3.20 & 1.32 & 41.48 \\
\hline Cash Balances / Assets & 1377 & 0.03 & 0.03 & 0.00 & 0.33 \\
\hline Number of Loans & 1380 & 220.88 & 854.18 & 1.00 & 8940.00 \\
\hline Loan Herfindahl Index & 1380 & 0.10 & 0.12 & 0.00 & 1.00 \\
\hline Share of $10 \%$ Largest Loans & 1380 & 0.54 & 0.13 & 0.20 & 1.00 \\
\hline Share of 5 Largest Loans & 1380 & 0.51 & 0.20 & 0.07 & 1.00 \\
\hline Deposits to Assets Ratio & 1377 & 0.66 & 0.12 & 0.01 & 0.91 \\
\hline Financial Assets Ratio & 1321 & 0.08 & 0.06 & 0.00 & 0.48 \\
\hline \multicolumn{6}{|c|}{ Estimated Idiosyncratic Shocks } \\
\hline Firm-level & 277707 & 0.02 & 0.27 & -1.42 & 1.15 \\
\hline Bank-level (size-weighted) & 1380 & -0.02 & 0.11 & -0.78 & 0.69 \\
\hline Granular IV & 1380 & -0.02 & 0.09 & -0.76 & 0.46 \\
\hline
\end{tabular}

Notes: This table shows summary statistics of key loan, firm, and bank characteristics. All stock and earnings values are in thousands of Norwegian Kronas (NOK). 1 US Dollar $=8.71$ NOK as of September 19, 2021. Firm shocks are estimated according to specification 1. Loan data is from the Norwegian Tax Authority. Firm data is from the credit rating agency Bisnode. Bank data is from the financial supervisory database ORBOF. Sample includes all bank loans to limited liability companies in Norway over 2003-2015. 


\section{Empirical strategy}

\subsection{Granularity of the Distribution of Loan Shares}

We begin by establishing that the distribution of loans shares in our dataset is fat-tailed. In Figure 1 we plot the histogram of all loan shares, pooled across all banks and years over 2003-2015. Eyeballing the distribution is enough to notice its extreme skewness. More formally, we fit the Pareto I density to the data and estimate a Pareto rate of 1.16. Any estimate below 2 implies that idiosyncratic shocks to large loans potentially survive risk pooling and cause portfolio-level disturbances. This follows directly from the proofs in Gabaix (2011). Interestingly, our estimate of the Pareto power implies that $80 \%$ of all credit is concentrated in $20 \%$ of the loans. Thus the loan share distribution provides yet another example of the famous "80-20" Pareto principle that occurs in a variety of settings in economics as well as in many social and physical sciences applications (Gabaix, 2009). In section 7, we introduce a parsimonious model of bank credit into the canonical framework of Gabaix (2011). In our model, the fat tail of the firm size distribution feeds directly into the fat tail of the loan share distribution under certain parameter restrictions. We estimate the main parameters of the model using our data and confirm that those restrictions are on average satisfied. 
Figure 1: Distribution of Bank Loan Shares
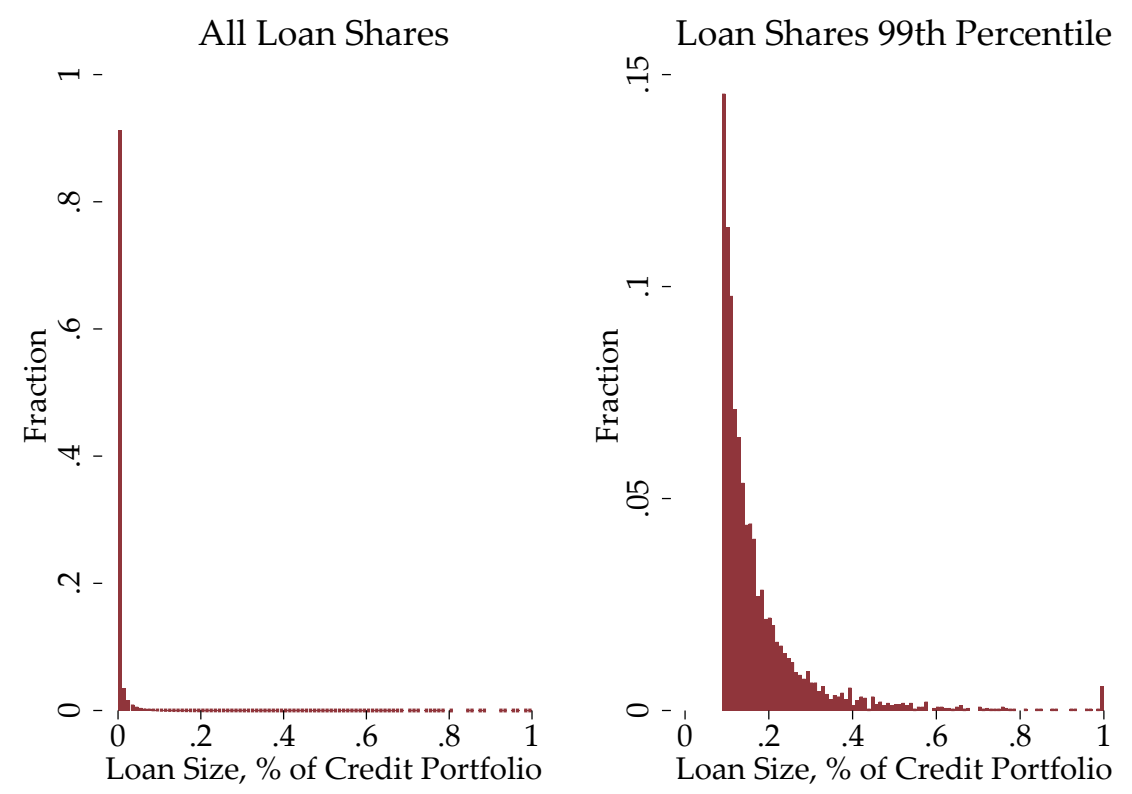

Notes: This graph presents the distribution of bank loan shares. The left picture plots the full distribution. The right picture zooms in on the 99th percentile of the shares. The share of each loan is computed as the ratio of a singular loan's amount to total corporate loans of a given bank in a given year. The figures plot the pooled shares for all banks and years. The Pareto rate of the 99th percentile is 1.16.

\subsection{Estimates of Idiosyncratic Firm Shocks}

The next step of our empirical approach consists in extracting idiosyncratic firm shocks, measured as unexplained idiosyncratic variation in firm value-added. Our approach follows closely a large number of studies in labor and macro economics that extract idiosyncratic sales or performance shocks. (Foster et al., 2008; Hsieh and Klenow, 2009; di Giovanni et al., 2014; Foster et al., 2017; Fagereng et al., 2018). ${ }^{14}$ To extract unexplained variation in firm value-added, we regress the log of firm value-added on a set of time-varying firm-level controls that includes measures of input usage and firm riskiness. Importantly, since our focus is on idiosyncratic variation, we remove common (across firms) components by controlling for the interaction of time, industry and county fixed effects. Finally, across-firm variation attributed to time-invariant firm characteristics is absorbed by firm fixed effects.

Formally, for a firm $\mathrm{j}$, operating in an industry $\mathrm{s}$ from a county $\mathrm{z}$ in year $\mathrm{t}$, we estimate the

\footnotetext{
${ }^{14}$ Using idiosyncratic shocks as "instruments" for estimating microeconomic or macroeconomic elasticities is increasingly common in applied microeconomics and finance (see Leary and Roberts (2014), Amiti et al. (2019) and Gabaix and Koijen (2020)).
} 
following regression:

$$
\ln \mathrm{VA}_{\mathrm{j}, \mathrm{t}}=\alpha_{\mathrm{j}, \mathrm{t}, \mathrm{s}(\mathrm{j}), \mathrm{z}(\mathrm{j})}+\beta_{1} \ln \mathrm{K}_{\mathrm{j}, \mathrm{t}}+\beta_{2} \ln \mathrm{W}_{\mathrm{j}, \mathrm{t}}+\lambda^{\prime} \mathbf{X}_{\mathbf{j}, \mathrm{t}}+\epsilon_{\mathrm{j}, \mathrm{t}}
$$

where VA stands for firm value-added ${ }^{15}$, K represents book capital, W the wage bill, and X are other controls including leverage, liquidity, credit rating, and a quadratic polynomial in age. The term $\alpha_{(\cdot)}$ captures a combination of fixed effects at the firm and industry $\times$ year $\times$ county levels. Here, $\mathrm{K}$ and $\mathrm{W}$ are proxies for capital and labor inputs, while $\mathrm{X}$ are various measures of firm riskiness. These factors should capture the banks' information set well. ${ }^{16}$ In addition to the specification in (1) we also consider a less conservative specification, which only includes fixed effects but not any of the other controls, in the spirit of di Giovanni et al. (2014).

The object of interest is the residual from this regression, $\epsilon_{\mathrm{j}, \mathrm{t}}$, which is the main right-hand side variable for the rest of the paper. Essentially, what we are trying to capture are unforeseen changes in firm performance that banks, despite observing multiple layers of data, could not have anticipated. Examples of such events include a factory collapse, fraud and mismanagement, operational and logistical accidents, human error, etc. In Section E of the Online Appendix we provide a headline and narrative-based explanation for some of the most negative shock realizations in our sample.

Figure 2 plots the distribution of our baseline shock measure $\epsilon_{\mathrm{j}, \mathrm{t}}$, pooled across all firms and years. It is noticeably left-skewed, with a larger mass in the left tail.

\footnotetext{
${ }^{15}$ Value added is measured as sales minus material, energy, and other costs.

${ }^{16}$ A potentially important factor that is missing from this specification is market prices. The share of publicly traded firms in our data is, however, very small. Moreover, credit rating arguably captures the same information that would be embedded in the stock price (albeit updated far less regularly).
} 


\section{Figure 2: Distribution of Idiosyncratic Firm Shocks}

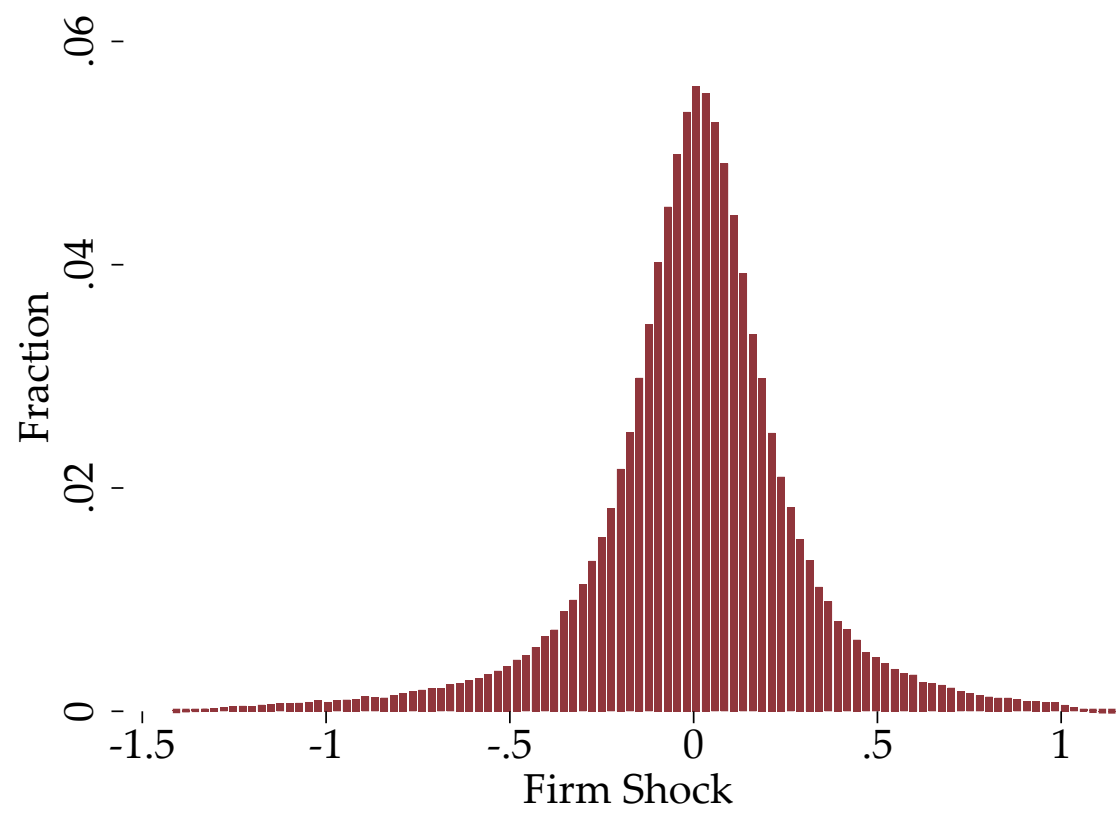

Notes: This graph plots the pooled distribution of idiosyncratic firm shocks estimated from equation (1).

Factor Analysis and Robustness Despite controlling for a variety of firm characteristics and fixed effects, there is still concern that our shocks $\epsilon_{\mathrm{j}, \mathrm{t}}$ may pick up some latent common components. In Section A.1 of the Online Appendix, we generalize the reduced-form specification in (1) and formally extract parameteric and non-parameteric common factors from the residual $\epsilon_{\mathrm{j}, \mathrm{t}}$. All our results and insights at the loan and bank levels remain unchanged. We also conduct a series of additional robustness tests in order to establish that our shocks are truly idiosyncratic. First, we confirm that $\epsilon_{\mathrm{j}, \mathrm{t}}$ are not correlated across firms or time. Second, we run several placebo regressions. We return to these robustness checks in Section 5.

\subsection{Loan Outcomes}

To identify the impact of idiosyncratic firms shocks on loan-level returns, we exploit the granular nature of our dataset. Individual bank-firm relationships enable us to control for timevarying bank supply factors, such as risk aversion or monitoring skills, by including bank $\times$ year fixed effects. Bank supply factors could confound our demand-side shocks. ${ }^{17}$ We also control for interacted county $\times$ year $\times$ industry fixed effects. This specification implies that the impact of shocks is identified by comparing loan-level returns across firms in the same county, industry,

\footnotetext{
${ }^{17}$ Coimbra and Rey (2019), among others, show that heterogeneity in risk appetite among financial intermediaries is a determining factor for financial and business cycles. Our fixed effects specification takes care of this issue.
} 
year, who are borrowing from the same bank. For some firm-bank relationships in our dataset we also observe the fraction of total loan volume that comes from credit lines. This allows us to also consider specifications which include a loan type fixed effect ${ }^{18}$. Formally, we estimate the following specification:

$$
\mathrm{R}_{\mathrm{i}, \mathrm{j}, \mathrm{t}}=\alpha_{\mathrm{i}, \mathrm{t}, \mathrm{s}(\mathrm{j}), \mathrm{z}(\mathrm{j}), \mathrm{l}(\mathrm{i}, \mathrm{j})}+\beta \epsilon_{\mathrm{i}, \mathrm{j}, \mathrm{t}}+v_{\mathrm{i}, \mathrm{j}, \mathrm{t}}
$$

where $i$ is a bank that lends to firm $j$ from county $z$, industry $s$, year $t$ via loan type $1 . R_{i, j, t}$ is the loan-level return and $\epsilon_{\mathrm{i}, \mathrm{j}, \mathrm{t}}$ is the estimated idiosyncratic shock of firm $\mathrm{j}$ in bank i's portfolio. Because the main RHS variable is estimated, our standard errors are corrected for the estimated regressor bias via bootstrapping. Importantly, our specification features a wide range of fixed effects captured by the term $\alpha_{(\cdot)}$. Specifically, in our most conservative specification we include the full interaction of bank $\times$ year $\times$ firm industry $\times$ firm county $\times$ loan type fixed effects.

\subsection{Granular Credit Risk: Bank outcomes}

After investigating how idiosyncratic firm shocks affect loan returns, we then move up to the level of a bank portfolio. We aggregate realized idiosyncratic firm shocks to the bank level by weighing shocks with loan shares and refer to the resulting measure as "granular credit risk". Intuitively, granular credit risk captures shocks to banks' clients that eventually do not average out and instead impact portfolio-level outcomes.

To evaluate the bank-level impact, we proceed by analyzing the following relationship between bank-level returns on all corporate loans $\mathrm{R}_{\mathrm{i}, \mathrm{t}}^{\mathrm{b}}$ and firm shocks for bank $\mathrm{i}$ at year $\mathrm{t}$ :

$$
\mathrm{R}_{\mathrm{i}, \mathrm{t}}^{\mathrm{b}}=\alpha_{\mathrm{i}}+\alpha_{\mathrm{t}}+\beta \bar{\epsilon}_{\mathrm{i}, \mathrm{t}}+v_{\mathrm{i}, \mathrm{t}}
$$

where $\alpha_{\mathrm{i}}$ and $\alpha_{\mathrm{t}}$ denote bank and time fixed effects, $\bar{\epsilon}_{\mathrm{i}, \mathrm{t}}=\sum_{\mathrm{j} \in \mathrm{J}_{\mathrm{i}}} \mathrm{s}_{\mathrm{i}, \mathrm{j}, \mathrm{t}} \epsilon_{\mathrm{i}, \mathrm{j}, \mathrm{t}}$ are bank-level aggregates of firm shocks that are weighted by loan shares $\mathrm{s}_{\mathrm{i}, \mathrm{j}, \mathrm{t}}$, and $v_{\mathrm{i}, \mathrm{t}}$ the error term. The portfolio loan return $\mathrm{R}_{\mathrm{i}, \mathrm{t}}^{\mathrm{b}}$ is computed as the loan-share weighted average of loan-level returns.

There is one key identification challenge associated with the naive specification above. Our loan-level analysis exploited within-bank-year variation to control for confounding credit supply shocks. This is no longer possible when we turn our focus to outcomes at the bank level. Consider a generic time $\mathrm{t}$ relationship between bank outcome $\mathrm{y}_{\mathrm{i}, \mathrm{t}}$, unobserved bank-side factor $\eta_{\mathrm{i}, \mathrm{t}}$, and demand-side idiosyncratic firm disturbance $\epsilon_{\mathrm{i}, \mathrm{j}, \mathrm{t}}$ :

$$
\mathrm{y}_{\mathrm{i}, \mathrm{t}}=\beta \sum_{\mathrm{j}} \mathrm{s}_{\mathrm{i}, \mathrm{j}, \mathrm{t}} \epsilon_{\mathrm{i}, \mathrm{j}, \mathrm{t}}+\varphi_{\mathrm{i}} \eta_{\mathrm{i}, \mathrm{t}}
$$

${ }^{18} \mathrm{~A}$ firm-bank relationship is classified as a credit line loan in year $\mathrm{t}$ if more than 50 percent of total credit in the relationship comes from credit lines. 
where $\mathrm{s}_{\mathrm{i}, \mathrm{j}, \mathrm{t}}$ is the normalized exposure of bank $\mathrm{i}$ to firm $\mathrm{j}\left(\sum_{\mathrm{j}} \mathrm{s}_{\mathrm{i}, \mathrm{j}, \mathrm{t}}=1\right)$. Estimation of Equation 4 may potentially result in a biased estimate of $\beta$ if $\eta_{\mathrm{i}, \mathrm{t}}$ and $\epsilon_{\mathrm{i}, \mathrm{j}, \mathrm{t}}$ are correlated.

In order to alleviate this concern, we adopt a newly proposed "granular instrumental variable" (Gabaix and Koijen, 2020) approach. Specifically, we assume that the demand-side disturbance $\epsilon_{\mathrm{i}, \mathrm{j}, \mathrm{t}}$ can be written as

$$
\epsilon_{\mathrm{i}, \mathrm{j}, \mathrm{t}}=\delta_{\mathrm{i}} \eta_{\mathrm{i}, \mathrm{t}}+\mathrm{u}_{\mathrm{i}, \mathrm{j}, \mathrm{t}}
$$

where $\delta_{\mathrm{i}}$ is the factor loading.

The granular instrumental variable ("GIV") is defined as the time-varying difference between exposure-weighted and equally-weighted firm shocks, each aggregated to the bank level. This way, the bank-time supply-side factor $\eta_{\mathrm{i}, \mathrm{t}}$, which is potentially correlated with firm disturbances, is purged out. The GIV is formally constructed the following way:

$$
\operatorname{GIV}_{\mathrm{i}, \mathrm{t}}=\sum_{\mathrm{j}} \mathrm{s}_{\mathrm{i}, \mathrm{j}, \mathrm{t}} \epsilon_{\mathrm{i}, \mathrm{j}, \mathrm{t}}-\sum_{\mathrm{j}} \frac{1}{\mathrm{~N}_{\mathrm{i}}} \epsilon_{\mathrm{i}, \mathrm{j}, \mathrm{t}}=\sum_{\mathrm{j}} \mathrm{s}_{\mathrm{i}, \mathrm{j}, \mathrm{t}} \mathrm{u}_{\mathrm{i}, \mathrm{j}, \mathrm{t}}-\sum_{\mathrm{j}} \frac{1}{\mathrm{~N}_{\mathrm{i}}} \mathrm{u}_{\mathrm{i}, \mathrm{j}, \mathrm{t}}
$$

where $\mathrm{N}_{\mathrm{i}}$ denotes the number of firm exposures of a given bank $i$. We now replace the naive approach in equation (3) with the following specification:

$$
\mathrm{R}_{\mathrm{i}, \mathrm{t}}^{\mathrm{b}}=\alpha_{\mathrm{i}}+\alpha_{\mathrm{t}}+\beta \hat{\mathrm{u}}_{\mathrm{i}, \mathrm{t}}+v_{\mathrm{it}}
$$

where $\hat{u}_{i, t}$ is the fitted value from the "first-stage" regression of the endogenous covariate $\bar{\epsilon}_{\mathrm{i}, \mathrm{t}}$ on the granular instrument $\mathrm{GIV}_{\mathrm{i}, \mathrm{t}}$. This way, all variation in $\bar{\epsilon}_{\mathrm{i}, \mathrm{t}}$ is driven by fluctuations originating from the "granular borrowers", i.e. those with a large credit share. Naturally, if there are no granular borrowers, this approach does not work as there is no variation in the instrument. But as we have seen from Figure 1, the distribution of loan shares is very skewed. The main identifying assumption of this empirical approach is the following condition:

$$
\sum_{j}^{N} \mathbb{E}\left[s_{i, j, t} u_{i, j, t} v_{i, t}\right]=0
$$

for all $\mathrm{i}$ and $\mathrm{t}$.

In words, identification is achieved if firm shocks $\mathrm{s}_{\mathrm{i}, \mathrm{j}, \mathrm{t}} \mathrm{u}_{\mathrm{i}, \mathrm{j}, \mathrm{t}}$ are not driven by the error term in bank-level regressions. This is the "exclusion" assumption. The main concern is that loan shares could be endogenous, i.e. correlated with firm shocks. This is not a problem for us for several reasons. First, credit demand in absolute terms correlates with firm size. Given how we extract idiosyncratic value-added shocks (i.e. controlling for size), our shock series is mechanically orthogonal to firm size. Similar logic applies to other firm factors such as leverage, liquidity, 
credit rating or age. Second, as a proxy for contemporaneous loan shares, our loan share measure is computed using average debt between periods $t$ and $t-1$. This mitigates any contemporaneity concerns. Finally, loan shares and firm shocks are reassuringly uncorrelated in our sample ${ }^{19}$.

Factor Analysis and Heterogeneous Loadings In Section A.2 of the Online Appendix we study an important extension of the baseline approach that relaxes the assumption of homogenous loadings on bank factors. In other words, we allow $\delta_{\mathrm{i}, \mathrm{j}}$ to be heterogeneous across firms. In principle, sensitivity to fluctuations of bank x year factors could vary significantly across the firm distribution. We run a series of Principal Component Analyses (PCA) on each bank's portfolio separately and extract common components non-parametrically. We find that all main results remain quantitatively unchanged when we use this generalized GIV approach.

\subsection{Granular Credit Risk Spillovers: Credit Supply and Firms}

In order to study the economic consequences of granular credit risk, we investigate the relationship between bank-level aggregated firm shocks and credit market outcomes. We follow a large literature in banking relying on the methodology in Khwaja and Mian (2008). Specifically, we focus on a sub-sample of firms borrowing from multiple banks and compare - for the same firm quantity and rate outcomes from banks that experienced good or bad granular credit shocks. We test whether banks pass on shocks originating from their granular borrowers to the rest of their credit portfolio (non-granular borrowers). We define non-granular borrowers as firms whose loan share is below a certain threshold (such as the $50 \%$ th or the $25 \%$ th percentile) of the loan share distribution. In response to negative shocks due to granular clients, bank may have to scale back their relationship with non-granular borrowers, alter the pricing of loans, or both.

We run the following regressions on yearly changes:

$$
\Delta \mathrm{y}_{\mathrm{i}, \mathrm{j}, \mathrm{t}}=\alpha_{\mathrm{i}}+\alpha_{\mathrm{j}, \mathrm{t}, \mathrm{s}(\mathrm{j}), \mathrm{z}(\mathrm{j})}+\beta \Delta \hat{\mathrm{u}}_{\mathrm{i}, \mathrm{t}}+v_{\mathrm{i}, \mathrm{j}, \mathrm{t}}
$$

where $\Delta \hat{\mathrm{u}}_{\mathrm{i}, \mathrm{t}}$ is the fitted value from the "first-stage" regression of the endogenous bank level shock $\Delta \bar{\epsilon}_{\mathrm{i}, \mathrm{t}}$ on the granular instrument $\Delta \mathrm{GIV}_{\mathrm{i}, \mathrm{t}}, \alpha_{\mathrm{j}, \mathrm{t}, \mathrm{s}(\mathrm{j}), \mathrm{z}(\mathrm{j})}$ is a firm x year $\mathrm{x}$ industry x county fixed effect and $\alpha_{\mathrm{i}}$ is a bank fixed effect. $\Delta \mathrm{y}_{\mathrm{i}, \mathrm{j}, \mathrm{t}}$ is either loan volumes or interest flows. The regression is run either on firms with a loan share below the $50^{\text {th }}$ or $25^{\text {th }}$ percentile of the loan share distribution. ${ }^{20}$

After investigating loan-level responses, we aggregate our data to the firm level and test whether there are any spillover effects from granular credit shocks to firm balance sheet aggregates such as

\footnotetext{
${ }^{19}$ The raw correlation between loan shares and firm shocks in our sample is -0.02 . The correlation is computed for each bank, and we report the average across banks.

${ }^{20}$ For completeness, in the Appendix we consider a discrete measure of non-granularity where we iteratively restrict the estimation sample to firms with a loan share below the $20,21, \ldots, 99$ percentiles.
} 
investment or cash balances. We also look at the impact of granular credit risk on firm bankruptcies, contemporaneously or with a lag. We run the following firm-level regressions:

$$
\Delta \mathrm{y}_{\mathrm{j}, \mathrm{t}}=\alpha_{\mathrm{s}, \mathrm{Z}, \mathrm{t}}+\beta \Delta \hat{\mathrm{u}}_{\mathrm{j}, \mathrm{t}}+v_{\mathrm{j}, \mathrm{t}}
$$

with similar notations as above. $\Delta \mathrm{y}_{\mathrm{j}, \mathrm{t}}$ are now firm-level outcomes such as (changes in) capital, sales, wage bill, cash as well as probability of bankruptcy (in levels). In these spillover regressions the bank $\times$ year series of GIV-instrumented firm shocks is treated as a typical liquidity shock to the intermediaries' balance sheet, which is then passed on to the rest of the economy as a supply-side disturbance. The difference between our paper and the rest of the literature is that the origin of this bank-side liquidity risk is (uninsured) idiosyncratic risk from large, granular borrowers ${ }^{21}$.

\section{Main Empirical Results}

We investigate how idiosyncratic firm value-added shocks affect loan returns in section 4.1. In section 4.2, we aggregate idiosyncratic firm shocks to the bank level and see whether the effect is still significant despite portfolio-level risk pooling. In section 4.3 we ask whether granular credit risk goes unhedged at the bank level. In section 4.4, we investigate potential spillover effects from granular credit risk onto other firms and their real economic consequences.

\subsection{Loan Outcomes}

Table 2 presents the effect of idiosyncratic firm shocks on loan returns obtained from estimating Equation (2). Overall, idiosyncratic firm shocks have a large and significant (at the 1\% level) effect on loan-level returns. In columns (1)-(2) we proxy firm shocks with the residual value-added variation after controlling for fixed effects only (as in di Giovanni et al. (2014)). ${ }^{22}$ In columns (3)-(5) the shock is extracted from Equation 1 with a full set of firm controls: leverage, liquidity, size, age, and credit rating. Firm shock measures are standardized. Our preferred specification is column (5) and the result is the following: a 1-standard-deviation firm shock affects returns by 36.1 basis points. In words, when comparing a bank's loan return across firms within the same year, industry, county, and through the same loan facility, a 1 standard deviation reduction in firm performance reduces loan returns by roughly a third of a percentage point.

Figure 1 of the Online Appendix reports loan outcome estimates at different horizons: we regress loan returns on leads and lags (in years) around the firm shock ("event" at date 0) and

\footnotetext{
${ }^{21}$ We test and discuss the insurability of granular credit risk in Section 4.3.

${ }^{22}$ This specification has no additional controls and extracts firm-level value-added variation that is orthogonal to industry $\times$ county $\times$ time $\times$ loan type and firm fixed effects.
} 
Table 2: Loan Outcomes

\begin{tabular}{lccccc}
\hline \hline & $(1)$ & $(2)$ & $(3)$ & $(4)$ & $(5)$ \\
\cline { 2 - 6 } & \multicolumn{4}{c}{ Dependent Variable: Return on Loan (RoL) } \\
\cline { 2 - 6 } Firm Shock & 0.134 & 0.146 & 0.334 & 0.335 & 0.361 \\
& $(0.012)$ & $(0.013)$ & $(0.015)$ & $(0.017)$ & $(0.019)$ \\
\hline Bank x Industry x Year FE & No & No & No & Yes & No \\
Bank x Industry x Year x Loan-type x County FE & No & Yes & No & No & Yes \\
Additional controls in equation 1 & No & No & Yes & Yes & Yes \\
Observations & 479754 & 434662 & 333289 & 317186 & 292825 \\
$\mathrm{R}^{2}$ & 0.000 & 0.195 & 0.001 & 0.114 & 0.167 \\
$\mathbb{E}($ RoL) & $7.988 \%$ & $7.975 \%$ & $9.012 \%$ & $9.029 \%$ & $9.098 \%$ \\
SD(RoL) & $7.993 \%$ & $7.928 \%$ & $8.921 \%$ & $8.928 \%$ & $8.923 \%$ \\
\hline \hline
\end{tabular}

Notes: This table reports results from the regression of loan-level returns on idiosyncratic firm shocks. The exact specification is described by equation (2). Columns (1)-(2) are based on firm shocks from specifications where (log) value-added is regressed only on a set of firm and county $x$ industry $\times$ year $\times$ loan type fixed effects. Columns (3)-(5) are based on specifications that include additional firm controls: total assets, wages, leverage, liquidity, credit rating, age, and age squared. Firm shocks are normalized by their standard deviation. For example, 0.334 should be interpreted as an increase in the return on loans of 33.4 basis points in response to a 1 standard deviation idiosyncratic firm shock. Loan types include regular and credit-line loans. Counties are 19 administrative areas $(f y l k e)$ in Norway. Industries are 99 2-digit sectors. Standard errors (in parentheses) are double clustered at the firm and year levels and corrected for the estimated regressor bias with bootstrapping. The last two rows report the unconditional sample mean and standard deviation of the dependent variable.

plot the dynamic of the interval estimates over time. First, we observe that there is no effect for years prior to the shock, which points at the absence of any pre-trends. Second, the impact of idiosyncratic firm shocks on loan outcomes is felt for a long time: at least for 3 years on average. We interpret this result through the lenses of relationship-based lending. Termination of a credit relationship is costly, for either side, because of the presence of asymmetric information in credit markets. Even if a bad idiosyncratic outcome reveals new information about the borrower's "type", ex-post monitoring of the repeated borrower may still be a more cost-effective alternative than forming a new relationship (Williamson, 1987). Lenders may understand and internalize the adverse selection problem in the market for switching borrowers (Sharpe, 1990). Finally, the cost of asymmetric information may be bigger for smaller firms, which are also potentially more likely to experience a negative idiosyncratic shock and have more to gain from sticking to the original lender (Chodorow-Reich, 2014). In equilibrium, the lender agrees that the borrower postpones a fraction of the loan repayment to the future period. ${ }^{23}$

\footnotetext{
${ }^{23}$ Our extensive margin analysis in Section 5.1 will reveal that it is indeed the intensive margin, i.e. temporary non-performance and payment delay, which drives our loan-level results, and not necessarily firm exit.
} 
Table 3: Bank Outcomes

\begin{tabular}{lcccccccc}
\hline \hline & $(1)$ & $(2)$ & $(3)$ & $(4)$ & $(5)$ & $(6)$ & $(7)$ & $(8)$ \\
\cline { 2 - 9 } & \multicolumn{7}{c}{ Dependent Variable: Bank Return on Loans (RoA) } \\
\cline { 2 - 9 } & \multicolumn{2}{c}{ OLS } & \multicolumn{7}{c}{ Instrumented with GIV } \\
\cline { 2 - 9 } & Pooled & Pooled & Pooled & Positive & Negative & Pooled & Positive & Negative \\
\hline Granular Credit Shock & 0.129 & 0.136 & 0.116 & 0.016 & 0.194 & 0.117 & 0.056 & 0.176 \\
& $(0.029)$ & $(0.027)$ & $(0.031)$ & $(0.094)$ & $(0.074)$ & $(0.030)$ & $(0.087)$ & $(0.072)$ \\
First stage F-stat & & & 1429.683 & 138.772 & 396.907 & 1137.722 & 150.136 & 263.982 \\
J-statistic & & & 0 & 0 & 0 & 0 & 0 & 0 \\
\hline Bank FE & Yes & Yes & Yes & Yes & Yes & Yes & Yes & Yes \\
Year FE & Yes & Yes & Yes & Yes & Yes & Yes & Yes & Yes \\
Bank Controls & No & Yes & No & No & No & Yes & Yes & Yes \\
Observations & 1211 & 1211 & 1211 & 508 & 694 & 1211 & 508 & 694 \\
$\mathrm{R}^{2}$ & 0.752 & 0.770 & 0.599 & 0.646 & 0.569 & 0.627 & 0.683 & 0.592 \\
$\mathbb{E}$ (RoA) & $6.350 \%$ & $6.350 \%$ & $6.350 \%$ & $6.460 \%$ & $6.289 \%$ & $6.350 \%$ & $6.460 \%$ & $6.289 \%$ \\
Sd(RoA) & 1.354 & 1.354 & 1.354 & 1.403 & 1.295 & 1.354 & 1.403 & 1.295 \\
\hline \hline
\end{tabular}

Notes: This table reports results from regressing bank-level return on loans on bank-level aggregated firm shocks $\bar{\epsilon}_{\mathrm{i}, \mathrm{t}}$. Columns (1)-(2) are standard OLS on equation (3), while columns (3)-(8) instrument the aggregated shock by the granular IV as in equation (7). The GIV is constructed following equation (6). Positive (negative) shock specifications include only observations in which the bank shock $\bar{\epsilon}_{\mathrm{i}, \mathrm{t}}$ is above (below) zero. Bank controls include lagged total assets, leverage, liquidity, number of loans, deposit to assets ratio and financial assets to assets ratio. The last two rows report the unconditional sample mean and standard deviation of the dependent variable. The F-stat is the Kleibergen-Paap rk Wald F statistic for the test of weak identification. J-stat is the Hansen's J-statistic for the instrument overidentification test. Standard errors (in parentheses) are clustered at the bank level and corrected for the estimated regressor bias with bootstrapping.

\subsection{Granular Credit Risk: Bank Outcomes}

The finding that firm-level idiosyncratic shocks impact loan returns merely reflects the fact that individual loans are inherently risky investments. There is little margin of adjustment for the bank to insure against bad loan-level outcomes. The natural next question is whether these idiosyncratic shocks average out at the level of bank portfolios. In other words, can/do banks take advantage of risk pooling and diversify idiosyncratic firm risk away? To answer this question we proceed by estimating the relationship in (7). Results are reported in Table 3, where we have normalized the bank shock by its standard deviation.

We report two sets of specifications: with and without the granular instrumental variable (GIV). In the first two columns (OLS estimates) we find that even at the level of banks' portfolios, idiosyncratic credit risk is associated with large and significant effects on bank returns. To address 
potential endogeneity concerns, columns (3)-(8) report results from the IV regression ${ }^{24}$. Our results show that a one standard deviation GIV-instrumented firm shock, on average, affects bank loan portfolio returns by 11-12bps. We have specifications with and without additional bank controls which include lagged values of book leverage, liquidity, total assets, number of loans, deposit-toasset ratio, and financial assets to total asset ratio ${ }^{25}$. Results are qualitatively and quantitatively robust to the exclusion of these controls ${ }^{26}$.

In Figure 4 of the Online Appendix we report bank loan outcomes by horizon. We find that the impact of GIV-instrumented firm shocks on bank RoA lasts for up to 1 year, i.e. a shock at $t$ has a significant effect on returns even at $t+1$. In addition, the effects of lags are not significant implying the absence of any pre-trends.

A second key set of results is related to the asymmetric effects of granular firm risk. In columns (4)-(5) and (7)-(8) of Table 3 we explore positive- and negative-only firm shocks with and without bank controls. Specifically, we condition on the endogenous covariate $\bar{\epsilon}_{\mathrm{i}, \mathrm{t}}$ in equation (3) being positive or negative only, and instrument it by the GIV. Only negative shocks have a significant impact on bank returns. The impact of positive shocks is not statistically significantly different from zero. A one standard deviation negative granular firm shock lowers bank returns by up to $19.4 \mathrm{bps}$, which is much larger than the average effect and amounts to roughly $15 \%$ percent of the standard deviation of banks' portfolio returns. Due to the payoff structure of the debt contract this very concave relationship is not surprising. Because of debt contracts, banks find it difficult to extract higher dividends from firms that are performing well, while at the same time remaining exposed to potential downside risk from firms that perform poorly. In case of a negative shock, the firm's loan may become nonperforming, the firm may default on the obligation, or exit the industry altogether ${ }^{27}$.

Figure 3 provides a visual representation of this concave relationship. The figure depicts the (binned) scatter plot of the impact of GIV-instrumented firm shocks on banks' returns on loans (RoA). Blue circles (red squares) represent positive and negative shocks, respectively. We construct

\footnotetext{
${ }^{24}$ In Figure 3 of the Online Appendix we plot the relationship between the GIV and the raw endogenous covariate $\bar{\epsilon}_{\mathrm{i}, \mathrm{t}}$. There is a strong, positive relationship between the two variables with a Pearson correlation of 0.863. Formal statistical diagnostic tests also show validity of the GIV as a good instrument. The first-stage F-statistic is above the Stock and Yogo (2005) criterion for 5\% maximal relative bias. The Hansen J-statistic cannot reject the null hypothesis of the instrument being exogenous.

${ }^{25}$ Theoretically, if the exclusion restriction holds, the GIV approach would not require any further bank-time controls. The reason is that GIV, by construction, would be purged from any bank-time factors. For robustness, we still include observable bank controls. Results do not change in any substantial matter, which adds validity to the method. In addition, in Section A. 2 we also control for latent bank-time factors, extracted using PCA. Results do not change.

${ }^{26}$ Bank-level return on corporate loans is the main dependent variable in this section. We have also experimented with loan writedowns and portfolio-level Sharpe ratios. Table 11 of the Online Appendix reports the results. We find some evidence that granular credit risk, when instrumented by the GIV, is weakly positively (negatively) associated with the Sharpe Ratio (writedowns).

${ }^{27}$ We explore the extensive margin in detail in Section 5.1.
} 
Figure 3: Granular Credit Risk and Bank Outcomes

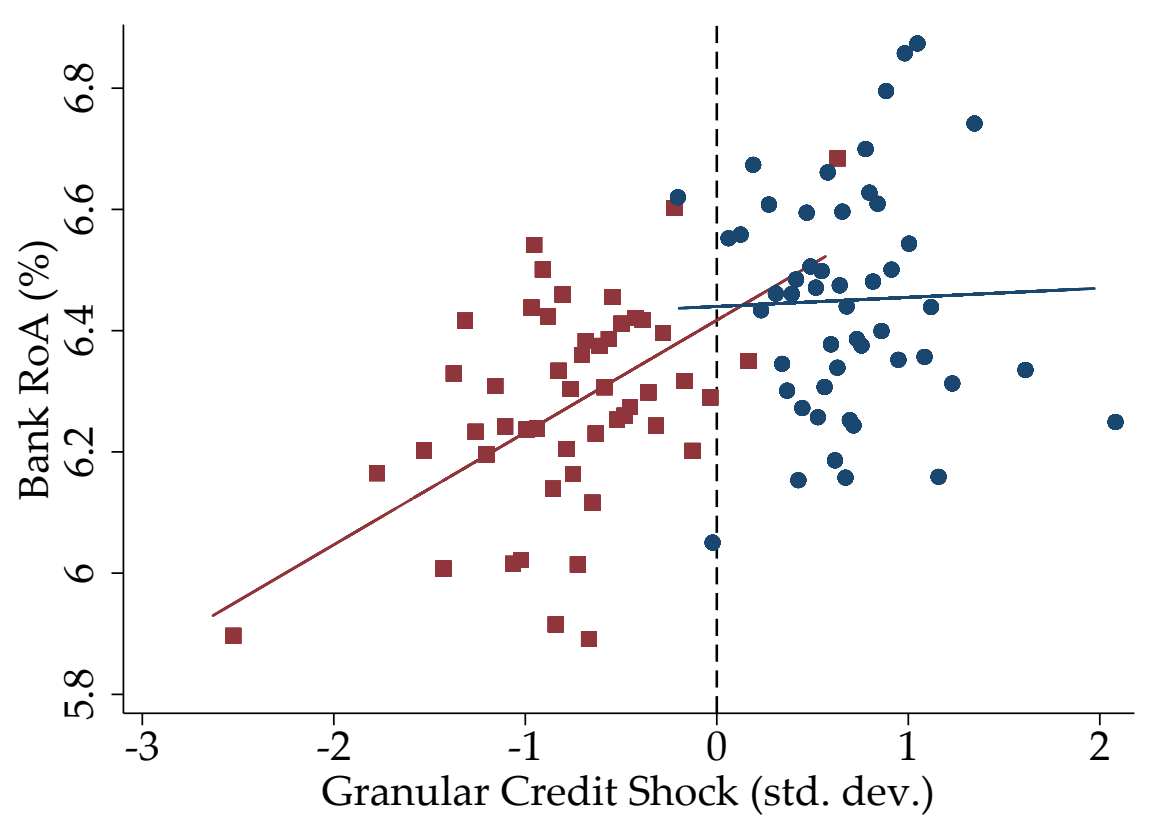

Notes: This figure visualises the relationship between residualized bank-level return on loans and residualized instrumented bank-level aggregated firm shocks. The red squares (blue circles) are binned scatterplots conditional on negative (positive) values of the weighted firm shock $\bar{\epsilon}_{\mathrm{i}, \mathrm{t}}$. The shock variable is normalized by its standard deviation. We construct the conditional binned scatterplot in three steps, and each step is performed separately on positive and negative values of $\bar{\epsilon}_{\mathrm{i}, \mathrm{t}}$. First, we residualize bank-level returns on loans and instrumented firm shocks. Instrumented shocks represent fitted values from regressing $\bar{\epsilon}_{\mathrm{i}, \mathrm{t}}$ on the GIV. The residualized return and shock values are obtained from regressing each variable on bank and time fixed effects, computing the residual, and adding back the mean of each variable. Second, we construct 50 equally-sized bins based on the residualized shock. Third, we plot the mean residual bank return within each bin versus the bin's mean residual shock. The red (blue) line represents the linear fit from regressing bank-level loan return on instrumented shocks, conditional on $\bar{\epsilon}_{\mathrm{i}, \mathrm{t}}<0(>0)$.

the binned scatter plots by first regressing both bank RoA and the GIV-instrumented firm shocks on bank and time FE, computing the residuals, and adding back the mean of each variable. We then construct 50 equally-sized bins of the residual shock variable. Figure 3 plots the mean residual bank RoA within each bin versus the bin's mean residual shock. Finally, we overlay the linear fits for the respective specifications. The asymmetry of the result is rather striking: the line of best fit for positive shocks is flat, while the slope for negative shocks is downward-sloping and highly significant. The bins are all equally-sized, so each dot represents $10+$ underlying bank $\times$ time observations. Our results are thus not driven by any individual outliers. We interpret the concave relationship as further validation that our measure of firm shocks is indeed economically informative. 
Table 4: Hedging Granular Credit Risk

\begin{tabular}{|c|c|c|c|c|c|}
\hline & (1) & (2) & (3) & (4) & (5) \\
\hline \multirow[t]{2}{*}{ Dependent Variable: $\Delta$ Income from } & Fees & Derivatives & Equity & Bonds & Dividends \\
\hline & \multicolumn{5}{|c|}{ Pooled } \\
\hline Granular Credit Shock & $\begin{array}{c}0.219 \\
(0.131)\end{array}$ & $\begin{array}{c}-0.658 \\
(1.214)\end{array}$ & $\begin{array}{l}-1.323 \\
(1.477)\end{array}$ & $\begin{array}{c}0.163 \\
(0.140)\end{array}$ & $\begin{array}{c}0.173 \\
(0.631)\end{array}$ \\
\hline Bank FE & Yes & Yes & Yes & Yes & Yes \\
\hline Year FE & Yes & Yes & Yes & Yes & Yes \\
\hline Observations & 1211 & 344 & 1058 & 1197 & 1174 \\
\hline \multirow[t]{2}{*}{$\mathrm{R}^{2}$} & 0.010 & 0.049 & 0.011 & 0.013 & 0.046 \\
\hline & \multicolumn{5}{|c|}{ Negative Shocks Only } \\
\hline Granular Credit Shock & $\begin{array}{c}0.330 \\
(0.236)\end{array}$ & $\begin{array}{l}-0.133 \\
(2.944)\end{array}$ & $\begin{array}{l}-3.420 \\
(5.466)\end{array}$ & $\begin{array}{c}0.461 \\
(0.470)\end{array}$ & $\begin{array}{c}-0.209 \\
(0.170)\end{array}$ \\
\hline Bank FE & Yes & Yes & Yes & Yes & Yes \\
\hline Year FE & Yes & Yes & Yes & Yes & Yes \\
\hline Observations & 697 & 197 & 606 & 690 & 680 \\
\hline $\mathrm{R}^{2}$ & 0.021 & 0.037 & 0.023 & 0.021 & 0.164 \\
\hline
\end{tabular}

Notes: This table reports results from regressing bank-level year-on-year growth rate in non-interest income components on bank-level aggregated firm shocks, instrumented by the granular IV. The top panel presents results for all shocks, positive or negative. The bottom panel presents results for negative shocks only $\left(\bar{\epsilon}_{\mathrm{i}, \mathrm{t}}<0\right)$. The granular IV is constructed based on equation (6). Standard errors (in parentheses) are clustered at the bank level. Data on all bank non-interest income is from the financial supervisory database ORBOF.

\subsection{Hedging}

We have so far established that idiosyncratic shocks to individual corporate clients affect bank portfolio returns. However, it is possible that financial intermediaries hedge granular credit risk with derivatives and other instruments. As a first pass attempt in answering this question, we collect bank-level data on income from fees, derivatives, equity and bond holdings, and dividends. We then correlate changes in returns from these sources with our GIV-instrumented shocks. The conjecture is that in the same state of the world in which banks are hit with bad idiosyncratic shocks to their loan books, returns are compensated through alternative departments within the same bank. For example, banks could command higher fees for late interest payments, hedge negative states with credit derivatives, short stocks of firms they are also lending to, etc. Table 4 reports the results.

As can be seen from the table, the data cannot consistently reject the null hypothesis of little to no insurance against granular credit risk. None of the measures of non-interest income are significantly associated with our shock measure. If anything, some forms of income are in fact positively correlated with idiosyncratic credit shocks, which questions their usefulness as a hedging 
instrument.

A drawback of this analysis is that the various hedging instruments analyzed in Table 4 are only observable at the bank level. A more detailed analysis would construct matched derivatives holdings at the level of individual credit relationships. This would increase the odds for banks to hedge firm-specific risk, something that we can not fully analyse by looking at portfolio-level data. This would be possible only for a very small subset of large firms that are (a) listed and (b) have a liquid market for credit derivatives such as credit default swaps (CDS). The mass of such firms is small and the CDS market is not very liquid in Norway. Regardless, insurability of granular credit risk is an important question, to which we can give only a partial answer given the data constraints. ${ }^{28}$

\subsection{Granular Credit Risk Spillovers: Credit Supply and Firm Outcomes}

Previous sections have documented that granular credit risk has quantitatively important effects on bank portfolio outcomes, and that this risk is unhedged. In this section, we ask whether banks hedge these shocks "ex-post", i.e. by passing it on to the rest of their corporate portfolio. We are interested in seeing whether banks react by reducing loan supply or raising interest rates, in particular for non-granular firms.

Table 5 reports our results on the supply of credit. Our approach follows closely Khwaja and Mian (2008). In all specifications we impose a stringent configuration of interacted firm $\times$ year $\times$ industry $\times$ county fixed effects. Our specifications regress year-on-year changes in the granular credit shock on year-on-year changes in loan-level credit supply. In columns (1)-(2), we look at the impact of bank-level granular credit shocks - either instrumented or not - on all firms and find no significant relationship. In columns (3)-(4) we restrict the sample to non-granular firms only. Non-granular firms are defined as those whose bank loan shares are below the $50^{\text {th }}$ (column (3)) or $25^{\text {th }}$ (column (4)) percentiles of the loan share distribution. ${ }^{29}$ For example, the median loan share is 0.000211 percent across all loans. We do find a statistically significant relationship in this case, particularly when the threshold for non-granular firms is the 25th percentile. In columns (5)-(6) we add a bank fixed effect to the baseline specification and results do not change substantially. Overall, a one-standard deviation decline in the granular credit shock reduces loan supply growth to non-granular borrowers by up to 71 basis points. This effect is strongly significant.

In Table 6 we repeat the same exercise but with interest flow as the left-hand-side variable. We find a strong negative relationship between year-on-year changes in granular credit risk and yearly growth in loan-level interest flows. We interpret these changes in flows as an effect on the

\footnotetext{
${ }^{28}$ Banks could also dilute single-name concentration risk by engaging in syndicated lending. In the case of Norway, however, syndicated loans constitute a very small fraction of external financing for firms.

${ }^{29}$ We look at alternative definitions of non-granularity in Section D of the Online Appendix.
} 
Table 5: Spillovers from Granular Credit Shocks: Credit Supply

\begin{tabular}{lcccccc}
\hline \hline & $(1)$ & $(2)$ & $(3)$ & $(4)$ & $(5)$ & $(6)$ \\
\cline { 2 - 6 } & \multicolumn{7}{c}{ Dependent Variable: $\Delta$ Loans } \\
\hline$\Delta$ Bank Shock & 0.023 & 0.022 & 0.165 & 0.625 & 0.168 & 0.717 \\
& $(0.043)$ & $(0.043)$ & $(0.129)$ & $(0.288)$ & $(0.136)$ & $(0.311)$ \\
\hline Year x Industry x County x Firm FE & Yes & Yes & Yes & Yes & Yes & Yes \\
Bank FE & No & No & No & No & Yes & Yes \\
Non-Granular Firms (50\%) & No & No & Yes & No & Yes & No \\
Non-Granular Firms (25\%) & No & No & No & Yes & No & Yes \\
Instrumented by GIV & No & Yes & Yes & Yes & Yes & Yes \\
Observations & 15279 & 15279 & 3449 & 348 & 3413 & 322 \\
$\mathrm{R}^{2}$ & 0.484 & & & & & \\
\hline \hline
\end{tabular}

Notes: This table reports results from regressing year-on-year changes in (log) bank debt at the bank-firm level on the year-on-year change in bank-level aggregated firm shocks which are either instrumented by the granular IV as in columns (2)-(6) or not, as in column (1). Specifications are based on equation (9). The GIV is constructed based on equation (6). Columns (1)-(2) include all firms. Columns (3)-(6) include only non-granular firms. Non-granular firms are defined as firms whose bank loan shares are less than the 50th (columns (3)-(4)) or the 25th (columns (5)-(6)) percentiles of the loan share distribution, which is pooled over all banks and years. The full distribution of loan shares is plotted on Figure 1. Standard errors (in parentheses) are double clustered at the bank and firm level.

loan interest rate. A one-standard deviation decline in the granular credit shock increases interest rate growth on loans to non-granular clients by up to 63.4 basis points. Taken together with the positive association with credit quantities, we have identified granular credit risk as a textbook supply-side disturbance: a negative granular credit shock results in a leftward shift in the supply schedule, leading to a reduction in quantities and elevation in credit market prices. In addition, the pass-through mechanism can also be interpreted as operating through a kind of bank credit supply network: two firms that may otherwise not be connected can impact each other's performance through their association with a common lender ${ }^{30}$.

Before proceeding with the rest of the section, we perform a quick but important robustness check. We relax our definition of non-granular firms and consider alternative percentiles of the loan share distribution. It is possible that our results are accidentally driven by the choice of the non-granularity cut-offs (50\% and 25\%). Specifically, we still regard non-granular firms as those with bank loan shares less than the Pth percentile of the pooled credit share distribution. But we now re-estimate our credit supply and interest rate spillover regressions for every $\mathrm{P}$ in the discrete interval [20,99]. Figure 6 of the Online Appendix reports point estimates and 90\% confidence

\footnotetext{
${ }^{30} \mathrm{We}$ control for firm county and industry fixed effects as well as the bank fixed effects. We cannot yet fully rule out, however, that these firms are not also associated through a production network as we do not have the data on firm linkages to test that hypothesis. We return to this point in Section 6.
} 
Table 6: Spillovers from Granular Credit Shocks: Interest Rates

\begin{tabular}{lcccccc}
\hline \hline & $(1)$ & $(2)$ & $(3)$ & $(4)$ & $(5)$ & $(6)$ \\
\cline { 2 - 7 } & \multicolumn{5}{c}{ Dependent Variable: $\Delta$ Interest Flow } \\
\hline Bank Shock & -0.004 & -0.017 & -0.361 & -0.341 & -0.421 & -0.634 \\
& $(0.064)$ & $(0.066)$ & $(0.189)$ & $(0.417)$ & $(0.190)$ & $(0.448)$ \\
\hline Year x Industry x County x Firm FE & Yes & Yes & Yes & Yes & Yes & Yes \\
Bank FE & No & No & No & No & Yes & Yes \\
Non-Granular Firms (50\%) & No & No & Yes & No & Yes & No \\
Non-Granular Firms (25\%) & No & No & No & Yes & No & Yes \\
Instrumented by GIV & No & Yes & Yes & Yes & Yes & Yes \\
Observations & 15279 & 15279 & 3449 & 348 & 3413 & 322 \\
$\mathrm{R}^{2}$ & 0.533 & & & & & \\
\hline \hline
\end{tabular}

Notes: This table reports results from regressing year-on-year changes in (log) interest flows at the bank-firm level on the year-on-year change in bank-level aggregated firm shocks, which are either instrumented by the granular IV (columns (2)-(6)) or not (column (1)). Specifications are based on equation (9). The granular instrument is constructed based on equation (6). Columns (1)-(2) includes all firms. Columns (3)-(6) include only non-granular firms. Non-granular firms are defined as firms whose bank loan shares are less than the 50th (columns (3)-(4)) or the 25th (columns (5)-(6)) percentiles of the loan share distribution, which is pooled over all banks and years. The full distribution of loan shares is plotted on Figure 1. Standard errors (in parentheses) are double clustered at the bank and firm level.

bands for each P. We see that the pass-through of granular credit shocks on credit quantities and prices is strongly and significantly associated with the degree of non-granularity: as firms get more non granular (leftward move along the x-axes), spillover effects become very large. For granular clients (rightward move along the x-axes), however, negative spillovers are minimal. Overall, all these observations are suggestive of a "pecking order" of credit relationships where banks keep credit relations with their main, granular clients unchanged but adjust lending conditions with their non-granular borrowers in order to compensate for portfolio losses.

Next, we ask whether the impact on non-granular firms ultimately leads to significant economic consequences. We aggregate our data to the firm level and consider several firm outcomes as dependent variables. Those include growth in sales, the wage bill, capital and the cash position. In all of the specifications, we include year $\times$ industry $\times$ credit rating, as well as firm and bank fixed effects. In addition, we focus on the samples of non-granular firms where non-granular firms are defined as those whose bank loan shares are below the $50^{\text {th }}$ or $25^{\text {th }}$ percentile of the global distribution of loan shares. In other words, we trace out the economic consequences of a credit supply shock on the same non-granular firms that we show were impacted in Tables 5 and 6.

Results are reported in Table 7. The most interesting results are in columns (2)-(3), where we document that a change in the granular credit shock at the bank level is positively associated 
Table 7: Firm Outcomes from Granular Credit Shocks

\begin{tabular}{lcccccc}
\hline \hline & $(1)$ & $(2)$ & $(3)$ & $(4)$ & $(5)$ & $(6)$ \\
\cline { 2 - 7 } & Capital & Capital & Capital & Sales & Wages & Cash \\
\hline$\Delta$ Bank shock & 0.040 & 0.241 & 0.129 & 0.001 & 0.007 & 0.142 \\
& $(0.030)$ & $(0.095)$ & $(0.251)$ & $(0.031)$ & $(0.040)$ & $(0.146)$ \\
\hline $\mathbb{E}($ dependent variable) & -0.081 & -0.095 & -0.105 & 0.026 & 0.034 & 0.067 \\
Sd(dependent variable) & 0.603 & 0.640 & 0.683 & 0.290 & 0.344 & 1.037 \\
Year $\times$ Industry $\times$ County FE & Yes & Yes & Yes & Yes & Yes & Yes \\
Firm FE & Yes & Yes & Yes & Yes & Yes & Yes \\
Non-Granular Firms (50\%) & No & Yes & No & Yes & Yes & Yes \\
Non-Granular Firms (25\%) & No & No & Yes & No & No & No \\
Instrumented by GIV & Yes & Yes & Yes & Yes & Yes & Yes \\
Observations & 90800 & 39861 & 15444 & 44547 & 45452 & 43994 \\
\hline \hline
\end{tabular}

Notes: This table reports results from firm-level regressions where the outcome variable is either firm-level year-onyear change in $\log$ (capital), $\log$ (sales), $\log$ (wage bill), or $\log$ (cash). The control variable is the year-on-year change in bank-level aggregated firm shocks which are instrumented by the granular IV. Specifications are based on equation (10). The granular instrument is constructed based on equation (6). Non-granular firms are defined as firms whose bank loan shares are less than the 50th or 25th percentile of the loan share distribution. For firms with multiple banking relationships, we define a firm as non-granular if the largest loan share of that firm across all credit relationships is less than the 50th or the 25th percentile of the loan share distribution. For these firms, the bank shock is computed as the average across all lending relationships. The full distribution of loan shares is plotted on Figure 1. All specifications include interacted year x industry x county fixed effects and firm fixed effects. Standard errors (in parentheses) are clustered at the firm level.

with capital growth at the firm level for non-granular borrowers. This suggests that a one-standard deviation negative credit supply shock causes a decline in firms' fixed capital investment growth by roughly 13-24 basis points. The impact on non-granular firms defined by the median loan share cut-off is strongly statistically significant. This result has immediate implications for the real macroeconomy. We also considered outcomes such as sales, the wage bill and the firms cash position. For these variables our coefficient estimates are imprecise, and in all of these cases we are unable to reject the null hypothesis.

Even if non-granular firms have relatively low loan shares, they constitute an important fraction of the economy. Specifically, non-granular firms that are defined by the median loan share cutoff account for at least $15 \%$ of total aggregate capital in the sample in any given year. Granular credit shocks therefore affect a sizable fraction of aggregate capital via credit spillovers. It is also important to emphasize that our estimates constitute a lower bound - we can not rule out further second- and third-order spillover effects to granular clients as well. Granular credit risk can therefore potentially affect an even larger fraction of aggregate investment through the broader credit supply network as well as through general equilibrium effects. 
Table 8: Firm Bankruptcy from Granular Credit Shocks

\begin{tabular}{|c|c|c|c|c|c|c|c|c|}
\hline \multirow[t]{2}{*}{ Probit Model } & (1) & $(2)$ & (3) & (4) & $(5)$ & (6) & (7) & (8) \\
\hline & \multicolumn{7}{|c|}{ Probability of bankruptcy ${ }_{t}$} & $\begin{array}{l}\text { Ever } \\
\text { bankrupt }\end{array}$ \\
\hline$\Delta$ BankShock $_{\mathrm{t}}$ & $\begin{array}{l}-0.609 \\
(0.110)\end{array}$ & $\begin{array}{c}-0.680 \\
(0.196)\end{array}$ & $\begin{array}{c}-1.056 \\
(0.307)\end{array}$ & & & & & \\
\hline$\Delta$ BankShock $_{\mathrm{t}-1}$ & & & & $\begin{array}{c}-0.322 \\
(0.123)\end{array}$ & $\begin{array}{c}-0.965 \\
(0.203)\end{array}$ & $\begin{array}{c}-0.946 \\
(0.334)\end{array}$ & & \\
\hline$\Delta$ BankShock $_{\mathrm{t}-3}$ & & & & & & & $\begin{array}{c}-0.703 \\
(0.239)\end{array}$ & \\
\hline$\Delta$ BankShock $_{\mathrm{t}}$ & & & & & & & & $\begin{array}{l}-1.273 \\
(0.281)\end{array}$ \\
\hline Non-Granular Firms (50\%) & No & Yes & No & No & Yes & No & Yes & Yes \\
\hline Non-Granular Firms (25\%) & No & No & Yes & No & No & Yes & No & No \\
\hline Instrumented by GIV & Yes & Yes & Yes & Yes & Yes & Yes & Yes & Yes \\
\hline Observations & 61819 & 35965 & 20161 & 50897 & 29451 & 16302 & 16648 & 35965 \\
\hline
\end{tabular}

Notes: This table reports results from firm probit regressions of likelihood of firm bankruptcy on the bank-level granular credit shock. In columns (1)-(7), the outcome variable is probability of contemporaneous firm bankruptcy. In column (8), the outcome variable is the probability that a firm ever goes bankrupt. In columns (1)-(3), the control variable is the contemporaneous mean (change in the) bank-level credit shock which is instrumented by the granular IV. In columns (4)-(7), the RHS variable is the GIV-instrumented bank-level credit shock lagged by either one or three years. Columns (1) and (4) are for all firms in sample. Remaining columns restrict the sample to non-granular firms only. Non-granular firms are defined as firms whose bank loan shares are less than the 50th or the 25th percentiles of the loan share distribution, which is pooled over all banks and years. For firms with multiple banking relationships, we define a firm as non-granular if the largest loan share of that firm across all credit relationships is less than the 50th or the 25 th percentile of the loan share distribution. For these firms, the bank shock is computed as the average across all lending relationships. The full distribution of loan shares is plotted on Figure 1. Standard errors in parentheses. Firm bankruptcy information is from the credit rating agency Bisnode.

Finally, we investigate whether the reduction in credit not only affects firm balance sheet outcomes but ultimately firm default. We ask whether a change in the granular credit shock at the bank level is associated with a higher frequency of bankruptcies at the firm level. Table 8 reports the results from our baseline probit regressions. In column (1), we include all firms in the estimation sample. In column (2), we restrict the sample to non-granular firms only, with the threshold being the $50^{\text {th }}$ percentile of the loan share distribution. For both specifications we find a strong negative association. For columns (4)-(6) and (7) we trace out the impact of granular credit shocks in t-1 and t-3, respectively, on the probability of bankruptcy at t. In columns (3) and (6) we run the same regressions but restricting the sample to firms with a loan share below the $25^{\text {th }}$ percentile of the distribution. Finally, in column (8) we regress the probability of a firm filing for bankruptcy at any point over its existence in our dataset on its average granular credit shock. That 
is, we ask if firms that ever default also experience, on average, worse granular credit supply shocks from their lenders. Overall, across all 8 specifications, we find a very strong negative association between granular credit risk and firm bankruptcy probability. The impact is quantitatively very large - a one-standard deviation negative granular credit supply shock increases the likelihood of bankruptcy by roughly 32-60 basis points for all firms, and 68-106 basis points for non-granular borrowers. Additionally, we do find that firms that went bankrupt at some point in the sample are also those that experienced abnormally bad granular credit supply shocks. Our results have direct implications for the aggregate economy and consumer welfare, considering that firm bankruptcy proceedings are very costly in practice.

We conclude this section by reiterating our main findings. First, idiosyncratic firm shocks have a large, long-lasting and significant effect on loan-level returns. Second, these shocks survive portfolio aggregation and impact bank-level outcomes. Importantly, these shocks originate from granular, i.e. large, borrowers which is precisely the reason why they do not wash out. Third, banks do not hedge granular credit risk with income from non-loan businesses such as derivatives or equity investments. Fourth, there are considerable loan-level spillovers of granular credit shocks on non-granular borrowers: affected banks reduce loan supply and increase interest rates on their less important, non-granular clients. Fifth, those affected clients in turn reduce their investment in physical capital and are much more likely to file for bankruptcy. Overall, our results show that idiosyncratic shocks to granular borrowers have important implications for the broader financial and real economy. In the language of financial regulators, single-name credit concentration risk is quantitatively important.

\section{Heterogeneity and Robustness}

In this section, we first provide further evidence on the underlying mechanisms behind our findings. In 5.1 we focus on whether certain firms are more likely to transmit idiosyncratic firm performance shock to their banks and in 5.2 whether certain banks are more exposed to granular credit risk. In 5.3 we discuss several important robustness checks.

\subsection{Firm Heterogeneity}

Loan Outcomes - Balance Sheet Heterogeneity We start by exploring heterogeneous effects of idiosyncratic firm shocks originating from firms with different characteristics. Specifically, we augment specification (2) by interacting our extracted shocks with lagged firm characteristics. We are interested in how the transmission mechanism differs for firms with high leverage, low asset size, low equity, short average debt duration, high bank credit reliance, low credit rating, and young 
age. Each characteristic is thus a dummy which equals 1 for firms in that particular category of interest and 0 otherwise.

Table 7 in the Online Appendix presents the results. There is overall rich firm heterogeneity behind our loan-level outcomes. Relative to the baseline, the pass-through of idiosyncratic firm shocks is stronger for firms with high leverage, low assets, low equity, short debt duration, high reliance on bank debt, lower-than-"A" credit ratings, and firms younger than 3 years. All of these firms, relative to the average firm, are more likely to be more "risky" from the bank's perspective. Interestingly, we find that interactions with firm size and debt duration are statistically different from other characteristics. For macro-prudential purposes, these results offer a new dimension for regulation of concentration risk: banks which are heavily exposed to, for example, small, risky, young firms are at much greater risk of suffering from detrimental idiosyncratic credit shocks than intermediaries that lend to liquid and non-levered corporates.

Loan Outcomes - Extensive Margin Are our loan-level results driven by the intensive or the extensive margin? We are interested in seeing whether the transmission of idiosyncratic firm shocks is different among firms that enter/exit the industry or go bankrupt. Our strategy is to construct a dummy variable for each of the three groups of firms. For entrants, the dummy takes the value of unity in the year following the entry, while for leavers and bankrupt firms the variable equals unity in the year prior to the event. We also consider an "ever-bankrupt" dummy which takes the value of unity for firms that filed for bankruptcy at any point during the 2003-2015 period. The latter variable captures potentially some unobserved intangible characteristics such as poor management skills, which are common for unsuccessful firms but cannot credibly be inferred from balance sheet information.

Table 8 in the Online Appendix reports the results. We see that the shock transmission mechanism is stronger (weaker) among firms which have just entered (about to exit) the industry. We do not find that the channel is stronger among firms which go bankrupt. Overall, the extensive margin is active but does not dominate our results. In other words, even conditional on firms being non-entrants, non-leavers, and not in bankruptcy, negative idiosyncratic shocks can cause lower bank returns. That implies that our results are driven by both the intensive and the extensive margin.

Loan Outcomes - Ownership and Industry Heterogeneity Next, we investigate whether our results are driven by firms with a particular ownership structure or industry affiliation. For example, is the shock transmission stronger among special financial vehicles or construction firms? In Table 9 of the Online Appendix we report firm ownership heterogeneity results, along with our baseline estimates. We see clearly that our results reflect conventional privately owned firms and not state, community, or special financial vehicles. Privately owned firms dominate our sample by a wide 
margin.

Table 10 explores heterogeneous effects by firm sector. Our baseline estimates are almost identical to results from manufacturing firms. Overall, there doesn't appear to be any abnormality across different industries; the real estate sector is the only one where pass-through appears to be significantly smaller.

Loan Outcomes - Geographical Heterogeneity Are our loan-level results driven by idiosyncratic shocks to firms located in particular geographical regions of Norway? Figure 2 in the Online Appendix plots a coloured map of Norway, where each of the 19 counties is colored with a different shade of blue. Darker regions represent a higher local pass-through coefficient of idiosyncratic firm shocks onto loan-level returns. Recall that our baseline average pass-through estimate at the loan level is 0.361. Based on the map we document two main results. First, there is interesting cross-regional heterogeneity in the estimates that is potentially worth exploring in future research. Second, this heterogeneity is not too drastic: county-wide averages are in the $[0.19,0.44]$ range $^{31}$. Finally, we see that our result is not driven solely by Oslo and neighboring counties but is in fact present throughout the country. We therefore conclude that our results are likely not driven by some unusual regional clustering of correlated idiosyncratic shocks.

\subsection{Bank Heterogeneity}

In this section, we explore whether various banks are affected differentially by granular credit shocks aggregated at the portfolio level. We explore several dimensions of bank heterogeneity: portfolio risk weights, (log of) risk-weighted assets (RWA), regulatory capital ratio, loan portfolio Herfindahl (HHI), (log of) number of loans, liquidity ratio, and profitability ratio. ${ }^{32}$ We compute portfolio risk weights by dividing RWA by book assets. The regulatory capital ratio is defined as regulatory capital over RWA. Liquidity is defined as the ratio of cash holdings to book assets. Profitability is defined as the ratio of profits before taxes to book assets. All characteristics are lagged. For each characteristic we define a dummy variable based on the median of the respective lagged distribution. Table 12 of the Online Appendix presents the results. The dependent variable is the return on loans at the bank level. Each column reports coefficients for interactions of GIVinstrumented bank-level firm shocks and dummies for respective lagged bank characteristics. All specifications include the time and bank fixed effects as well as the usual set of bank controls.

\footnotetext{
${ }^{31}$ The exception is the northernmost county, Finnmark, where we find a point estimate of -0.10 . However, this county is also by far the least populated area of Norway.

${ }^{32}$ We use RWA as a proxy for bank size, broadly defined. We have also experimented with book assets, book equity, and regulatory capital as alternative size measures. Results do not change. In addition, we also condition on whether banks are domestically or foreign owned. Baseline results are quantitatively very close to the sub-sample of privately-owned banks; estimates based on foreign banks are consistently imprecise.
} 
From the table we observe several notable results. First, the number of loans does not materially affect the transmission of granular credit shocks, in the sense that the pass-through is also significant for banks with a high number of loans (column (5)). This suggests that granular credit risk is not merely a "small N" problem. Second, the pass-through is stronger for banks with low RWA (column (2)) and high capital ratios (column (3)). The two effects are interconnected, since in the crosssection larger banks are more levered and thus have lower capital ratios. ${ }^{33}$ Third, the pass-through is twice as large for banks with high loan portfolio concentration (column (4)). This is reassuring, since given the same volatility of idiosyncratic firm shocks, higher concentration should make banks more exposed to shocks stemming from the right tail of the loan share distribution. Last but not least, in column (1) we see that banks with higher risk weights tend to be more exposed to granular credit shocks. ${ }^{34}$ This is potentially an important finding because credit concentration risk and the risk-taking channel may form complementarities that could impact an array of macroeconomic outcomes from the financial boom-and-bust cycle to the transmission of monetary policy (Bruno and Shin, 2015). ${ }^{35}$ In order to inspect and better understand this mechanism, we now perform an additional exercise below.

We examine the impact of granular credit risk on bank returns, interacting the granular credit risk shock with both portfolio risk weights and other bank characteristics. Table 13 in the Online Appendix reports the results. Overall, we observe that (with the exception of the left column in specification (6)) estimates for banks with high risk weights are strikingly always higher than for banks with low risk weights. This strongly suggests that the credit concentration risk and risktaking channels are positively associated. The most notable are results in columns (1), (3), and (6). These suggest that the pass-through of granular credit shocks, conditional on the sample of banks with high risk weights, is strongest if banks are small, have concentrated loan portfolios, and record high profits. The result on profits (column (6)) is particularly intriguing since it is consistent with the risk-taking channel: in good states of the world, i.e. when individual firm performance is high, banks with low risk aversion build riskier, concentrated portfolios and record higher profits. However, as our paper argues, this comes at the (potentially unhedged) cost of greater exposure to granular credit risk and eventual portfolio losses during the bad state, i.e. when firm performance is low. Overall, our results add an interesting new angle of portfolio concentration to the literature

${ }^{33}$ The observation that smaller banks are more exposed to granular credit shocks is in line with the existing theories that emphasize the role of bank size heterogeneity in the transmission of aggregate and idiosyncratic disturbances (Stavrakeva, 2019; Davila and Walther, 2020; Jamilov, 2021). In particular, smaller banks tend to have a greater balance sheet sensitivity with respect to exogenous shocks.

${ }^{34}$ Risk weights are not correlated with any of the proxies of bank size: RWA, capital, book assets, or book equity. They are also uncorrelated with the bank-level share of corporate credit to total assets.

${ }^{35}$ It would be logical that banks with high risk weights are exposed to firms that are inherently riskier, similarly to the "evergreening" behavior analyzed by Peek and Rosengren (2005) or assortative matching in the credit market as in (Chang et al., 2021). Our firm balance sheet heterogeneity analysis in Table 7 concluded that returns on loans that are extended to riskier firms are more likely to be affected by idiosyncratic firm shocks. 
on endogenous financial cycles driven by the risk taking of financial intermediaries (Coimbra and Rey, 2019).

\subsection{Robustness Checks}

In this section, we provide several additional robustness checks. First, we gauge the external validity of our findings by comparing concentration in loan portfolios of Norwegian banks to that of U.S. equity investors. Second, we show that our results are robust to production network effects. Third, we check robustness with respect to the Great Financial Crisis (GFC). Fourth, we check that idiosyncratic firm shocks have a pairwise correlation of approximately zero. Fifth, we conduct two placebo tests at various levels of aggregation to lend further support to our baseline results. Sixth, we compare the impact of idiosyncratic borrower risk to that of aggregate shocks. Finally, in order to check if our idiosyncratic shock measure is serially correlated, we estimate a linear panel fixed effects model with AR(1) disturbances at all levels of aggregation.

International Comparison of Exposure Concentration A relevant question to consider is how concentration of Norwegian banks' loan portfolios measures up relative to other countries and/or asset classes. Our empirical analysis has underlined that granularity in the distribution of exposure shares is a necessary condition for the transmission of idiosyncratic shocks to granular exposures to portfolio-level outcomes of the investor. But is this setup unique to Norway? Across various applied studies, we see that portfolio concentration is ubiquitous and important for our understanding of aggregate financial fluctuations. Studying US banks, Kundu and Vats (2021) find that statelevel idiosyncratic shocks transmit through bank networks across states and have macroeconomic implications. Chodorow-Reich et al. (2021) document granularity and concentration in portfolios of life insurers and demonstrate how it matters for the equity market. Camanho et al. (2020) use the granular IV methodology in the context of foreign exchange market fluctuations and fund-level rebalancing decisions.

To supplement our own empirical findings for Norway and these other studies, we perform a quick test of external validity. Namely, we compute the time-varying degree of concentration in equity holdings of U.S. institutional investors. Specifically, for each institutional investor in the SEC 13F holdings data from Thomson/Refinitiv we compute the excess Herfindal index as below ${ }^{36}$ :

$$
\mathrm{eHHI}_{\mathrm{i}, \mathrm{t}}=\sqrt{\sum_{\mathrm{j}} \mathrm{s}_{\mathrm{i}, \mathrm{j}, \mathrm{t}}^{2}-\frac{1}{\mathrm{~N}_{\mathrm{i}, \mathrm{t}}}}
$$

where $s_{i, j, t}$ is the share of exposure $\mathrm{j}$ in investor $\mathrm{i}$ 's portfolio in quarter $\mathrm{t}$ and $\mathrm{N}_{\mathrm{i}, \mathrm{t}}$ is the number

${ }^{36}$ We thank Ralph Koijen, our discussant, for suggesting this idea. 
of exposures. We aggregate by taking value-weighted averages for all investors and also for each individual investor type; we obtain the corrected types from Koijen and Yogo (2018).

Results are plotted on Figure 8 in the Online Appendix. We observe that in terms of portfolio concentration the Norwegian corporate loan sector is not very dissimilar to the universe of U.S. equity investors - the weighted Herfindahl is in the 0.1-0.13 ballpark for both sectors. Panel (b) of Figure 8 plots heterogeneity by investor type. We see that loan concentration in Norwegian banks is closest (in fact, quantitatively almost identical) to that of Investment Advisors, the category which constitutes more than $70 \%$ of the entire sample. All in all, we therefore conclude that the Norwegian context is not exceptional and our analysis and conclusions can potentially extend to other circumstances, countries, and asset classes.

Production Network Spillovers A potential threat to identification in Tables 7 and 8 is that the coefficient estimates are driven by production network spillovers rather than spillovers through common lenders. For instance, granular borrowers could be linked to non-granular borrowers not only via their common lender but also by being an important customer of the non-granular borrower, or vice-versa. If that is the case, production network spillovers could be an alternative explanation for the positive association between the Granular Credit Shock and real outcomes for non-granular borrowers. To alleviate this concern, we do a robustness exercise where we use aggregate inputoutput tables for the Norwegian economy to restrict attention to non-granular borrowers that are sufficiently downstream, i.e. firms that have low dependence on the demand from other firms.

Specifically, for each sector $i$, we compute how much different sectors $\mathrm{j}$ account for sector i's sales - including i's own sector - and refer to that as the inter-sector exposure between sector $\mathrm{i}$ and $\mathrm{j}$. We then compute the maximum inter-sector exposure across all j's for each i, and restrict attention to firms in sectors in the first quartile of the maximum inter-sector exposure. These firms have low exposure to all other sectors, and are typically firms far downstream, i.e. firms selling primarily to households. For these firms, demand from granular borrowers are of limited importance. In Tables 14 and 15 in the Online Appendix, we redo the firm spillover exercise for this restricted sample. Point estimates remain similar, albeit slightly noisier. In particular, from Table 14 we observe that the association with capital growth, particularly of non-granular firms, remains economically and statistically significant. And from Table 15, while contemporaneous effects are now insignificant, in columns (4)-(8) we see the same strong negative association between granular credit shocks and firm bankruptcy.

The exercise above relies on the definition of downstream supply chains, i.e. our chosen cut-off for inter-sector exposures. We now consider a discrete measure of inter-firm linkages. Specifically, we iteratively restrict the estimation sample to firms operating in sectors in the Pth percentile of the distribution of maximum inter-sector exposures. Firms in the lower percentiles are more 
downstream. We re-run our firm and bankruptcy regressions for each $\mathrm{P}$ in $[5,50]$. Figure 7 in the Online Appendix reports the results. On the left panel we present point estimates and 90\% confidence bands for the same regression specification as in Column (2) of Table 14 but with P on the $\mathrm{x}$-axis. On the right panel, we present point estimates and $90 \%$ confidence bands for the same probit specification as in Column (5) of Table 15 but with $\mathrm{P}$ on the $\mathrm{x}$-axis. From both panels we see that our results are not influenced by the choice of the cut-off: point estimates are essentially quantitatively unchanged and by and large always statistically significant. For very low values of $\mathrm{P}$, the sample size dwindles and estimates become very noisy. If anything, we notice that the impact on the probability of bankruptcy is vaguely greater for more downstream firms, i.e. accounting for production networks actually strengthens our findings. Overall, this suggests that production network spillovers do not explain our firm spillover results.

Robustness to GFC In order to investigate whether the relationship between granular credit risk and loan or bank outcomes is robust to the Great Financial Crisis, we redo our estimation focusing on years before or after the GFC. Table 16 in the Online Appendix reports the results. We highlight three main observations. First, our results do not vanish for either of the two sub-periods. Second, this is true for both loan-level and bank-level estimations. Third, estimates are slightly noisier for the pre-GFC period, although still statistically significant.

Pairwise Correlations Test An important question that must be addressed is potential piecewise correlation of our idiosyncratic firm shocks. Systematic residual correlation across firms may indicate that our shocks are still driven by common factors, which would invalidate our conjecture that fluctuations are truly idiosyncratic. For example, we could be capturing some unobserved network effects such as the ones induced by firm trade credit relationships. To test this, we compute pairwise correlation coefficients across any two pairs of firms in our sample. Figure 9 of the Online Appendix presents the result. In total we have 1,861,485 pairs across a balanced panel sub-sample of our data. The average pairwise correlation is 0.019 and the standard deviation is 0.342. This implies that the average correlation coefficient can not be statistically distinguished from zero. This provides reassuring evidence in support of our idiosyncratic firm shocks being truly idiosyncratic and not being driven by unobserved factors that induce cross-sectional correlation, such as production networks.

Placebo Regressions To ensure that we do not falsely reject the null hypothesis due to potentially serially correlated error-terms, we follow Chetty et al. (2009) and implement a nonparametric permutation test for whether the true effect of idiosyncratic firm shocks on loan returns is zero. In order to do so, we randomly reassign the estimated firm-level shocks and redo the analysis at 
the loan and bank levels. Placebo Monte-Carlo permutations results are reported in Table 17 of the Online Appendix. We find that we can reject the null hypothesis of no association (at the $1 \%$ level) under this non-parametric distribution. In words, it's highly unlikely that our results are due to random chance. Furthermore, at the level of the bank, we confirm that our finding of strong asymmetric effects is not coincidental since the permuted positive-only shock estimate has a p-value of 0.82 , while the negative-only shock estimate has a p-value of 0.000 .

Further, to illustrate how our idiosyncratic shocks pick up economically meaningful information, we run a series of placebo regressions where firm shocks are randomly drawn from a uniform distribution instead of being extracted from the economic specification 1. The results from using these drawn shocks at the loan- and bank-level are reported in Table 18 of the Online Appendix. Across all specifications and levels of aggregation we find no association between these random shocks and loan or bank outcomes.

Impact of Aggregate Shocks In this paper our primary focus is on the effect of idiosyncratic firm shocks on banks and the broader economy. But how do idiosyncratic shocks compare to aggregate risk? Section 4.3 demonstrates that idiosyncratic borrower-level risk is not always insured against in practice, but the margin of adjustment when it comes to hedging aggregate risk is surely even tougher. We re-estimate our baseline bank-level regression with two proxies of aggregate risk on the right-hand side: Norway's real GDP and the price of Brent oil. We look at oil prices because exports of crude oil and natural gas accounted for 17\% of the country's GDP in 2015.

Results are reported in Table 19 of the Online Appendix. Column (1) restates the baseline estimates from Table 3, Column (6). In columns (2)-(3) the main regressors are now (standardized) real GDP and oil prices, respectively. Point estimates for GDP and oil prices are greater by factors of 3 and 5, respectively, and are statistically significant but nevertheless remain within the same order of magnitude as the estimate in Column (1). Of course, neither of the two aggregate variables are truly "shocks" and these regression estimates are likely biased upwards. Therefore, the relative effect of idiosyncratic borrower risk compared to aggregate risk is most likely larger than what we can capture with this simple exercise.

Fitting a Fixed Effects Model with AR(1) Disturbance We now run our firm shocks through an autoregressive linear model of order 1 in order to establish whether shocks are persistent or not. We also want to facilitate future structural analysis of models with a financial sector that is subject to "idiosyncratic granular borrower risk". Specifically, we fit the full cross-section of firm shocks into a linear fixed effects model with an AR(1) disturbance term. Results are reported in Table 20 of the Online Appendix. Parameters of the process - autoregressive coefficient and standard deviation of the error term - are reported for all levels of aggregation. Overall, we find that the idiosyncratic 
firm shock is volatile (standard deviation of roughly 0.2 ) and not persistent at all (auregressive coefficient of roughly $0.12-0.32$ ). A volatile iid process is likely to approximate granular credit risk rather well.

\section{Discussion}

In this section, we discuss several issues that are relevant for our empirical analysis. First, we discuss the literature on firm and bank credit networks and its implications for our results and methodology. Second, we discuss potential origins of large loan exposures.

\subsection{Network Effects}

A vibrant new literature emphasizes the role of bank and firm credit networks in the amplification and propagation of non-systematic shocks. One stream of the literature shows that bank credit supply shocks propagate along firm production networks, causing sizable real economic effects (Huremovic et al., 2020; Dewachter et al., 2020). We relate to this literature in two ways. First, in our analysis of economic spillovers, we essentially identify a credit supply network: there exists a pass-through mechanism for idiosyncratic borrower risk between two potentially unrelated firms that are "connected" via the balance sheet of their common lender. Second, a negative granular credit shock, passed onto non-granular borrowers via higher rates or lower quantities of credit, is a leftward shift of the credit supply curve and maps into the bank credit supply shocks in Huremovic et al. (2020) and Dewachter et al. (2020). We establish the first-degree direct effect of these shocks on firm performance and bankruptcy rates. However, because we do not observe firm-level inputoutput or trade-credit networks, we can not speak of higher-degree effects from these networks. Thus, our analysis of economic spillovers of granular credit shocks in Section 4.4 establishes a lower bound on the total pass-through to the real economy.

Another stream of the literature such as Elliott et al. (2020) has recently shown that when banks are individually exposed to the same set of firm industries, idiosyncratic industry-specific risk gets amplified as opposed to getting mitigated by wholesale interbank trading markets. More broadly, mismeasured idiosyncratic firm disturbances could actually masquerade some unobserved/unmeasured borrower-side network-level risk. In the first stage of our analysis, it is possible that our measure of firm value-added shocks is in fact some kind of common local production network risk. This problem is mitigated considerably by the following four reasons. First, in Section 5.3 we explicitly account for production network effects at the sectoral level by leveraging input-output tables of the Norwegian economy. We find that production network linkages do not explain our results, in particular the spillovers from granular credit shocks on the rest of the 
economy. Second, when extracting firm value-added shocks, we impose a stringent combination of industry, location, and time fixed effects. Any unobserved network factor would have therefore to operate within the same year, industry, and county. Observations are sufficiently dispersed across geographical regions, with four out of 19 counties having more than 100,000 loan $\times$ year observations and the average being just over 50,000. In addition, our industry identifiers are very granular with only 3 out of the 99 two-digit industries having more than 100,000 loan $\times$ year observations. Third, we plotted in Figure 9 the pairwise cross-sectional correlation of firm shocks and found no indication of common shocks. Finally, the presence of local production network effects would not invalidate our GIV approach. As long as the sequence of idisoyncratic shocks is unrelated to bank-side factors, our exogeneity assumption in equation (8) holds regardless of whether the firm-level shocks truly are firm-level or composite outcomes of very local network structures. The question of networks is therefore ultimately a matter of composition, not of identification.

\subsection{Origins of Large Exposures}

Credit concentration is an equilibrium object that is an outcome of more fundamental factors such as monitoring technology, risk preferences, information structure and expectations. Although writing down a micro-founded model of banking concentration is beyond the scope of this paper, discussing theoretical causes of concentration is useful for at least two reasons. First, the orthogonality of loan shares to idiosyncratic firm shocks is a key component of our empirical strategy, as highlighted in equation (8). Second, our paper is related to a large literature on the trade-off between risk concentration and economic performance and any normative implication would have to take into account the underlying causes of concentration.

One reason for the large degree of credit concentration observed in our data could simply be the shape of the distribution of firm sizes; credit concentration could also be linked to asymmetric information or behavioral biases, both of which could materialize as home bias. Juelsrud and Wold (2020) document a substantial degree of within-county bias in the Norwegian banking system (see Figure 5). Using loan-level data, Juelsrud and Wold (2020) show that over 2003-2015 the average proportion of bank credit to firms that are headquartered in the same region as the lender was $55 \%$. This compares to a random-assignment counterfactual of less than $10 \%$, implying a home bias of $45 \%$. Home bias is, of course, a perennial stylized fact in international finance, banking, and macroeconomics (Coeurdacier and Rey, 2013).

In what follows, we discuss these three potential causes of portfolio concentration: asymmetric information, behavioral biases and the distribution of firm sizes. 
Asymmetric Information. Concentrated lending could be a by-product of persistent credit relationships. When information acquisition on new clients is costly, lenders may find it optimal to do business with a recurring set of borrowers, for instance by increasing the number of new commitments per relationship such as offering additional fixed-term loans or extending new credit lines (Sufi, 2007). Along the intensive margin, an increase in the exposure of an informed lender signals a higher quality of the underlying borrower, thereby reducing the cost of asymmetric information (Leland and Pyle, 1977). Van Nieuwerburgh and Veldkamp (2009) show in a rational inattention framework that investors may choose to learn only about assets for which they had an information advantage to start with (such as home assets), thus amplifying initial information asymmetries.

Ivashina (2009) proposes and tests a theory where the price of a loan is determined by a trade-off between diversification and asymmetric information. If a bank raises its exposure to a single borrower, two effects take place. First, the lender demands a higher premium for being more exposed to borrower-specific idiosyncratic risk. Second, assuming that expenditures on monitoring scale with exposure, concentration also reduces information asymmetry between the lender and the borrower, thus reducing the premium. In equilibrium, the price of the contract depends on the degree of information asymmetry and the magnitude of idiosyncratic fluctuations.

In our data, we observe a substantial degree of credit concentration. This is true at all levels of aggregation: single name, geographical, sectoral. In light of Ivashina (2009), this may suggest that Norwegian lenders attach large benefits to information acquisition. This is intuitive, given that the majority of firms in our data are not publically listed and are instead locally-focused small enterprises. Information collection and monitoring is therefore costly, and potentially increases with distance. This could explain both the regional home bias and the single name credit concentration facts. Banks' portfolio-level (over-)exposure to single borrowers solves the structural asymmetric information problem, but at the cost of an elevated vulnerability towards idiosyncratic shocks. Sensitivity to a given distribution of idiosyncratic borrower shocks (the loan share distribution $\mathrm{s}_{\mathrm{i}, \mathrm{j}, \mathrm{t}}$ ) can be explained by the banks' decision to invest in localized information acquisition, which is in turn driven by pre-determined factors such as the returns to information acquisition. This class of explanations validates our empirical approach.

Behavioral Biases. A second theory that could rationalize credit concentration rests on behavioral biases ${ }^{37}$. Huberman (2015) for example shows that some investors tend to ignore portfolio diversification theory and invest in familiar assets. Our exogeneity assumption (8) is valid under this "familiarity effect" at the bank-level. In that case, overexposure of bank i in firm $j$ at time $t$ is largely independent of the firm's present characteristics but is instead a function of i's subjective beliefs.

${ }^{37}$ Fuster et al. (2010) review the extensive literature on the departures from rational expectations in finance and macroeconomics. 
Thus, behavioural biases of this kind would also be compatible with our empirical approach.

Distribution of firm sizes. Finally, credit concentration could be a by-product of the underlying firm size distribution also being fat tailed, which is definitely the case for Norway. Studies by Carvalho and Gabaix (2013) and Carvalho and Grassi (2019), among others, have shown that the presence of a small number of large firms can explain a substantive percentage of aggregate macroeconomic fluctuations. Similarly, Gaubert and Itskhoki (2021) show that up to 20\% of international export intensity can be attributed to granular firms. In the case of bank lending, if large firms are also large borrowers - a condition which is true in our data - the Pareto rate of the credit share distribution is driven by the Pareto rate of the firm size density. While this is a very natural explanation for the observed credit concentration and the one we pursue below in Section 7, it is worth nothing that in our data we also observe substantial heterogeneity in portfolio Herfindahl indices across banks, even among lenders of the same region. Banks do not all hold the same portfolio. Thus, (local) firm size concentration is not enough to completely explain either the home bias in bank lending or portfolio concentration. Financial frictions - be it informational, technological, or behavioral - are important as well.

For the purpose of the empirical analysis, we note that the three classes of models that we put forward to explain the origin of credit concentration (asymmetric information, behavioural biases, distribution of firm sizes) are all compatible with our empirical approach and identification strategy. ${ }^{38}$

\section{Theoretical Motivation}

Throughout the paper, we have exploited the stylized fact that the distribution of bank credit exhibits a fat tail. In this section, we provide one simple possible theoretical rationalization for this observation. ${ }^{39}$ In the data, the right tail of the loan distribution is populated by a small number of very large loan contracts (as a share of the bank portfolio). These large loan contracts are almost always underwritten to big firms, a fact which we verify from our dataset. It is well known that the size distribution of firms is fat-tailed. If firm credit is a function of firm size, then we can precisely derive how the granularity of the firm distribution translates into the granularity of credit and affects portfolio-level outcomes.

A theoretical challenge encountered when formalizing this intuition is the fact that both firm loan and firm size distributions could potentially have infinite variances. In this particular case, standard central limit theorems break down. Following Gabaix (2011), we therefore resort to

\footnotetext{
${ }^{38}$ Those theories would have, however, different normative implications.

${ }^{39}$ As noted in section 6.2 , other frictions would have to be added to fully account for the data.
} 
Lévy's generalized central limit theorems that can accommodate distributions with fat tails. In this section, we provide sufficient conditions for distributional parameter values to ensure that assuming the firm size distribution has a fat tail - the firm credit distribution also has a fat tail.

A Simple Model of Firm Debt Suppose there are N firms in the economy ${ }^{40}$. Before production can begin, firms must obtain funding. By assumption, each firm $i$ is cash-strapped and has to start the period by borrowing $\mathrm{L}_{\mathrm{it}}$ from a bank. The growth rate of firm debt demand evolves according to:

$$
\frac{\Delta \mathrm{L}_{\mathrm{i}, \mathrm{t}+1}}{\mathrm{~L}_{\mathrm{it}}}=\sigma_{\mathrm{i}} \epsilon_{\mathrm{i}, \mathrm{t}+1}
$$

where $\sigma_{\mathrm{i}}$ is the volatility of firm-level debt growth and $\epsilon_{\mathrm{i}, \mathrm{t}+1}$ are i.i.d. random variables. Economywide total stock of firm debt is:

$$
\mathrm{D}_{\mathrm{t}}=\sum_{\mathrm{i}}^{\mathrm{N}} \mathrm{L}_{\mathrm{it}}
$$

and growth of financial debt in the economy is

$$
\frac{\Delta \mathrm{D}_{\mathrm{t}+1}}{\mathrm{D}_{\mathrm{t}}}=\sum_{\mathrm{i}}^{\mathrm{N}} \sigma_{\mathrm{i}} \frac{\mathrm{L}_{\mathrm{it}}}{\mathrm{D}_{\mathrm{t}}} \epsilon_{\mathrm{i}, \mathrm{t}+1}
$$

The variance of growth of total debt is the weighted sum of the variance of the volatility of idiosyncratic shocks to debt demand, with the shares equaling the squared share of firm $i$ 's borrowing in the total economy. Assuming $\sigma_{\mathrm{i}}=\sigma \forall \mathrm{i}$, we have:

$$
\sigma_{\mathrm{D}}=\left[\sum_{\mathrm{i}}^{\mathrm{N}} \sigma\left(\frac{\mathrm{L}_{\mathrm{it}}}{\mathrm{D}_{\mathrm{t}}}\right)^{2}\right]^{\frac{1}{2}}
$$

It is clear from equation 14 that the variance of total debt depends on the distribution of firmlevel debt demand $\mathrm{L}_{\mathrm{it}}$. In our data, we see that firm-level borrowing is strongly positively correlated with firm size. Let firm size, proxied by either total assets or sales, be $y_{i t}$. Assume idiosyncratic volatility of firm growth $\sigma_{\mathrm{y}}$ is constant and common to all firms. Following Gabaix (2011), we assume that $\mathrm{y}_{1}, \ldots, \mathrm{y}_{\mathrm{N}}$ are drawn from a power law distribution:

$$
\mathbb{P}(y>x)=(1+x)^{-\alpha}
$$

with the exponent $\alpha \geq 1$. Note that we set the location and scale parameters to zero and unity, for simplicity. In the literature, this precise specification of a power law corresponds to a Pareto distribution of Type II.

${ }^{40}$ Alternatively, suppose there are $\mathrm{N}$ borrowers in a given bank's portfolio and we treat the bank as the "economy". 
Now, we assume a specific functional form for the amount of borrowing $\mathrm{L}_{\mathrm{it}}$ as a function of size $y_{i t}$ :

$$
\mathrm{L}_{\mathrm{it}}=\mathrm{y}_{\mathrm{it}}^{\lambda_{\mathrm{i}}}
$$

where $\lambda_{\mathrm{i}}>0 \forall \mathrm{i}$. We proceed with the assumption that $\lambda_{\mathrm{i}}=\lambda$ is homogenous across all firms.

Drawing from the literature on statistics, economics, and actuarial sciences, we know that once $\mathrm{y}_{\mathrm{i}}$ follows a power law, then $\mathrm{y}_{\mathrm{i}}^{\lambda}$ follows a Champernowne (1952) distribution, also known as the Burr Type XII, with parameters $\{\tau, \alpha\}$ where $\tau=1 / \lambda$ (Rodriguez, 1976). In economics, this distribution is commonly referred to as the Singh-Maddala (SM) density (Singh and Maddala, 1976). It has been used widely to model household income and wealth inequality. Formally:

$$
\mathbb{P}(\mathrm{L}>\mathrm{x}) \sim\left(1+\mathrm{x}^{\tau}\right)^{-\alpha}
$$

with $\tau>0$. For the special case of $\tau=1$, firm debt becomes linear in size, the distribution collapses to a Pareto Type II, and we are back to Gabaix (2011). In general, the rate of decay of $\sigma_{\mathrm{D}}$, as the sample size grows, will depend on the value of structural parameters. For the special case of $1<\tau \alpha<2$, the SM random variable has an infinite variance and standard limit theorems break down. There is therefore a direct link between the fat tail of the firm distribution and of the credit distribution. This result is summarized in our main proposition below:

Proposition 1. Let firm sizes $\mathrm{y}_{\mathrm{i}} \ldots \mathrm{y}_{\mathrm{N}}$ be drawn from a power law distribution with exponent $\alpha \geq 1$. Suppose each firm has non-rationed access to the credit market, through which on demand it borrows a fraction $\mathrm{y}^{\lambda-1}$ of its size, with $\lambda>0$. Firm-level borrowing is thus $\mathrm{L}=\mathrm{y}^{\lambda}$, which grows with a constant idiosyncratic volatility $\sigma$. L follows the Singh-Maddala distribution with power and shape parameters $\{\alpha, \tau\}$ :

$$
\mathbb{P}(\mathrm{L}>\mathrm{x}) \sim\left(1+\mathrm{x}^{\tau}\right)^{-\alpha}
$$

with $\tau=1 / \lambda$. Then, as $\mathrm{N} \rightarrow \infty$ :

- For $1<\alpha \tau<2$, by the Lévy's central limit theorem, the volatility of aggregate debt $D$ is given by $\sigma_{\mathrm{D}} \sim \sigma \frac{1}{\mathrm{~N}^{1-1 /(\alpha \tau)}} \sqrt{\eta}$, where $\eta$ is a Lévy random variable with exponent $\frac{\alpha \tau}{2}$

- For $\alpha \tau \geq 2$, by the Lindeberg-Lévy classical central limit theorem, the volatility of aggregate debt $D$ is given by $\sigma_{\mathrm{D}} \sim \sigma \frac{1}{\mathrm{~N}^{1 / 2}} \sqrt{\eta}$, where $\eta$ is a constant

Proof: Section G of the Online Appendix.

Our notation means that $\sigma_{\mathrm{D}} \sim \sigma \frac{1}{\mathrm{~N}^{1-1 /(\alpha \tau)}} \sqrt{\eta}$ implies convergence in distribution of $\sigma_{\mathrm{D}} \mathrm{N}^{1-1 /(\alpha \tau)}$ to $\sigma \sqrt{\eta}$, where $\eta$ is a stable Lévy random variable. What we have shown is that the distribution of firm debt could have either thin or fat tails. If $\alpha \tau \geq 2, \sigma_{\mathrm{D}}$ decays according to $\frac{1}{\sqrt{\mathrm{N}}}$. However, 
if $1<\alpha \tau<2$, then $\sigma_{\mathrm{D}}$ decays at the rate of $\frac{1}{\mathrm{~N}^{1-\frac{1}{\alpha \tau}}}$, i.e. more slowly. In this case, idiosyncratic shocks to borrowers could drive the total debt portfolio and, as in our main empirical experiments, affect aggregate outcomes.

\subsection{Model Parameter Estimation}

In this section, we test whether the parameter restriction $1<\alpha \tau<2$ can be supported by our data. First, we fit the Generalized Pareto density into the size distribution of firms. Most studies in the literature treat sales as the size proxy. We, apart from sales, also consider total equity and total assets as alternative size proxies that could be relevant for deciding on how much bank credit to request. This step grants us three estimates of $\alpha$. Second, we back out firm-specific $\lambda_{\mathrm{i}}$ directly from equation (16) and then take the median of the resulting distribution. We conduct this step for all three definitions of size as well. As a result, we have three estimates for $\alpha \tau$ - the sufficient statistic that determines the speed of decay of $\sigma_{\mathrm{D}}$.

Table 21 in the Online Appendix reports the results from maximum likelihood estimation of $\alpha$ and other parameters. Our estimates confirm that the $1<\alpha \tau<2$ restriction is supported in the data. We find that $\alpha$ is in the $[1.26,1.49]$ range and $\alpha \tau$ is between 1.38 and 1.64, i.e. firmly within the $(1,2)$ bounds. Our estimation results suggest that both the firm size and the firm loan distributions can be reasonably approximated with fat-tailed densities. The aggregate credit distribution can be affected by firm-level disturbances: credit risk is granular.

\section{Conclusion}

This paper has developed the first bottom-up causal quantification of single-name credit concentration risk on bank-level outcomes and on the economy. While the previous literature focused on the effects of sectoral or geographic exposure risk, we drill down to the very granular level of single-name concentration risk. Empirically, we show there is a causal link between idiosyncratic firm shocks and returns on bank credit. Unexpected shocks to firm value-added affect loan-level and bank-level performance. We capture strong asymmetries associated with the debt contract structure by showing that negative firm shocks lead to a reduction in bank returns, while positive shocks have zero impact. We explored numerous dimensions of heterogeneity at all levels of aggregation.

We find strong evidence of a second-level pass-through effect of granular borrower risk onto other firms. Banks, in response to negative shocks to their granular borrowers, cut credit supply and increase interest rates on loans to their non-granular borrowers. Affected non-granular firms, in turn, reduce investment in physical capital. Affected firms are also more likely to file for bankruptcy following a negative granular shock to their credit provider. These results suggest that single-name 
credit concentration risk carries significant implications for the macroeconomy.

The first key message of the paper is therefore that idiosyncratic firm shocks do not wash out and still matter at the level of the bank portfolio. Conventional wisdom that banks are subject only to aggregate risk due to pooling and the law of large number is not borne out in the data. Concentration risk matters quantitatively. Our evidence from non-interest income data further suggests that banks do not compensate for loan book losses through earnings from alternative sources such as derivatives or equity holdings. The second key message of the paper is that there are important granular credit risk spillovers affecting the real economy.

Methodologically, we make progress on identification of firm demand-side shocks at the level of bank portfolios by employing the "granular instrument variable" approach developed in recent work by Gabaix and Koijen (2020, 2021). This method takes advantage of the fact that the distribution of loan shares features a fat tail and allows for a tightly-identified pass-through of granular risk. We also present a simple theory of the "granularity of credit" building on the well-known fact that the size of firms follows a power law distribution. Using our high quality comprehensive dataset we can estimate the parameters of the Pareto distribution governing the distribution of loans and confirm its granularity.

Our results have implications for the regulation of large credit exposures. Our pass-through estimates in Table 3 could be used to compute the granular Value-at-Risk, i.e. the bank capital that is at risk if a granular borrower suffers a bad negative shock. Our estimate of the loan share Pareto power of section 7 could be used as a tool for understanding when banks are becoming prone to granular credit risk. A drop in the Pareto power estimate to 2 or below could constitute a regulatory "red flag". In practice, the parameter could be computed for each financial institution in the cross-section. The system-wide weighted average Pareto estimate could become a novel timeseries indicator of aggregate concentration whose changes could track fluctuations in system-wide credit concentration risk.

\section{References}

Acharya, V., I. Hasan, AND A. Saunders (2006): "Should banks be diversified? Evidence from individual bank loan portfolios," Journal of Business, 79.

Agarwal, S., R. Correa, B. Morais, J. Roldan, and C. Ruiz-Ortega (2020): “Owe a Bank Millions, the Bank Has a Problem: Credit Concentration in Bad Times," International Finance Discussion Papers, 1288.

Aмiтi, M., O. Iтsкнокі, AND J. Konings (2019): "International Shocks, Variable Markups, and Domestic Prices," Review of Economic Studies, 86. 
Amiti, M. And D. Weinstein (2018): "How Much Do Idiosyncratic Bank Shocks Affect Investment? Evidence from Matched Bank-Firm Data," Journal of Political Economy, 126.

Beck, T., O. D. Jonghe, And K. Mulier (2017): "Bank sectoral concentration and (systemic) risk: Evidence from a worldwide sample of banks," CEPR Working Paper, DP12009.

BIS (2013): "Supervisory framework for measuring and controlling large exposures," Consultative Document.

Boyd, J. H. AND E. C. Prescott (1986): “Financial intermediary-coalitions,” Journal of Economic Theory, 38.

Bremus, F., C. Buch, K. Russ, And M. Schnitzer (2018): "Big Banks and Macroeconomic Outcomes: Theory and Cross-Country Evidence of Granularity," Journal of Money, Credit and Banking, 50.

BRuno, V. AND H. SHIN (2015): "Capital flows and the risk-taking channel of monetary policy," Journal of Monetary Economics, 71.

Camanho, N., H. Hau, And H. Rey (2020): "Global portfolio rebalancing and exchange rates," NBER Working Paper 24320.

Carvalho, V. and X. Gabaix (2013): “The Great Diversification and its Undoing," American Economic Review, 103(5).

Carvalho, V. M. And B. Grassi (2019): “Large Firm Dynamics and the Business Cycle,” American Economic Review, 109(4), 1375-1425.

Champernowne, D. G. (1952): “The Graduation of Income Distributions,” Econometrica, 20, 591-615.

Chang, B., M. Gomez, And H. Hong (2021): "Sorting Out the Real Effects of Credit Supply," NBER Working Paper, 28842.

Chetty, R., A. Looney, And K. Kroft (2009): "Salience and taxation: Theory and evidence," American economic review, 99, 1145-77.

Chodorow-Reich, G. (2014): “The Employment Effects of Credit Market Disruptions: Firm-level Evidence from the 2008-09 Financial Crisis," Quarterly Journal of Economics, 129.

Chodorow-Reich, G., A. Ghent, And V. Haddad (2021): “Asset Insulators,” Review of Financial Studies, 34.

Choi, N., M. Fedenia, H. Skiba, And T. Sokolyk (2017): "Portfolio concentration and performance of institutional investors worldwide," Journal of Financial Economics, 123.

Coeurdacier, N. ANd H. Rey (2013): "Home Bias in Open Economy Financial Macroeconomics," Journal of Economic Literature, 51(1).

Coimbra, N. AND H. Rey (2019): “Financial Cycles with Heterogeneous Intermediaries,” NBER Working Paper, 23245.

Davila, E. AND A. Walther (2020): “Does Size Matter? Bailouts with Large and Small Banks,” 
Journal of Financial Economics, 136(1).

Dewachter, H., J. Tielens, And J. V. Hove (2020): “The Production Network Sources of Bank Influence," Working Paper.

Di Giovanni, J., A. Levchenko, And A. Mejean (2014): "Firms, destinations, and aggregate fluctuations," Econometrica, 82(4).

di Giovanni, J., A. Levchenko, And I. Mejean (2018): “The Micro Origins of International Business Cycle Comovement," American Economic Review, 108(1).

Diamond, D. (1984): "Financial Intermediation and Delegated Monitoring," Review of Economic Studies, 51(3).

Doerr, S. AND P. Schaz (2021): "Geographic diversification and bank lending during crises," Journal of Financial Economics, 140.

Elliott, M., C.-P. Georg, AND J. Hazell (2020): "Systemic Risk Shifting in Financial Networks," Journal of Economic Theory (Forthcoming).

Fagereng, A., L. Guiso, and L. Pistaferri (2018): "Portfolio Choices, Firm Shocks, and Uninsurable Wage Risk," Review of Economic Studies, 85(1).

Foster, L., J. Haltiwanger, and C. Syverson (2008): "Reallocation, Firm Turnover, and Efficiency: Selection on Productivity or Profitability?" American Economic Review, 98(1).

Foster, L. S., C. A. Grim, J. Haltiwanger, and Z. Wolf (2017): "Macro and Micro Dynamics of Productivity: From Devilish Details to Insights," .

Fuster, A., D. Laibson, ANd B. Mendel (2010): "Natural Expectations and Macroeconomic Fluctuations," Journal of Economic Perspectives, 24(4).

Gabaix, X. (2009): "Power Laws in Economics and Finance," Annual Review of Economics, 1. (2011): "The Granular Origins of Aggregate Fluctuations," Econometrica, 79(3).

Gabaix, X. AND R. KoIJen (2020): "Granular Instrumental Variables," NBER Working Paper 28204.

(2021): "In search of the origins of financial fluctuations: The inelastic markets hypothesis," NBER Wokring Paper 28967.

GaUbert, C. ANd O. ITsKhoкi (2021): "Granular Comparative Advantage," Journal of Political Economy, 129.

Goetz, M. R., L. Laeven, And R. Levine (2016): "Does the Geographic Expansion of Banks Reduce Risk?" Journal of Financial Economics, 120(2).

Greenwald, D., J. Krainer, and P. Paul (2020): “The Credit Line Channel,” Working Paper.

Guiso, L., L. Pistaferri, AND F. Schivardi (2005): "Insurance within the Firm," Journal of Political Economy, 113(5).

Hsien, C. And P. Klenow (2009): "Misallocation and Manufacturing TFP in China and India," The Quarterly Journal of Economics, 124(4). 
Huberman, G. (2015): “Familiarity Breeds Investment," The Review of Financial Studies, 14, $659-680$.

Huremovic, K., G. Jimenez, E. Moral-Benito, J. L. Peydro, and F. Vega-Redondo (2020): "Production and Financial Networks in Interplay: Crisis Evidence from Supplier-Customer and Credit Registers," Working Paper.

IvashinA, V. (2009): "Asymmetric information effects on loan spreads," Journal of Financial Economics, 92(2).

JAMILOV, R. (2021): “A Macroeconomic Model with Heterogeneous Banks," Manuscript.

Jimenez, G., A. Mian, J. L. Peydro, and J. Saurina (2020): "The Real Effects of the Bank Lending Channel," Journal of Monetary Economics, 115.

Jimenez, G., S. Ongena, J. L. Peydro, and J. Saurina (2014): “Hazardous times for monetary policy: What do twenty-three million bank loans say about the effects of monetary policy on credit risk-taking?" Econometrica, 82.

Juelsrud, R. E. AND E. G. Wold (2020): "Risk-weighted capital requirements and portfolio rebalancing," Journal of Financial Intermediation, 41.

KhwAJA, A. I. AND A. Mian (2008): "Tracing the impact of bank liquidity shocks: Evidence from an emerging market," American Economic Review, 98, 1413-42.

Klein, M., J. Peek, and E. Rosengren (2002): "Troubled Banks, Impaired Foreign Direct Investment: The Role of Relative Access to Credit," American Economic Review, 92.

Koijen, R. And M. Yogo (2018): “A Demand System Approach to Asset Pricing,” Journal of Political Economy, Forthcoming.

Kundu, S. And N. VATS (2021): "Banking Networks and Economic Growth: From Idiosyncratic Shocks to Aggregate Fluctuations," SSRN Working Paper 3556299.

Leary, M. And M. Roberts (2014): “Do Peer Firms Affect Corporate Financial Policy?" The Journal of Finance, 69(1).

Leland, E. AND D. H. Pyle (1977): "Information asymmetries, financial structure, and financial intermediation," Journal of Finance, 32.

Lin, H. And D. Paravisini (2012): “The Effect of Financing Constraints on Risk," Review of Finance.

Mendicino, C., K. Nikolov, J. Rubio-Ramirez, J. Suarez, and D. Supera (2020): “Twin Default Crises," ECB Working Paper 2414.

NRK.NO (2011): "Slutt for Hera Vekst," https://www.nrk.no/innlandet/slutt-for-hera-vekst1.7792540 .

PARAVisini, D. (2008): “Local Bank Financial Constraints and Firm Access to External Finance," Journal of Finance, 63.

PARAvisini, D., V. RAPPOPORT, AND P. Schnabl (2020): “Specialization in Bank Lending: Evi- 
dence from Exporting Firms," NBER Working Paper 21800.

Peek, J. and E. Rosengren (2005): "Unnatural Selection: Perverse Incentives and the Misallocation of Credit in Japan," American Economic Review, 95.

Peek, J. And E. S. Rosengren (2000): "Collateral Damage: Effects of the Japanese Bank Crisis on Real Activity in the United States," American Economic Review, 90.

Rodriguez, R. (1976): “A Guide to the Burr Type XII Distributions," Institute of Statistics Mimeo Series 1064.

Sharpe, S. (1990): “Asymmetric Information, Bank Lending and Implicit Contracts: A Stylized Model of Customer Relationships," Quarterly Journal of Economics, 45.

Singh, S. ANd G. Maddala (1976): “A Function for Size Distribution of Incomes,” Econometrica, 44(5).

Stavrakeva, V. (2019): “Optimal Bank Regulation and Fiscal Capacity," Review of Economic Studies, 87.

Stock, J. And M. Yogo (2005): “Testing for Weak Instruments in Linear IV Regression,” 80-108.

SufI, A. (2007): “Bank Lines of Credit in Corporate Finance: An Empirical Analysis," Review of Financial Studies, 22.

VAn Nieuwerburgh, S. ANd L. VeldKamp (2009): "Information immobility and the home bias puzzle," The Journal of Finance, 64, 1187-1215.

Williamson, S. (1987): “Costly Monitoring, Loan Contracts, and Equilibrium Credit Rationing," Quarterly Journal of Economics, 102. 


\section{Online Appendix for "Granular Credit Risk"}

Sigurd Galaasen Rustam Jamilov Ragnar Juelsrud Hélène Rey

December 16,2021

\section{Contents}

A Factor Analysis $\quad 2$

A.1 Factor Extraction at the Firm Level . . . . . . . . . . . . . . . . . . 2

A.2 Factor Extraction at the Bank Level . . . . . . . . . . . . . . . 5

B Additional Loan-Level Results $\quad 9$

C Additional Bank-Level Results $\quad 15$

$\begin{array}{ll}\text { D Additional Results on Spillovers } & 21\end{array}$

$\begin{array}{ll}\text { E Narratives } & 25\end{array}$

F Robustness Tests and Auxiliary Empirical Findings $\quad 27$

G Proof of Proposition 1 


\section{A Factor Analysis}

\section{A.1 Factor Extraction at the Firm Level}

Our baseline firm shock measure is the residual $\epsilon_{\mathrm{j}, \mathrm{t}}$ obtained from estimating equation (1) in main text, repeated here:

$$
\ln \mathrm{VA}_{\mathrm{j}, \mathrm{t}}=\alpha_{\mathrm{j}, \mathrm{t}, \mathrm{s}(\mathrm{j}), \mathrm{z}(\mathrm{j})}+\beta_{1} \ln \mathrm{K}_{\mathrm{j}, \mathrm{t}}+\beta_{2} \ln \mathrm{W}_{\mathrm{j}, \mathrm{t}}+\lambda^{\prime} \mathbf{X}_{\mathbf{j}, \mathbf{t}}+\epsilon_{\mathrm{j}, \mathrm{t}}
$$

The residual $\epsilon_{\mathrm{j}, \mathrm{t}}$, although orthogonal to a range of time-varying firm characteristics and fixed effects, may still contain components which are common across firms. To address this concern we now consider a robustness exercise in which we extract both parametric and non-parametric factors explicitly. Formally, we assume that the residual can be expressed as:

$$
\epsilon_{\mathrm{j}, \mathrm{t}}=\delta_{\mathrm{j}, \mathrm{t}}^{\mathrm{x}} \eta_{\mathrm{t}}^{\mathrm{x}}+\delta_{\mathrm{j}}^{\prime} \eta_{\mathrm{t}}+\mathrm{u}_{\mathrm{j}, \mathrm{t}}
$$

for a vector of parametric $\eta_{\mathrm{t}}^{\mathrm{x}}$ and non-parametric $\eta_{\mathrm{t}}$ factors. For the parametric factors, the firm-specific time-varying loading vector $\delta_{\mathrm{j}, \mathrm{t}}^{\mathrm{x}}$ is assumed to be a function of observable firm characteristics. For the non-parametric factors we assume a constant firm-specific loading vector $\delta_{\mathrm{j}}$. The goal is to estimate both common components $\left(\delta_{\mathrm{j}, \mathrm{t}}^{\mathrm{x}} \eta_{\mathrm{t}}^{\mathrm{x}}\right.$ and $\left.\delta_{\mathrm{j}}^{\prime} \eta_{\mathrm{t}}\right)$ and to replace our firm shock measure $\epsilon_{\mathrm{j}, \mathrm{t}}$ with a more robust alternative $\mathrm{u}_{\mathrm{j}, \mathrm{t}}$.

We proceed in two steps. First, we extract parametric common components by estimating a richer version of equation (18), in which we interact all time-varying firm-specific regressors $\left(\ln \mathrm{K}_{\mathrm{j}, \mathrm{t}}, \ln \mathrm{W}_{\mathrm{j}, \mathrm{t}}, \mathbf{X}_{\mathbf{j}, \mathbf{t}}\right)$ with year dummies. Hence, $\delta_{\mathrm{j}, \mathrm{t}}^{\mathrm{x}}$ is given by the vector of explanatory variables in equation (18). Formally, we re-estimate equation (18) assuming time-varying coefficients: ${ }^{1}$

$$
\ln \mathrm{VA}_{\mathrm{j}, \mathrm{t}}=\alpha_{\mathrm{j}, \mathrm{t}, \mathrm{s}(\mathrm{j}), \mathrm{z}(\mathrm{j})}+\beta_{1, \mathrm{t}} \ln \mathrm{K}_{\mathrm{j}, \mathrm{t}}+\beta_{2, \mathrm{t}} \ln \mathrm{W}_{\mathrm{j}, \mathrm{t}}+\lambda_{\mathrm{t}}^{\prime} \mathbf{X}_{\mathbf{j}, \mathrm{t}}+\check{\epsilon}_{\mathrm{j}, \mathrm{t}}
$$

In the second step, we perform Principal Component Analysis (PCA) on the residual $\check{\epsilon}_{\mathrm{j}, \mathrm{t}}$ by estimating:

$$
\check{\epsilon}_{\mathrm{j}, \mathrm{t}}=\delta_{\mathrm{j}}^{\prime} \eta_{\mathrm{t}}+\mathrm{u}_{\mathrm{j}, \mathrm{t}}
$$

Since our firm panel is unbalanced, we employ an iterative Expectation Maximization (EM) algorithm as in Gabaix and Koijen (2021), and estimate principal components recursively. Starting with the first factor, the algorithm repeatedly regresses $\check{\epsilon}_{\mathrm{j}, \mathrm{t}}$ on $\eta_{\mathrm{t}}^{1}$ and then $\check{\epsilon}_{\mathrm{j}, \mathrm{t}}$ on $\delta_{\mathrm{j}}^{1}$ until convergence. For factors $\mathrm{f}=2, \ldots, \mathrm{f}{ }^{\max }$, least squares iterations are performed on the remaining residual from

${ }^{1}$ We make one adjustment relative to the specification in equation (18), by replacing the quadratic age specification with one-year age fixed effects. 
Table 1: Loan Outcomes with Firm Factors Extraction

\begin{tabular}{lccc}
\hline \hline & $(1)$ & $(2)$ & $(3)$ \\
\cline { 2 - 4 } & \multicolumn{3}{c}{ Dep. Var.: Return on Loan } \\
\cline { 2 - 4 } (1) Firm Shock: $\check{\epsilon}_{\mathrm{j}, \mathrm{t}}$ & 0.307 & 0.307 & 0.333 \\
& $(0.016)$ & $(0.017)$ & $(0.018)$ \\
(2) Firm Shock: $\mathrm{u}_{\mathrm{j}, \mathrm{t}}$ & 0.279 & 0.279 & 0.299 \\
& $(0.016)$ & $(0.017)$ & $(0.018)$ \\
(3) Firm Shock: $\mathrm{u}_{\mathrm{j}, \mathrm{t}}^{2}$ & 0.239 & 0.237 & 0.255 \\
& $(0.016)$ & $(0.017)$ & $(0.018)$ \\
\hline Bank x Industry x Year FE & No & Yes & No \\
Bank x Industry x Year x Loan-type x County FE & No & No & Yes \\
\hline \hline
\end{tabular}

Notes: This table reports results from the regression of loan-level returns on loans on three alternative measures of idiosyncratic firm shocks. Row (1) refers to the shock measure after extracting parametric common components. Row (2) refers to the shock measure after extracting parametric common components and one latent common component. Row (3) refers to the shock measure after extracting parametric common components and two latent common components. All shocks have been normalized by their standard deviations. Standard errors (in parentheses) are double clustered at the firm-year level.

equation (21) after extracting $\mathrm{f}-1$ components, denoted $\mathrm{u}_{\mathrm{j}, \mathrm{t}}^{\mathrm{f}-1} \cdot{ }^{2}$ In our analysis below we consider $\mathrm{f}^{\max }=2$ components and denote by $\mathrm{u}_{\mathrm{j}, \mathrm{t}}^{1}$ and $\mathrm{u}_{\mathrm{j}, \mathrm{t}}^{2}$ the residuals obtained after extracting one and two factors, respectively. ${ }^{3}$

We then run our loan-level regressions based on equation (2) in main text with the three new estimated firm shock measures: $\check{\epsilon}_{\mathrm{j}, \mathrm{t}}, \mathrm{u}_{\mathrm{j}, \mathrm{t}}^{1}$ and $\mathrm{u}_{\mathrm{j}, \mathrm{t}}^{2}$. In other words, we substitute the baseline shock variable $\epsilon_{\mathrm{j}, \mathrm{t}}$ with potentially more refined and idiosyncratic versions. In order to obtain bank-level estimates, we proceed as in the main text. First, we aggregate by computing loan size-weighted averages of the three new shock measures $\bar{\epsilon}_{\mathrm{i}, \mathrm{t}}$, $\overline{\mathrm{u}}_{\mathrm{i}, \mathrm{t}}^{1}$, and $\overline{\mathrm{u}}_{\mathrm{i}, \mathrm{t}}^{2}$. Second, we construct three new Granular IVs using equation (6). Third, we run our two-stage panel regressions for $\bar{\epsilon}_{\mathrm{i}, \mathrm{t}}, \overline{\mathrm{u}}_{\mathrm{i}, \mathrm{t}}^{1}$, and $\overline{\mathrm{u}}_{\mathrm{i}, \mathrm{t}}^{2}$, instrumenting each with their respective $\mathrm{GIV}_{\mathrm{i}, \mathrm{t}}^{\check{\epsilon}}, \mathrm{GIV}_{\mathrm{i}, \mathrm{t}}^{\mathrm{u}^{1}}$, and $\mathrm{GIV}_{\mathrm{i}, \mathrm{t}}^{\mathrm{u}^{2}}$.

Table 1 reports loan outcomes after factor extraction. Columns (1)-(3) are based on the same set of controls and fixed effects as columns (3)-(5) in Table 2. Rows (1)-(3) show results for the three new shock measures. Recall that baseline estimates from Table 2 are in the 0.334-0.361 range. We see that after the extraction of parametric and two non-parametric factors, estimates are still large, statistically significant, and quantitatively very close to our baseline results.

${ }^{2}$ Following the suggestion in Stock and Watson (2016), iterations are initiated with factors that are extracted from the balanced sub-sample of firms.

${ }^{3}$ The $\mathrm{f}^{\mathrm{max}}$ threshold is chosen by performing a standard PCA on a balanced sub-sample of firms, and applying the $\mathrm{IC}_{\mathrm{p} 2}$ criterion in Bai and $\mathrm{Ng}(2002)$ to determine the number of factors. 
Table 2: Bank Outcomes with Firm Factors Extraction - New Shocks, New GIV

\begin{tabular}{lcccccccc}
\hline \hline & $(1)$ & $(2)$ & $(3)$ & $(4)$ & $(5)$ & $(6)$ & $(7)$ & $(8)$ \\
\cline { 2 - 9 } & \multicolumn{7}{c}{ Dependent Variable: Bank Return on Loans (RoA) } \\
\cline { 2 - 9 } & \multicolumn{7}{c}{ OLS } & \multicolumn{5}{c}{ Instrumented with GIV } \\
\cline { 2 - 9 } & Pooled & Pooled & Pooled & Positive & Negative & Pooled & Positive & Negative \\
\hline (1) Granular Credit Shock: $\overline{\check{\epsilon}}_{\mathrm{j}, \mathrm{t}}$ & 0.118 & 0.125 & 0.106 & 0.015 & 0.212 & 0.105 & 0.027 & 0.186 \\
& $(0.027)$ & $(0.026)$ & $(0.035)$ & $(0.081)$ & $(0.075)$ & $(0.030)$ & $(0.071)$ & $(0.073)$ \\
(2) Granular Credit Shock: $\overline{\mathrm{u}}_{\mathrm{j}, \mathrm{t}}^{1}$ & 0.092 & 0.092 & 0.079 & -0.117 & 0.160 & 0.072 & -0.087 & 0.136 \\
& $(0.025)$ & $(0.024)$ & $(0.031)$ & $(0.078)$ & $(0.073)$ & $(0.029)$ & $(0.075)$ & $(0.068)$ \\
(3) Granular Credit Shock: $\overline{\mathrm{u}}_{\mathrm{j}, \mathrm{t}}^{2}$ & 0.106 & 0.100 & 0.090 & -0.082 & 0.136 & 0.083 & -0.067 & 0.119 \\
& $(0.027)$ & $(0.025)$ & $(0.032)$ & $(0.072)$ & $(0.058)$ & $(0.029)$ & $(0.072)$ & $(0.053)$ \\
\hline Bank FE & Yes & Yes & Yes & Yes & Yes & Yes & Yes & Yes \\
Year FE & Yes & Yes & Yes & Yes & Yes & Yes & Yes & Yes \\
Bank Controls & No & Yes & No & No & No & Yes & Yes & Yes \\
\hline \hline
\end{tabular}

Notes: This table reports results from regressing bank-level return on loans on bank-level aggregated firm shocks. Columns (1)-(2) are standard OLS, while columns (3)-(8) instrument the weighted shock with a granular IV. Row (1) is based on the shock $\breve{\mathrm{e}}_{\mathrm{j}, \mathrm{t}}$ and instrument $\mathrm{GIV}_{\mathrm{i}, \mathrm{t}}^{\breve{\mathrm{\epsilon}}}$, which refer to the residual after extracting parametric common components. Row (2) is based on the shock $\mathrm{u}_{\mathrm{j}, \mathrm{t}}^{1}$ and instrument $\mathrm{GIV}_{\mathrm{i}, \mathrm{t}}^{\mathrm{u}}$, which refer to the residual after extracting parametric common components and one latent common component. Row (3) is based on the shock $\mathrm{u}_{\mathrm{j}, \mathrm{t}}^{2}$ and instrument $\mathrm{GIV}_{\mathrm{i}, \mathrm{t}}^{\mathrm{u}^{2}}$, which refer to the residual after extracting parametric common components and two latent common components. Standard errors (in parentheses) are clustered at the bank level.

Table 2 reports results at the bank level. Columns (1)-(8) are based on the same specifications and sets of controls and fixed effects as columns (1)-(8) in Table 3 from main text. Recall that baseline estimates from Table 3 are roughly 0.117 and 0.180 for the specifications with pooled and only negative shocks, respectively. We find that our strictest model, which extracts parametric and two non-parameteric factors, leads to estimates of 0.083 and 0.119 for pooled and only negative shocks specifications, respectively. All coefficients are very similar to our baseline results and are statistically significant at least at the 5\% level.

We now consider an alternative approach where instead of replacing the baseline shock measure $\epsilon_{\mathrm{j}, \mathrm{t}}$ itself, we keep $\epsilon_{\mathrm{j}, \mathrm{t}}$ as the shock variable and build the Granular IV based on the three new shocks $\mathrm{GIV}_{\mathrm{i}, \mathrm{t}}^{\check{\epsilon}}, \mathrm{GIV}_{\mathrm{i}, \mathrm{t}}^{\mathrm{u}}$, and $\mathrm{GIV}_{\mathrm{i}, \mathrm{t}}^{\mathrm{u}^{2}}$. In other words, we keep the same endogenous regressor but instrument it with new, more robust instruments. Results are reported in Table 3. All estimates are quantitatively in line with our baseline results. Coefficients from specifications with pooled or negative only shocks are all statistically significant at least at the $5 \%$ level. 
Table 3: Bank Outcomes with Firm Factors Extraction - Old Shocks, New GIV

\begin{tabular}{|c|c|c|c|c|c|c|}
\hline & (1) & $(2)$ & (3) & (4) & (5) & $(6)$ \\
\hline & \multicolumn{6}{|c|}{ Dependent Variable: Bank Return on Loans (RoA) } \\
\hline & Pooled & Positive & Negative & Pooled & Positive & Negative \\
\hline (1) $\mathrm{GIV}_{\mathrm{i}, \mathrm{t}}^{\check{\epsilon}}$ & $\begin{array}{c}0.110 \\
(0.035)\end{array}$ & $\begin{array}{c}0.003 \\
(0.078)\end{array}$ & $\begin{array}{c}0.182 \\
(0.071)\end{array}$ & $\begin{array}{c}0.111 \\
(0.030)\end{array}$ & $\begin{array}{c}0.035 \\
(0.070)\end{array}$ & $\begin{array}{c}0.165 \\
(0.068)\end{array}$ \\
\hline (2) $\operatorname{GIV}_{\mathrm{i}, \mathrm{t}}^{\mathrm{u}^{1}}$ & $\begin{array}{c}0.114 \\
(0.032)\end{array}$ & $\begin{array}{l}-0.021 \\
(0.092)\end{array}$ & $\begin{array}{c}0.216 \\
(0.074)\end{array}$ & $\begin{array}{c}0.112 \\
(0.028)\end{array}$ & $\begin{array}{c}0.035 \\
(0.095)\end{array}$ & $\begin{array}{c}0.189 \\
(0.065)\end{array}$ \\
\hline (3) $\mathrm{GIV}_{\mathrm{i}, \mathrm{t}}^{\mathrm{u}^{2}}$ & $\begin{array}{c}0.144 \\
(0.038)\end{array}$ & $\begin{array}{c}0.039 \\
(0.140)\end{array}$ & $\begin{array}{c}0.266 \\
(0.084)\end{array}$ & $\begin{array}{c}0.133 \\
(0.032)\end{array}$ & $\begin{array}{c}0.061 \\
(0.135)\end{array}$ & $\begin{array}{c}0.234 \\
(0.071)\end{array}$ \\
\hline Bank FE & Yes & Yes & Yes & Yes & Yes & Yes \\
\hline Year FE & Yes & Yes & Yes & Yes & Yes & Yes \\
\hline Bank Controls & No & No & No & Yes & Yes & Yes \\
\hline Instrumented with GIV & Yes & Yes & Yes & Yes & Yes & Yes \\
\hline
\end{tabular}

Notes: This table reports results from regressing bank-level return on loans on bank-level aggregated firm shocks $\bar{\epsilon}_{\mathrm{i}, \mathrm{t}}$ instrumented by three alternative Granular IVs. In row (1) the GIV is based on $\bar{\epsilon}_{\mathrm{i}, \mathrm{t}}$, which refers to the shock measure after extracting parametric common components. In row (2) the GIV is based on $\overline{\mathrm{u}}_{\mathrm{i}, \mathrm{t}}^{1}$, which refers to the shock measure after extracting parametric common components and one latent common component. In row (3) the GIV is based on $\overline{\mathrm{u}}_{\mathrm{i}, \mathrm{t}}^{1}$, which refers to the shock measure after extracting parametric common components and two latent common components. Standard errors (in parentheses) are clustered at the bank level.

\section{A.2 Factor Extraction at the Bank Level}

By subtracting the unweighted mean from bank-level weighted firm shocks, our Granular IV in equation (6) of the main text removes a common bank factor with loadings $\delta_{\mathrm{i}}$ that are assumed to be identical across firms. In this section, we relax the assumption of homogeneous loadings and consider a generalized GIV by extracting common factors at the bank level. Formally, we now extract common components for each bank separately. This implies running the EMPCA algorithm separately on each bank's sample of borrowers, i.e. for all firms $\mathrm{j}$ borrowing from bank $\mathrm{i}$ at time t:

$$
\check{\epsilon}_{\mathrm{i}, \mathrm{j}, \mathrm{t}}^{\mathrm{d}}=\delta_{\mathrm{i}, \mathrm{j}}^{\prime} \eta_{\mathrm{i}, \mathrm{t}}+\mathrm{u}_{\mathrm{i}, \mathrm{j}, \mathrm{t}}, \forall \mathrm{i}
$$

where $\breve{\epsilon}_{\mathrm{i}, \mathrm{j}, \mathrm{t}}^{\mathrm{d}}$ denotes the demeaned firm shock $\check{\epsilon}_{\mathrm{j}, \mathrm{t}}$ (the residual net of parametric factors from equation (20)). The demeaning is performed cross-sectionally at the bank level, such that:

$$
\check{\epsilon}_{\mathrm{i}, \mathrm{j}, \mathrm{t}}^{\mathrm{d}}=\check{\epsilon}_{\mathrm{j}, \mathrm{t}}-\frac{1}{\mathrm{~N}_{\mathrm{i}, \mathrm{t}}} \sum_{\mathrm{j}} \check{\epsilon}_{\mathrm{j}, \mathrm{t}}
$$


Table 4: Bank Factors Extraction - Controlling for Factors Directly

\begin{tabular}{|c|c|c|c|c|c|c|c|c|}
\hline & (1) & $(2)$ & (3) & (4) & $(5)$ & (6) & (7) & $(8)$ \\
\hline & \multicolumn{8}{|c|}{ Dependent Variable: Bank Return on Loans (RoA) } \\
\hline & \multicolumn{2}{|c|}{ OLS } & \multicolumn{6}{|c|}{ Instrumented with GIV } \\
\hline & Pooled & Pooled & Pooled & Positive & Negative & Pooled & Positive & Negative \\
\hline Granular Credit Shock: $\bar{\epsilon}_{\mathrm{j}, \mathrm{t}}$ & $\begin{array}{c}0.125 \\
(0.026)\end{array}$ & $\begin{array}{c}0.122 \\
(0.025)\end{array}$ & $\begin{array}{c}0.105 \\
(0.030)\end{array}$ & $\begin{array}{c}0.027 \\
(0.071)\end{array}$ & $\begin{array}{c}0.186 \\
(0.073)\end{array}$ & $\begin{array}{c}0.103 \\
(0.029)\end{array}$ & $\begin{array}{c}0.026 \\
(0.071)\end{array}$ & $\begin{array}{c}0.180 \\
(0.073)\end{array}$ \\
\hline Bank FE & Yes & Yes & Yes & Yes & Yes & Yes & Yes & Yes \\
\hline Year FE & Yes & Yes & Yes & Yes & Yes & Yes & Yes & Yes \\
\hline Bank Controls & Yes & Yes & Yes & Yes & Yes & Yes & Yes & Yes \\
\hline$\eta_{\mathrm{i}, \mathrm{t}}$ controls & No & Yes & No & No & No & Yes & Yes & Yes \\
\hline
\end{tabular}

Notes: This table reports the results from regressing bank-level return on loans on bank-level aggregated firm shocks. The firm level shock is based on $\check{\epsilon}_{\mathrm{j}, \mathrm{t}}$. Column (1) and (3)-(5) repeats the estimation with bank controls from Table 2. The other columns adds the first two latent bank-level factors obtained from running PCA separately on each banks' sample of borrowers using equation (22) to the set of bank controls.

where $\mathrm{N}_{\mathrm{i}, \mathrm{t}}$ denotes bank i's number of corporate borrowers $\mathrm{j}$ in year $\mathrm{t} .{ }^{4}$ We extract up to $\mathrm{f}=2$ factors, following the algorithm outlined in A.1, and keep the residuals $\mathrm{u}_{\mathrm{j}, \mathrm{t}}^{\mathrm{f}}$, with $\mathrm{f} \in\{1,2\} .^{5}$

Our main exercise is to use the extracted bank factors $\eta_{\mathrm{i}, \mathrm{t}}^{1}$ and $\eta_{\mathrm{i}, \mathrm{t}}^{2}$ as explicit controls in our bank-level regressions. This approach is similar to the application that is proposed in Gabaix and Koijen (2021). Specifically, we run the following specification:

$$
\mathrm{R}_{\mathrm{i}, \mathrm{t}}^{\mathrm{b}}=\alpha_{\mathrm{i}}+\alpha_{\mathrm{t}}+\beta_{1} \hat{\mathrm{u}}_{\mathrm{i}, \mathrm{t}}+\beta_{2} \eta_{\mathrm{i}, \mathrm{t}}^{1}+\beta_{3} \eta_{\mathrm{i}, \mathrm{t}}^{2}+v_{\mathrm{it}}
$$

Results are reported in Table 4. In columns (2) and (6)-(8) we have added the two extracted factors to the list of our usual bank-level controls. Results are essentially unchanged relative to our baseline estimation. This indicates that endogeneity issues due to unobserved time-varying bank factors are minor.

As an additional and final robustness check, we focus on the residuals extracted from equation

${ }^{4}$ Notice that demeaning the firm shock prior to constructing the loan-size weighted shock is identical to constructing the GIV as the difference between the size-weighted minus unweighted raw firm shocks $\epsilon$. Consequently, if we extract zero factors in equation (22) we get the same bank-level estimates as in row (1) of Table 2 . Hence $\sum_{\mathrm{j}} \mathrm{s}_{\mathrm{i}, \mathrm{j}, \mathrm{t}} \breve{\epsilon}_{\mathrm{i}, \mathrm{j}, \mathrm{t}}^{\mathrm{d}}$ is identical to the GIV $\mathrm{i}_{\mathrm{t}, \mathrm{t}}$ based on $\check{\epsilon}_{\mathrm{j}, \mathrm{t}}$.

${ }^{5}$ Because very few banks in our sample have fully balanced sub-samples (portfolios) with many borrowers, we now initiate the algorithm with random guesses of realizations for each factor $\mathrm{f}\left(\eta_{1}^{\mathrm{f}}, \eta_{2}^{\mathrm{f}}, \ldots, \eta_{\mathrm{T}}^{\mathrm{f}}\right)$ with 100 different seeds and pick the specification that produces the lowest average sum of squared residuals $\mathrm{u}_{\mathrm{j}, \mathrm{t}}^{\mathrm{max}}$ after extracting $\mathrm{f}^{\max }=2$ components. 
Table 5: Bank Factors Extraction - New Shocks, New GIV

\begin{tabular}{lcccccccc}
\hline \hline & $(1)$ & $(2)$ & $(3)$ & $(4)$ & $(5)$ & $(6)$ & $(7)$ & $(8)$ \\
\cline { 2 - 9 } & \multicolumn{2}{c}{ Dependent Variable: Bank Return on Loans (RoA) } \\
\cline { 2 - 9 } & \multicolumn{2}{c}{ OLS } & \multicolumn{5}{c}{ Instrumented with GIV } \\
\cline { 2 - 9 } & Pooled & Pooled & Pooled & Positive & Negative & Pooled & Positive & Negative \\
\hline (1) Granular Credit Shock: $\bar{u}_{i, t}^{1}$ & 0.047 & 0.045 & 0.065 & 0.088 & 0.143 & 0.060 & 0.105 & 0.132 \\
& $(0.025)$ & $(0.022)$ & $(0.025)$ & $(0.066)$ & $(0.044)$ & $(0.021)$ & $(0.051)$ & $(0.038)$ \\
(2) Granular Credit Shock: $\bar{u}_{i, t}^{2}$ & 0.034 & 0.024 & 0.056 & -0.018 & 0.122 & 0.046 & -0.022 & 0.104 \\
& $(0.022)$ & $(0.020)$ & $(0.024)$ & $(0.059)$ & $(0.057)$ & $(0.020)$ & $(0.053)$ & $(0.053)$ \\
\hline Bank FE & Yes & Yes & Yes & Yes & Yes & Yes & Yes & Yes \\
Year FE & Yes & Yes & Yes & Yes & Yes & Yes & Yes & Yes \\
Bank Controls & No & Yes & No & No & No & Yes & Yes & Yes \\
\hline \hline
\end{tabular}

Notes: This table reports results from regressing bank-level return on loans on bank-level aggregated firm shocks. Columns (1)-(2) are standard OLS, while columns (3)-(8) instrument the weighted shock with a granular IV. Rows (1)(2) are based on firm shocks $u_{i, j, t}^{1}$ and $u_{i, j, t}^{2}$ obtained from running PCA separately on each bank's sample of borrowers using equation (22). These are the residuals remaining after extracting 1 and 2 common components, respectively, at the bank level. Standard errors (in parentheses) are clustered at the bank level.

(22). Similarly to our aggregate factor extraction exercise in Section A.1, we run two separate specifications. First, we substitute the baseline endogenous covariate $\bar{\epsilon}_{\mathrm{j}, \mathrm{t}}$ with the two new measures $\overline{\mathrm{u}}_{\mathrm{i}, \mathrm{t}}^{1}$ and $\overline{\mathrm{u}}_{\mathrm{i}, \mathrm{t}}^{2}$, which are robust to heterogeneous $\delta_{\mathrm{i}, \mathrm{j}}$. For these two shock measures, we construct new Granular IVs the usual way: $\operatorname{GIV}_{\mathrm{i}, \mathrm{t}}^{\mathrm{u}^{1}}$ and $\mathrm{GIV}_{\mathrm{i}, \mathrm{t}}^{\mathrm{u}^{2}}$. Second, instead of replacing the baseline shock measure $\bar{\epsilon}_{\mathrm{j}, \mathrm{t}}$, we retain it as the shock variable but instrument it with the $\mathrm{GIV}_{\mathrm{i}, \mathrm{t}}^{\mathrm{u}^{1}}$ or $\mathrm{GIV}_{\mathrm{i}, \mathrm{t}}^{\mathrm{u}^{2}}$. Results from the two exercises are reported in Tables 5 and 6. Our main focus is on columns (6) and (8) in both tables. We see that all results remain qualitatively robust, however the point estimates drop slightly and the negative-only estimates become noisier. ${ }^{6}$

${ }^{6}$ Because the panel is highly unbalanced, the effective time dimension is very small. This means that if use more than two factors, we may be over-fitting the data. In other words, with more factors we could be falsely re-labeling truly idiosyncratic variation as common shocks, which in turn makes estimation less accurate. Gabaix and Koijen (2021) discuss a similar issue. 
Table 6: Bank Factors Extraction - Old Shocks, New GIV

\begin{tabular}{lcccccccc}
\hline \hline & $(1)$ & $(2)$ & $(3)$ & $(4)$ & $(5)$ & $(6)$ & $(7)$ & $(8)$ \\
\cline { 2 - 8 } & \multicolumn{7}{c}{ Dependent Variable: Bank Return on Loans (RoA) } \\
\cline { 2 - 8 } & \multicolumn{2}{c}{ OLS } & \multicolumn{7}{c}{ Instrumented with GIV } \\
\cline { 2 - 8 } & Pooled & Pooled & Pooled & Positive & Negative & Pooled & Positive & Negative \\
\hline \multirow{2}{*}{$(1) \mathrm{GIV}_{\mathrm{i}, \mathrm{u}}^{1}$} & 0.118 & 0.125 & 0.100 & 0.122 & 0.165 & 0.093 & 0.132 & 0.116 \\
& $(0.027)$ & $(0.026)$ & $(0.039)$ & $(0.148)$ & $(0.100)$ & $(0.032)$ & $(0.120)$ & $(0.088)$ \\
(2) GIV ${ }_{\mathrm{i}, \mathrm{t}}^{2}$ & 0.118 & 0.125 & 0.124 & 0.180 & 0.273 & 0.101 & 0.139 & 0.218 \\
& $(0.027)$ & $(0.026)$ & $(0.052)$ & $(0.158)$ & $(0.242)$ & $(0.044)$ & $(0.128)$ & $(0.218)$ \\
\hline Bank FE & Yes & Yes & Yes & Yes & Yes & Yes & Yes & Yes \\
Year FE & Yes & Yes & Yes & Yes & Yes & Yes & Yes & Yes \\
Bank Controls & No & Yes & No & No & No & Yes & Yes & Yes \\
\hline \hline
\end{tabular}

Notes: This table reports results from regressing bank-level return on loans on bank-level aggregated firm shocks $\bar{\epsilon}_{\mathrm{j}, \mathrm{t}}$, instrumented by two alternative Granular IVs. Rows (1)-(2) are based on firm shocks $\mathrm{u}_{\mathrm{i}, \mathrm{j}, \mathrm{t}}^{1}$ and $\mathrm{u}_{\mathrm{i}, \mathrm{j}, \mathrm{t}}^{2}$ obtained from running PCA separately on each bank's sample of borrowers using equation (22). These are the residuals remaining after extracting 1 and 2 common components, respectively, at the bank level. Standard errors (in parentheses) are clustered at the bank level. 


\section{B Additional Loan-Level Results}

Figure 1: Loan Outcomes by Horizon

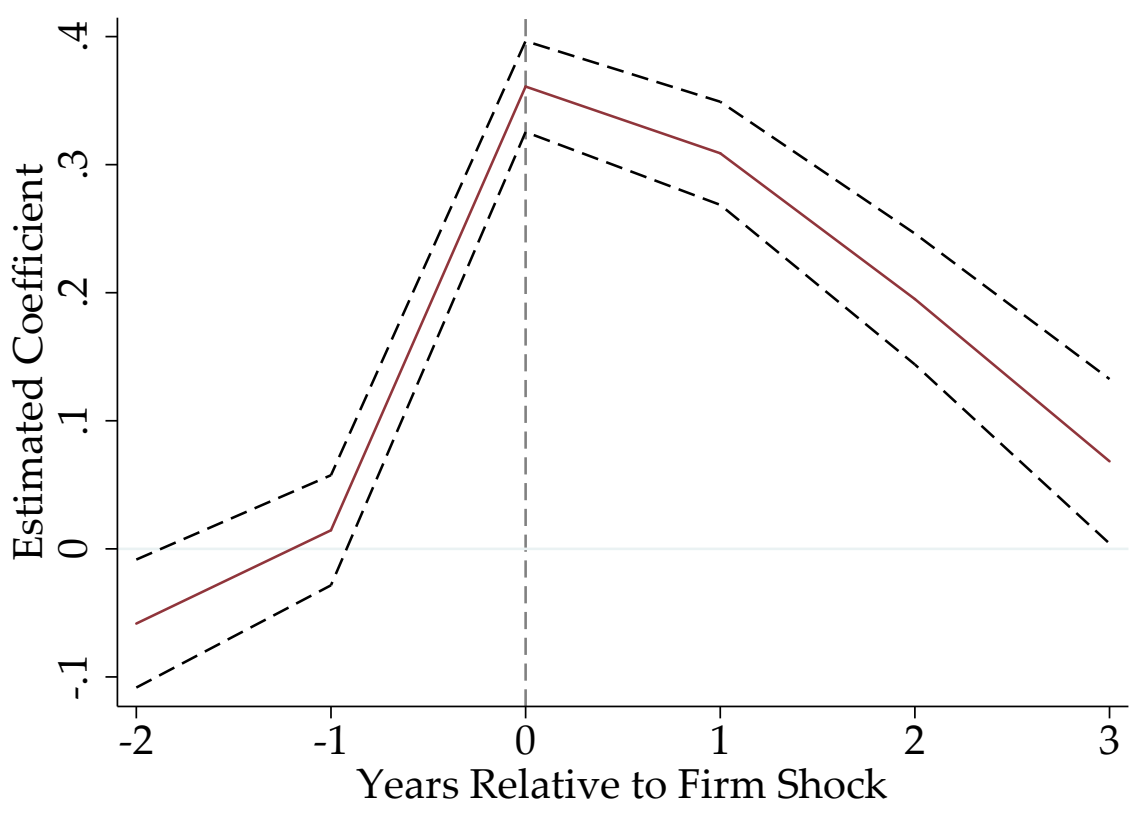

Notes: This graph plots results in the form of an event study where we regress loan-level returns on leads and lags of the idiosyncratic firm shock. Coefficients are plotted by horizon (in years) of the dependent variable. Specifications are based on equation (2). Firm shocks are estimated based on specification (1). Dashed lines are 95\% confidence bands. 


\section{Figure 2: Geographical Origins of Granular Credit Risk}

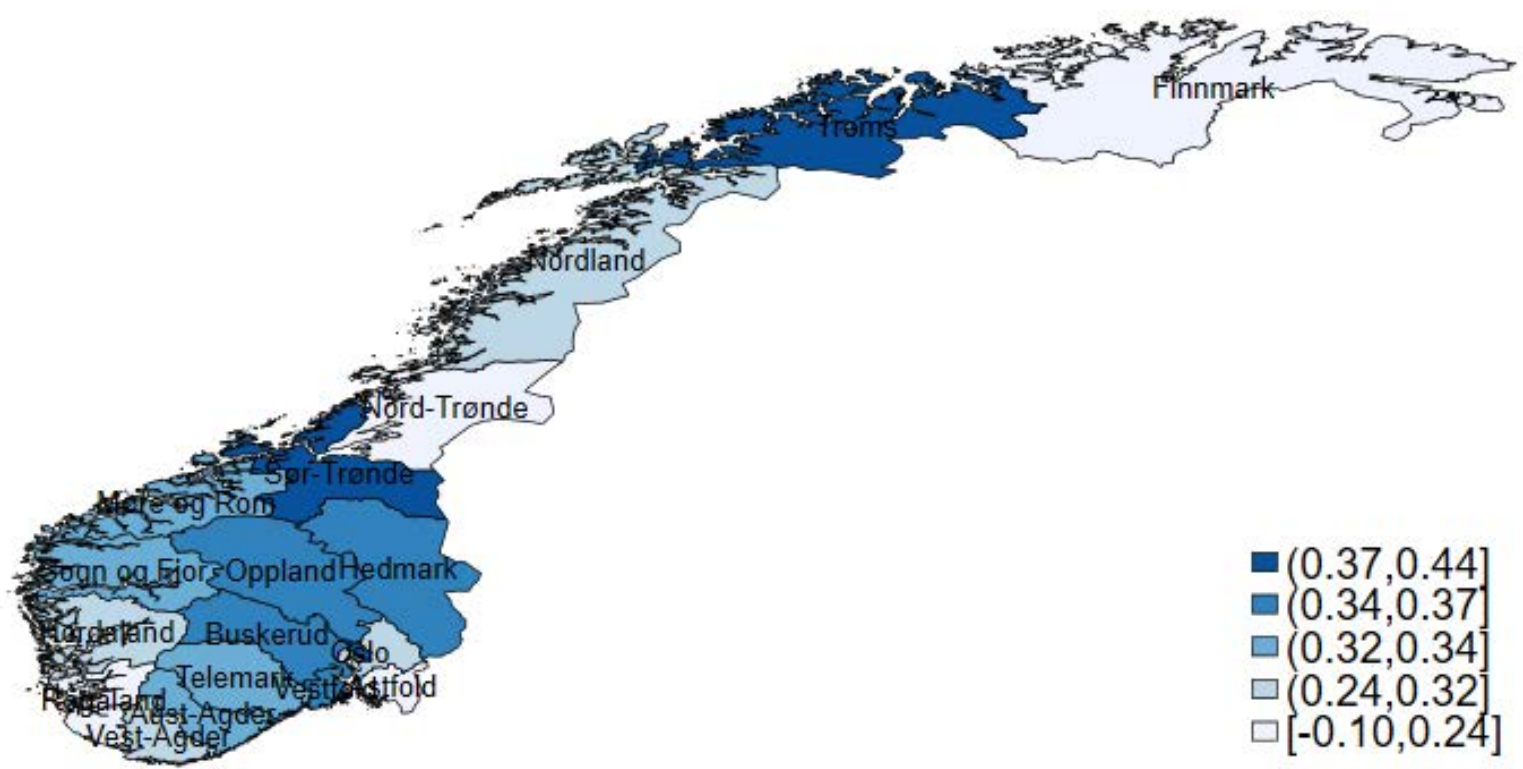

Notes: This picture is a colored map of 19 administrative counties (fylke) of Norway. Each shade of blue represents the county-specific strength of the pass-through from idiosyncratic firm shocks to return on loans. These correspond to county-specific slope shifters (slope dummies) introduced into the main loan regression 2. Shapefiles are from the Norwegian Mapping Authority (Kartverket). 
Table 7: Loan Outcomes - Firm Balance Sheet Heterogeneity

\begin{tabular}{|c|c|c|c|c|c|c|c|c|}
\hline & $(1)$ & (2) & (3) & (4) & (5) & (6) & (7) & $(8)$ \\
\hline & \multicolumn{8}{|c|}{ Dependent Variable: Return on Loan } \\
\hline Baseline & $\begin{array}{c}0.361 \\
(0.018)\end{array}$ & & & & & & & \\
\hline Shock x Low Leverage $\mathrm{t}_{-1}$ & & $\begin{array}{c}0.345 \\
(0.020)\end{array}$ & & & & & & \\
\hline Shock x High Leverage $\mathrm{t}_{-1}$ & & $\begin{array}{c}0.450 \\
(0.047)\end{array}$ & & & & & & \\
\hline Shock x High Assets $\mathrm{t}_{\mathrm{t}-1}$ & & & $\begin{array}{c}0.345 \\
(0.018)\end{array}$ & & & & & \\
\hline Shock x Low Assets ${ }_{t-1}$ & & & $\begin{array}{c}0.976 \\
(0.170)\end{array}$ & & & & & \\
\hline Shock x High Equity ${ }_{t-1}$ & & & & $\begin{array}{c}0.352 \\
(0.020)\end{array}$ & & & & \\
\hline Shock x Low Equity $\mathrm{t}_{-1}$ & & & & $\begin{array}{c}0.410 \\
(0.044)\end{array}$ & & & & \\
\hline 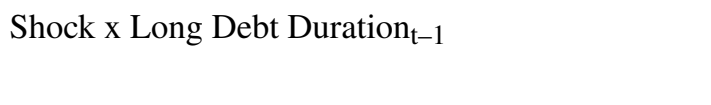 & & & & & $\begin{array}{c}0.289 \\
(0.020)\end{array}$ & & & \\
\hline Shock x Short Debt Duration ${ }_{t-1}$ & & & & & $\begin{array}{c}0.753 \\
(0.046)\end{array}$ & & & \\
\hline Shock x Low Bank Reliance $_{t-1}$ & & & & & & $\begin{array}{c}0.314 \\
(0.022)\end{array}$ & & \\
\hline Shock x High Bank Reliance ${ }_{t-1}$ & & & & & & $\begin{array}{c}0.497 \\
(0.031)\end{array}$ & & \\
\hline Shock x High Credit Rating ${ }_{t-1}$ & & & & & & & $\begin{array}{c}0.250 \\
(0.025)\end{array}$ & \\
\hline Shock x Low Credit Rating ${ }_{t-1}$ & & & & & & & $\begin{array}{c}0.483 \\
(0.026)\end{array}$ & \\
\hline Shock x Old Firms $\mathrm{t}_{\mathrm{t}-1}$ & & & & & & & & $\begin{array}{c}0.313 \\
(0.020)\end{array}$ \\
\hline Shock x Young Firms $\mathrm{t}_{\mathrm{t}-1}$ & & & & & & & & $\begin{array}{c}0.576 \\
(0.041)\end{array}$ \\
\hline Bank x Industry x Year x Loan-type x County FE & Yes & Yes & Yes & Yes & Yes & Yes & Yes & Yes \\
\hline Additional controls & Yes & Yes & Yes & Yes & Yes & Yes & Yes & Yes \\
\hline Observations & 292825 & 292825 & 292825 & 292825 & 292825 & 292825 & 292825 & 292825 \\
\hline $\mathrm{R}^{2}$ & 0.167 & 0.167 & 0.167 & 0.167 & 0.167 & 0.167 & 0.167 & 0.167 \\
\hline
\end{tabular}

Notes: This table reports results from loan-level regressions of loan returns on idiosyncratic firm shocks interacted with various lagged firm characteristics. Each characteristic is a dummy which takes the value of 1 for firms which are in the highest decile of leverage (defined as equity over assets), share of bank credit to total credit, and share of short-term debt to total debt; firms in the lowest deciles of total assets and total equity; firms with an below-A credit rating; and firms younger than 3 years. Baseline is the pooled estimation from Table 2. Standard errors (in parentheses) are double clustered at the firm-year level. 
Table 8: Loan Outcomes - Extensive Margin

\begin{tabular}{lccccc}
\hline \hline & $(1)$ & $(2)$ & $(3)$ & $(4)$ & $(5)$ \\
\cline { 2 - 5 } & \multicolumn{5}{c}{ Dependent Variable: Return on Loan } \\
\cline { 2 - 6 } & Baseline & Firm Exit & Firm Entry & Firm Bankruptcy & Ever Bankrupt \\
\hline \multirow{2}{*}{ Firm Shock } & 0.361 & 0.387 & 0.322 & 0.365 & 0.360 \\
& $(0.018)$ & $(0.019)$ & $(0.019)$ & $(0.018)$ & $(0.019)$ \\
Exit / Entry / Bankruptcy & & 0.613 & -1.707 & 0.699 & 0.572 \\
& & $(0.075)$ & $(0.073)$ & $(0.161)$ & $(0.079)$ \\
Interaction & & -0.259 & 0.260 & -0.133 & 0.014 \\
& & $(0.067)$ & $(0.059)$ & $(0.133)$ & $(0.068)$ \\
\hline Full Fixed Effects & Yes & Yes & Yes & Yes & Yes \\
Observations & 292825 & 292825 & 292825 & 292825 & 292825 \\
$\mathrm{R}^{2}$ & 0.167 & 0.167 & 0.169 & 0.167 & 0.167 \\
\hline \hline
\end{tabular}

Notes: This table reports estimates from loan-level regressions of loan returns on firm shocks interacted with firm entry, exit, and bankruptcy dummies. Firm entry (exit) dummies equal 1 for firms which entered (exited) the year before (following) the firm shock. Firm bankruptcy is a dummy that equals 1 for firms which declare bankruptcy the year following the firm shock. Ever bankrupt is a dummy that equals 1 for firms which have ever declared bankruptcy during the 2003-2015 period, and not necessarily directly following the firm shock. All specifications include Bank x Firm Industry x Year x Loan-type x Firm County interacted fixed effects. Standard errors (in parentheses) are double clustered at the firm-year level. 
Table 9: Loan Outcomes - Firm Ownership Heterogeneity

\begin{tabular}{lccccc}
\hline \hline & $(1)$ & $(2)$ & $(3)$ & $(4)$ & $(5)$ \\
\cline { 2 - 5 } & \multicolumn{5}{c}{ Dependent Variable: Return on Loan } \\
\cline { 2 - 6 } & All Firms & Private Firms & State Firms & Community Firms & Financial Vehicles \\
\hline Firm Shock & 0.335 & 0.336 & 0.478 & 0.089 & 1.145 \\
& $(0.016)$ & $(0.019)$ & $(0.654)$ & $(0.120)$ & $(0.966)$ \\
Bank x Year x County FE & Yes & Yes & Yes & Yes & Yes \\
Observations & 330490 & 234074 & 162 & 2526 & 389 \\
$\mathrm{R}^{2}$ & 0.051 & 0.053 & 0.243 & 0.282 & 0.214 \\
\hline \hline
\end{tabular}

Notes: This table reports estimates from loan-level regressions of loan returns on firm shocks originating from firms with different ownership structure. Each column presents results from a specification in which only that particular ownership type is included. Numbers of observations do not add up because many firms are not assigned ownership classifications. Standard errors (in parentheses) are double clustered at the firm-year level. 
Table 10: Loan Outcomes - Firm Industry Heterogeneity

\begin{tabular}{lcccccc}
\hline \hline & $(1)$ & $(2)$ & $(3)$ & $(3)$ & $(4)$ & $(5)$ \\
\cline { 2 - 6 } & \multicolumn{5}{c}{ Dependent Variable: Return on Loan } \\
\cline { 2 - 7 } & All Firms & Manufacturing & Mining & Construction & Real Estate & Agriculture \\
\hline \multirow{2}{*}{ Firm Shock } & 0.335 & 0.356 & 0.401 & 0.414 & 0.064 & 0.215 \\
& $(0.016)$ & $(0.050)$ & $(0.251)$ & $(0.040)$ & $(0.034)$ & $(0.055)$ \\
Bank x Year x County FE & Yes & Yes & Yes & Yes & Yes & Yes \\
Observations & 330490 & 34232 & 1097 & 60169 & 8531 & 7773 \\
$\mathrm{R}^{2}$ & 0.051 & 0.091 & 0.364 & 0.082 & 0.197 & 0.201 \\
\hline \hline
\end{tabular}

Notes: This table reports estimates from loan-level regressions of loan returns on firm shocks coming from firms from different sectors. Each column presents results from a specification in which firms from only that particular sector are included. Mining includes petroleum industries. Numbers of observations do not add up because many firms are not assigned industry classifications. Standard errors (in parentheses) are double clustered at the firm-year level. 


\section{Additional Bank-Level Results}

\section{Figure 3: First Stage - Firm Shocks and the Granular IV}

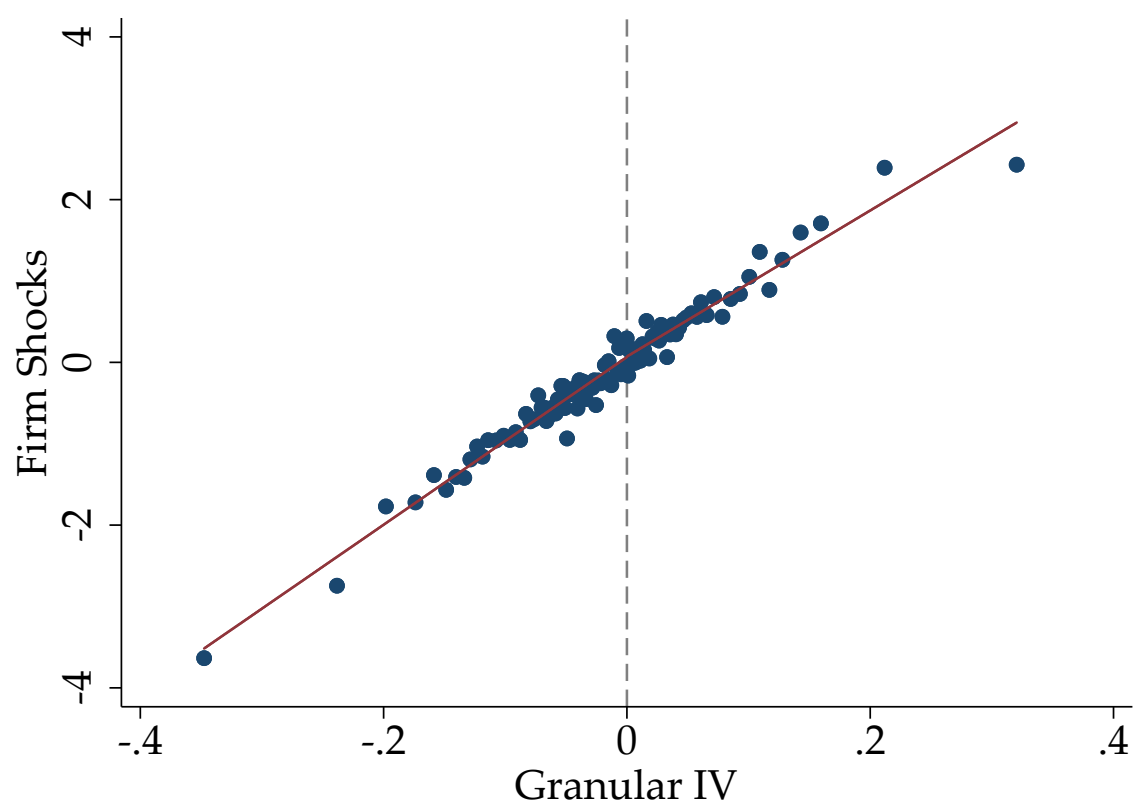

Notes: This figure plots the relationship between the endogenous covariate $\bar{\epsilon}_{\mathrm{i}, \mathrm{t}}$ and the instrument, GIV $\mathrm{i,t}$. On the vertical axis we have the idiosyncratic firm shock which is loan size-weighted and aggregated to the level of a bank. Idiosyncratic firm shocks are extracted from specification 1. The granular instrument (horizontal axis) is constructed based on equation (6). Correlation between the two variables is 0.863 . 


\section{Figure 4: Bank Outcomes by Horizon}
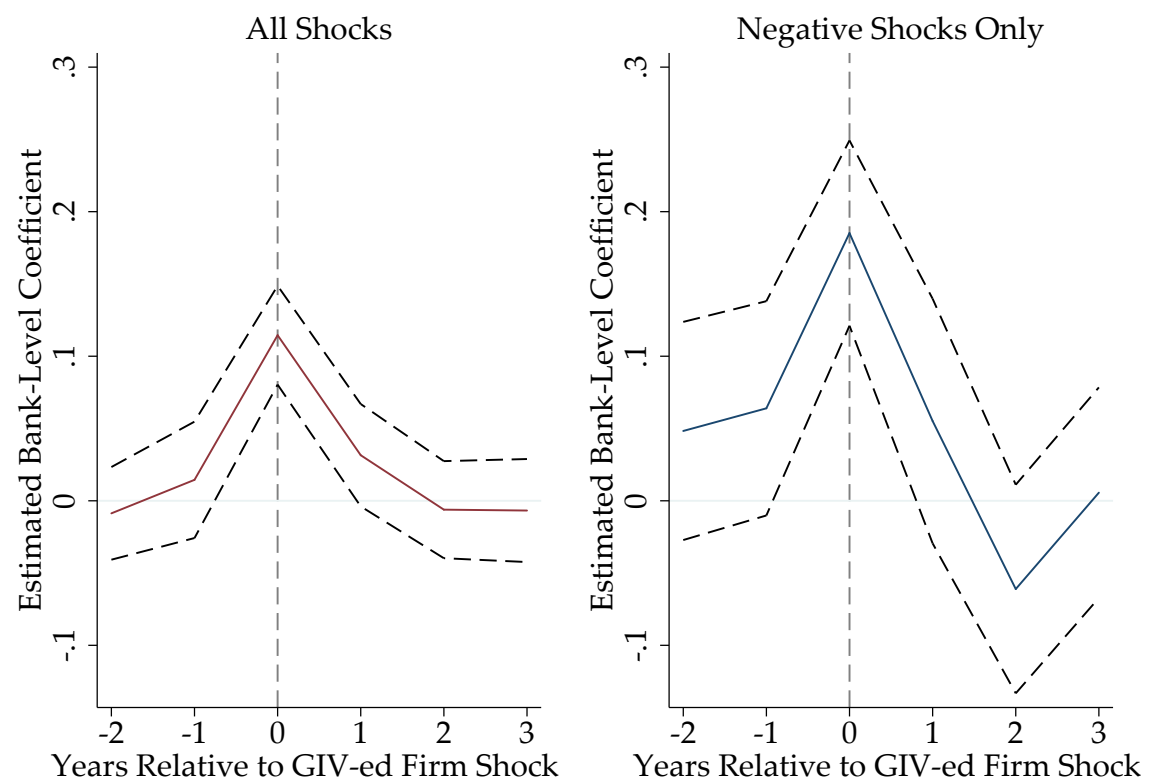

Notes: This figure plots results in the form of an event study where we regress bank-level returns on leads and lags of the bank-level aggregated firm shock $\bar{\epsilon}_{\mathrm{i}, \mathrm{t}}$ instrumented by the granular IV. Specifications are based on equation (7). The GIV is constructed following equation (6). The left panel includes all shocks, and the right panel includes negative shocks only $\left(\bar{\epsilon}_{\mathrm{i}, \mathrm{t}}<0\right)$. Coefficients are plotted by horizon (in years) of the dependent variable. Dashed lines are $95 \%$ confidence bands. 
Table 11: Bank Loan Portfolio Writedowns and Sharpe Ratio

\begin{tabular}{lcccc}
\hline \hline & $(1)$ & $(2)$ & $(3)$ & $(4)$ \\
\hline \multirow{4}{*}{ Granular Credit Shock } & \multicolumn{2}{c}{ Writedowns } & \multicolumn{2}{c}{ Sharpe Ratio } \\
\cline { 2 - 5 } & $(0.009)$ & $(0.011)$ & $(0.069)$ & $(0.037)$ \\
\hline \multirow{2}{*}{ Bank FE } & Yes & Yes & Yes & Yes \\
Year FE & Yes & Yes & Yes & Yes \\
Bank Controls & Yes & Yes & Yes & Yes \\
Instrumented by GIV & No & Yes & No & Yes \\
Observations & 1184 & 1184 & 1206 & 1206 \\
$\mathrm{R}^{2}$ & 0.937 & 0.071 & 0.654 & 0.025 \\
\hline \hline
\end{tabular}

Notes: This table reports results from regressing bank-level (log) loan writedowns and the Sharpe ratio on bank-level aggregated firm shocks $\bar{\epsilon}_{\mathrm{i}, \mathrm{t}}$. Columns (1) and (3) are OLS on equation (3), while in columns (2) and (4) the aggregated shocks are instrumented by the granular IV as in equation (7). The GIV is constructed following equation (6). Bank controls include lagged bank total assets, leverage, liquidity, number of loans, deposit to assets ratio and financial assets to assets ratio. Standard errors (in parentheses) are clustered at the bank level. 
Table 12: Bank Outcomes - Heterogeneity

\begin{tabular}{|c|c|c|c|c|c|c|c|}
\hline & (1) & (2) & (3) & (4) & (5) & (6) & (7) \\
\hline & \multicolumn{7}{|c|}{ Dependent Variable: Bank Return on Loans (RoA) } \\
\hline Bank Shock x Low Risk Weights & $\begin{array}{c}0.104 \\
(0.042)\end{array}$ & & & & & & \\
\hline Bank Shock x High Risk Weights & $\begin{array}{c}0.137 \\
(0.040)\end{array}$ & & & & & & \\
\hline Bank Shock x Low RWA & & $\begin{array}{c}0.173 \\
(0.037)\end{array}$ & & & & & \\
\hline Bank Shock x High RWA & & $\begin{array}{c}0.029 \\
(0.036)\end{array}$ & & & & & \\
\hline Bank Shock x Low Capital Ratio & & & $\begin{array}{c}0.090 \\
(0.040)\end{array}$ & & & & \\
\hline Bank Shock x High Capital Ratio & & & $\begin{array}{c}0.134 \\
(0.039)\end{array}$ & & & & \\
\hline Bank Shock x Low Loan HHI & & & & $\begin{array}{c}0.068 \\
(0.040)\end{array}$ & & & \\
\hline Bank Shock x High Loan HHI & & & & $\begin{array}{c}0.138 \\
(0.039)\end{array}$ & & & \\
\hline Bank Shock x Low Number of Loans & & & & & $\begin{array}{c}0.135 \\
(0.046)\end{array}$ & & \\
\hline Bank Shock x High Number of Loans & & & & & $\begin{array}{c}0.090 \\
(0.030)\end{array}$ & & \\
\hline Bank Shock x Low Liquidity & & & & & & $\begin{array}{c}0.095 \\
(0.045)\end{array}$ & \\
\hline Bank Shock x High Liquidity & & & & & & $\begin{array}{c}0.135 \\
(0.038)\end{array}$ & \\
\hline Bank Shock x Low Profitability & & & & & & & $\begin{array}{c}0.109 \\
(0.045)\end{array}$ \\
\hline Bank Shock x High Profitability & & & & & & & $\begin{array}{r}0.126 \\
(0.037) \\
\end{array}$ \\
\hline Bank FE & Yes & Yes & Yes & Yes & Yes & Yes & Yes \\
\hline Year FE & Yes & Yes & Yes & Yes & Yes & Yes & Yes \\
\hline Observations & 1208 & 1208 & 1208 & 1211 & 1211 & 1211 & 1211 \\
\hline $\mathrm{R}^{2}$ & 0.101 & 0.106 & 0.101 & 0.103 & 0.102 & 0.102 & 0.101 \\
\hline
\end{tabular}

Notes: This table reports results from regressions of bank-level returns on corporate loans on GIV-instrumented idiosyncratic shocks interacted with lagged bank characteristics. In all columns, characteristics are cut based on the 50th percentile. Risk weights are obtained by dividing risk-weighted assets (RWA) by book assets. The regulatory capital ratio is defined as regulatory capital over RWA. Loan HHI refers to the within-bank Herfindahl index of loan concentration. Liquidity is defined as cash holdings over book assets. Profitability is defined as profit before taxes over book assets. All specifications include the following bank controls: lagged total assets, leverage, liquidity, number of loans, deposit to assets ratio, and financial assets to total assets ratio. Standard errors (in parentheses) are clustered at the bank level. 
Table 13: Bank Outcomes - Inspecting the Risk-Taking Channel

\begin{tabular}{|c|c|c|c|c|c|c|}
\hline & \multicolumn{2}{|c|}{ (1) } & \multicolumn{2}{|c|}{ (2) } & \multicolumn{2}{|c|}{ (3) } \\
\hline & Low RWA & High RWA & Low CapRatio & High CapRatio & Low HHI & High HHI \\
\hline \multirow[t]{2}{*}{ Bank Shock x Low Risk Weights } & 0.156 & -0.005 & 0.070 & 0.119 & 0.056 & 0.117 \\
\hline & $(0.050)$ & $(0.058)$ & $(0.054)$ & $(0.051)$ & $(0.067)$ & $(0.048)$ \\
\hline \multirow[t]{2}{*}{ Bank Shock x High Risk Weights } & 0.212 & 0.061 & 0.108 & 0.168 & 0.075 & 0.187 \\
\hline & $(0.070)$ & $(0.039)$ & $(0.058)$ & $(0.062)$ & $(0.051)$ & $(0.063)$ \\
\hline Bank FE & Yes & Yes & Yes & Yes & Yes & Yes \\
\hline Year FE & Yes & Yes & Yes & Yes & Yes & Yes \\
\hline Observations & 1208 & 1208 & 1208 & 1208 & 1208 & 1208 \\
\hline \multirow[t]{3}{*}{$\mathrm{R} 2$} & 0.105 & 0.105 & 0.101 & 0.101 & 0.103 & 0.103 \\
\hline & \multicolumn{2}{|c|}{ (4) } & \multicolumn{2}{|c|}{ (5) } & \multicolumn{2}{|c|}{ (6) } \\
\hline & Low NumLoans & High NumLoans & Low Liquid & High Liquid & Low Profit & High Profit \\
\hline \multirow[t]{2}{*}{ Bank Shock x Low Risk Weights } & 0.120 & 0.079 & 0.060 & 0.131 & 0.114 & 0.086 \\
\hline & $(0.063)$ & $(0.043)$ & $(0.076)$ & $(0.048)$ & $(0.057)$ & $(0.057)$ \\
\hline \multirow[t]{2}{*}{ Bank Shock x High Risk Weights } & 0.162 & 0.105 & 0.127 & 0.149 & 0.095 & 0.163 \\
\hline & $(0.065)$ & $(0.045)$ & $(0.047)$ & $(0.074)$ & $(0.049)$ & $(0.059)$ \\
\hline Bank FE & Yes & Yes & Yes & Yes & Yes & Yes \\
\hline Year FE & Yes & Yes & Yes & Yes & Yes & Yes \\
\hline Observations & 1208 & 1208 & 1208 & 1208 & 1208 & 1208 \\
\hline $\mathrm{R} 2$ & 0.102 & 0.102 & 0.101 & 0.101 & 0.101 & 0.101 \\
\hline
\end{tabular}

Notes: This table reports results from regressions of bank-level returns on corporate loans on GIV-instrumented idiosyncratic shocks, double interacted with bank risk weights and additional characteristics. In all specifications, characteristics are cut based on the lagged 50th percentile. For example, column (1) presents estimates for banks with low risk weights and low risk-weighted assets (RWA), low risk weights and high RWA, high risk weights and low RWA, and high risk weights and high RWA. Similarly for all other columns. Risk weights are obtained by dividing risk-weighted assets (RWA) by book assets. The regulatory capital ratio (CapRatio) is defined as regulatory capital over RWA. HHI refers to the within-bank Herfindahl index of loan concentration. NumLoans refers to the (log) number of loans in the portfolio. Liquid refers to the liquidity ratio, defined as cash holdings over book assets. Profit refers to the profitability ratio, defined as profit before taxes over book assets. All specifications include the following bank controls: lagged total assets, leverage, liquidity, number of loans, deposit to assets ratio, and financial assets to total assets ratio. Standard errors (in parentheses) are clustered at the bank level. 


\section{Figure 5: Home Bias in Within-Region Banking}

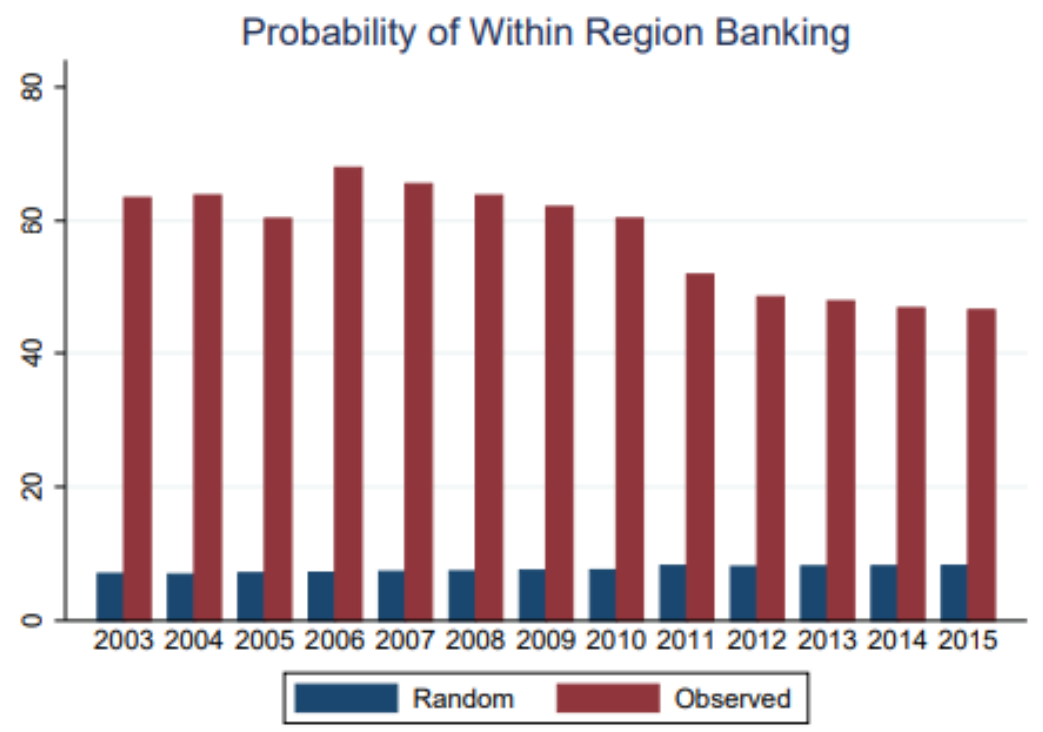

Notes: This figure shows the extent to which there is home-bias in the Norwegian corporate credit market. Source: Juelsrud and Wold (2020). Specifically, red bars show the observed fraction of loans within a given year in our sample where the firm and the bank are located in the same county (within-region loans). The blue bars show the counterfactual share of within-region loans, where we assume random matching between firms and banks. Given random matching, the probability that a firm $\mathrm{i}$ borrows from a bank $\mathrm{j}$ operating in that region is the sum of the aggregate/national market share of bank $\mathrm{j}$. 


\section{Additional Results on Spillovers}

Figure 6: Spillovers from Granular Credit Shocks: Discrete Measure of Non-Granularity

(a) Credit Supply

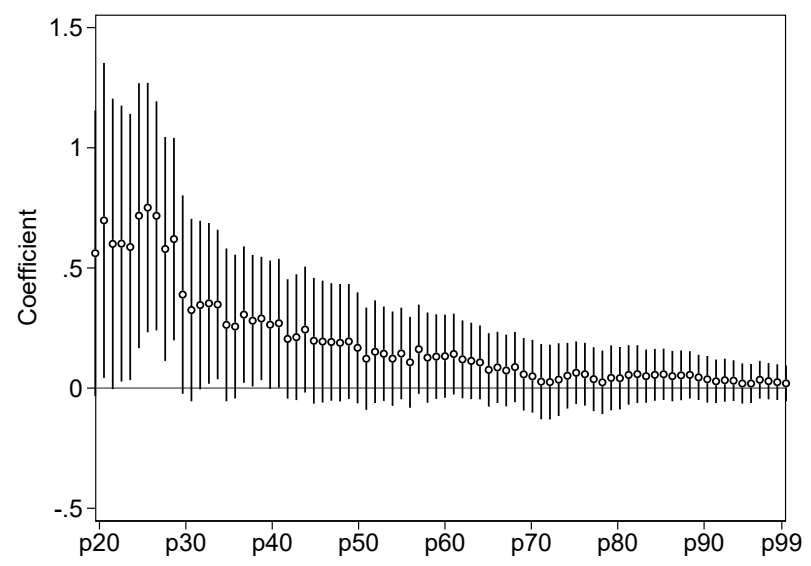

(b) Interest Rates

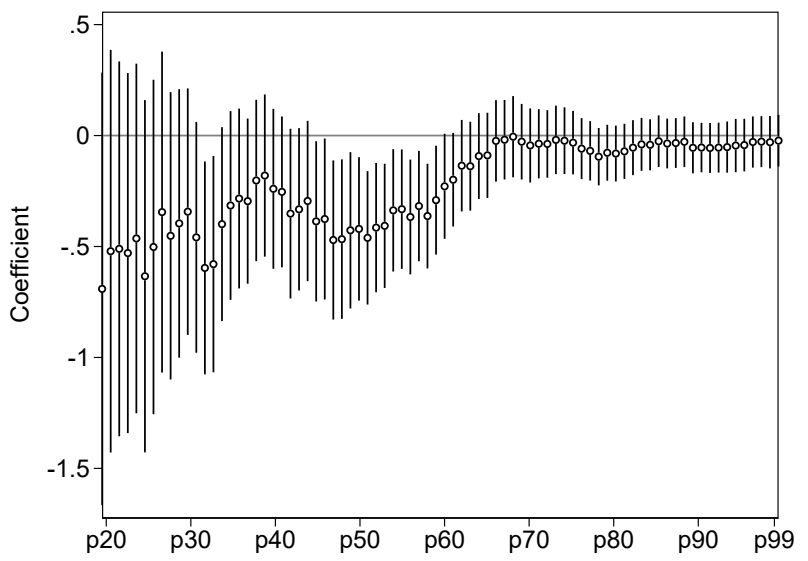

Notes: This figure reports results from regressing year-on-year changes in log of bank debt (left panel) and changes in $\log$ of interest rates (right panel) at the bank-firm level on the year-on-year change in bank-level aggregated firm shocks which are instrumented by the granular IV. The sample includes non-granular firms only. Non-granular firms are defined as firms whose bank loan shares are less than the Pth percentile of the loan share distribution, which is pooled over all banks and years. Percentiles $\mathrm{P}=20,21, \ldots, 99$ are shown on the $\mathrm{x}$-axes and the $\mathrm{y}$-axes show point estimates and $90 \%$ confidence bands for each respective percentile. All regressions include Year $\times$ Industry $\times$ County $\times$ Firm and Bank fixed effects. 
Table 14: Firm Outcomes from Granular Credit Shocks: Accounting for Production Networks

\begin{tabular}{lcccccc}
\hline \hline & $(1)$ & $(2)$ & $(3)$ & $(4)$ & $(5)$ & $(6)$ \\
& Capital & Capital & Capital & Sales & Wage bill & Cash \\
\hline \multirow{2}{*}{$\Delta$ Bank Shock } & 0.089 & 0.311 & 0.383 & 0.004 & -0.099 & 0.165 \\
& $(0.061)$ & $(0.190)$ & $(0.650)$ & $(0.075)$ & $(0.108)$ & $(0.290)$ \\
\hline E(dependent variable) & -0.088 & -0.093 & -0.101 & 0.019 & 0.025 & 0.065 \\
SD(dependent variable) & 0.579 & 0.641 & 0.712 & 0.333 & 0.357 & 0.917 \\
Year-industry-county FE & Yes & Yes & Yes & Yes & Yes & Yes \\
Firm FE & Yes & Yes & Yes & Yes & Yes & Yes \\
Non-Granular Firms (50\%) & No & Yes & No & Yes & Yes & Yes \\
Non-Granular Firms (25\%) & No & No & Yes & No & No & No \\
Instrumented by GIV & Yes & Yes & Yes & Yes & Yes & Yes \\
Observations & 17002 & 7480 & 2736 & 8250 & 8474 & 8279 \\
\hline \hline
\end{tabular}

Notes: This table reports results from firm-level regressions where the outcome variable is either firm-level year-onyear change in $\log$ (capital), $\log$ (sales), $\log$ (wage bill), or $\log$ (cash). The sample is restricted only to firms operating in sectors for which other sectors (including the firms own sector) account for at most $6.7 \%$ of the total demand (first quartile of inter-sector exposures). Sectoral linkages are obtained using the input-output tables for the Norwegian economy. The main independent variable is the year-on-year change in bank-level aggregated firm shocks which are instrumented by the granular IV. Specifications are based on equation (10). The granular instrument is constructed based on equation (6). Non-granular firms are defined as firms whose bank loan shares are less than the 50th or 25th percentile of the loan share distribution. For firms with multiple banking relationships, we define a firm as non-granular if the largest loan share of that firm across all credit relationships is less than the 50th or the 25th percentile of the loan share distribution. For these firms, the bank shock is computed as the average across all lending relationships. The full distribution of loan shares is plotted on Figure 1. All specifications include interacted year x industry x county fixed effects and firm fixed effects. Standard errors (in parentheses) are clustered at the firm level. 
Table 15: Firm Bankruptcy from Granular Credit Shocks: Accounting for Production Networks

\begin{tabular}{|c|c|c|c|c|c|c|c|c|}
\hline \multirow[t]{2}{*}{ Probit Model } & (1) & (2) & (3) & (4) & (5) & (6) & (7) & (8) \\
\hline & \multicolumn{7}{|c|}{ Probability of bankruptcy $\mathrm{t}_{\mathrm{t}}$} & $\begin{array}{l}\text { Ever } \\
\text { bankrupt }\end{array}$ \\
\hline$\Delta$ Bank Shock $_{\mathrm{t}}$ & $\begin{array}{l}-0.170 \\
(0.255)\end{array}$ & $\begin{array}{c}0.184 \\
(0.440)\end{array}$ & $\begin{array}{c}0.281 \\
(0.655)\end{array}$ & & & & & \\
\hline$\Delta$ Bank Shock $_{\mathrm{t}-1}$ & & & & $\begin{array}{l}-0.203 \\
(0.271)\end{array}$ & $\begin{array}{l}-1.154 \\
(0.444)\end{array}$ & $\begin{array}{l}-2.435 \\
(0.714)\end{array}$ & & \\
\hline$\Delta$ Bank Shock $\mathrm{t}_{-3}$ & & & & & & & $\begin{array}{l}-0.777 \\
(0.511)\end{array}$ & \\
\hline$\Delta$ Bank Shockt & & & & & & & & $\begin{array}{l}-0.833 \\
(0.664)\end{array}$ \\
\hline Non-Granular Firms (50\%) & No & Yes & No & No & Yes & No & Yes & Yes \\
\hline Non-Granular Firms (25\%) & No & No & Yes & No & No & Yes & No & No \\
\hline Instrumented by GIV & Yes & Yes & Yes & Yes & Yes & Yes & Yes & Yes \\
\hline Observations & 13590 & 8209 & 4704 & 11391 & 6795 & 3855 & 4097 & 8209 \\
\hline
\end{tabular}

Notes: This table reports results from firm probit regressions of likelihood of firm bankruptcy on the bank-level granular credit shock. The sample is restricted only to firms operating in sectors for which other sectors (including the firms own sector) account for at most $6.7 \%$ of the total demand (first quartile of inter-sector exposures). Sectoral linkages are obtained using the input-output tables for the Norwegian economy. In columns (1)-(7), the outcome variable is probability of contemporaneous firm bankruptcy. In column (8), the outcome variable is the probability that a firm ever goes bankrupt. In columns (1)-(3), the main independent variable is the contemporaneous mean (change in the) bank-level credit shock which is instrumented by the granular IV. In columns (4)-(7), the main independent variable is the GIV-instrumented bank-level credit shock lagged by either one or three years. Columns (1) and (4) are for all firms in sample. Remaining columns restrict the sample to non-granular firms only. Non-granular firms are defined as firms whose bank loan shares are less than the 50th or the 25th percentiles of the loan share distribution, which is pooled over all banks and years. For firms with multiple banking relationships, we define a firm as non-granular if the largest loan share of that firm across all credit relationships is less than the 50th or the 25th percentile of the loan share distribution. For these firms, the bank shock is computed as the average across all lending relationships. The full distribution of loan shares is plotted on Figure 1. Standard errors in parentheses. Firm bankruptcy information is from the credit rating agency Bisnode. 
Figure 7: Firm Outcomes and Bankruptcy from Granular Credit Shocks: Accounting for Production Networks with a Discrete Measure of Downstream Supply Chains

(a) Capital

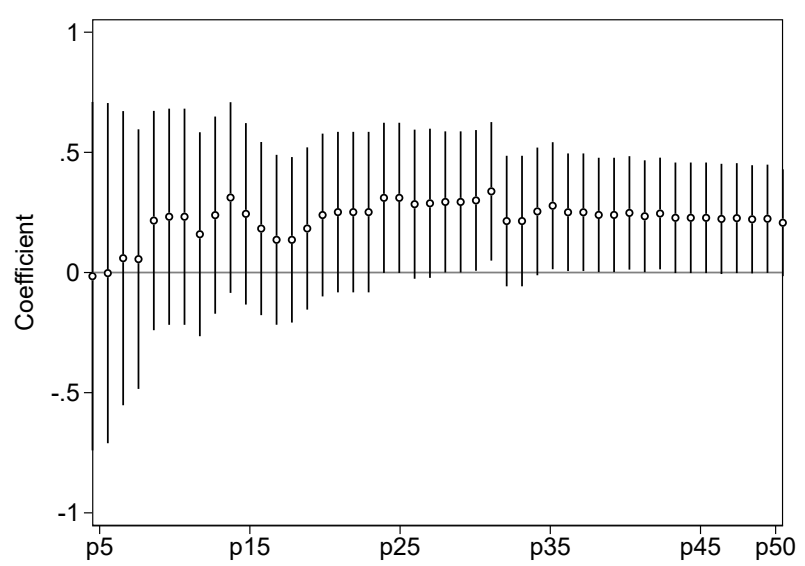

(b) Probability of Bankruptcy

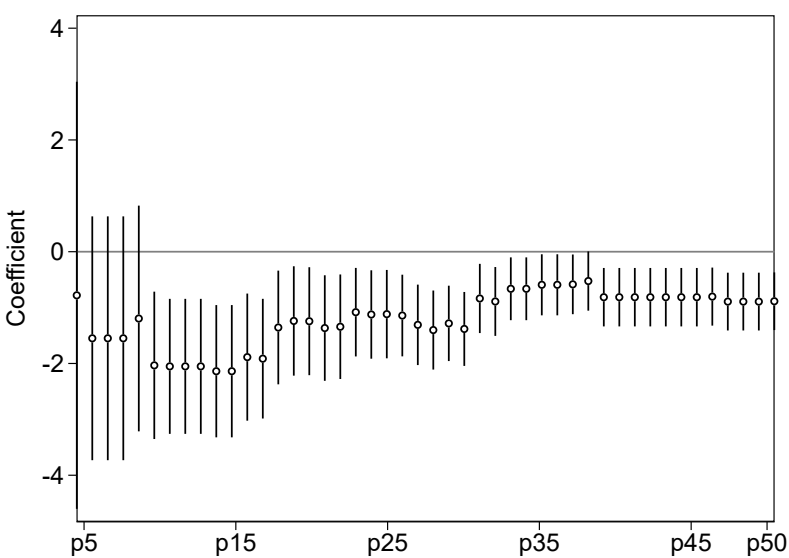

Notes: This figure reports results from either firm-level regressions of year-on-year changes in (log)capital (left panel) or probit regressions of likelihood of firm bankruptcy (right panel) on changes in the bank-level granular credit shock, instrumented by the GIV. The sample is restricted only to firms operating in sectors in the Pth percentile of the distribution of maximum inter-sector exposures. The inter-sector exposure is defined in Section 5.3 and obtained using input-output tables for the Norwegian economy. The samples, indicated by their percentile cut-offs $P=5,6, \ldots, 50$, are shown on the $x$-axes and the $y$-axes show point estimates and $90 \%$ confidence bands obtained on each respective sample. In the left panel we report estimation results obtained by running the same regression specification as in Table 14 Column (2). In the right panel estimation results are obtained from running the same specification as in Table 15 Column (5). 


\section{E Narratives}

In this section we validate our baseline idiosyncratic firm shock $\epsilon_{\mathrm{j}, \mathrm{t}}$ with a narrative-based approach. It is important to confirm that $\epsilon_{\mathrm{j}, \mathrm{t}}$ truly reflect economically meaningful information about firm performance. We focus on the bottom 1 st percentile of realizations of $\epsilon_{\mathrm{j}, \mathrm{t}}$ in the final shock distribution used in our analysis and search through the Norwegian news media for corresponding narratives. ${ }^{7}$ In a lot of cases, some of which are outlined below, we find that our idiosyncratic shock matches actual, sizable economic events.

One of the most adverse shocks in our sample was experienced by Hera Vekst - a waste management company - in 2008. For that year, we estimate an unexpected idiosyncratic shock $\epsilon_{\mathrm{j}, \mathrm{t}}$ of -1.39 , corresponding to approximately an unexpected drop in value added of $-139 \%$. This drop was seemingly generated by the sudden closure of the company's main facility, enforced by local authorities. Local authorities enforced the closure due to the company's repeated violation of air pollution standards. According to local news reports, the smell from the waste management facility was "far in excess of what the local population should tolerate" (nrk.no, 2011).

The company Nergard Sild, a mid-sized herring farmer, experienced an idiosyncratic shock $\epsilon_{\mathrm{j}, \mathrm{t}}$ of -1.2 in 2010 according to our estimates. National news reports attributed this loss to overinvestment in a processing facility for herring (nrk.no, 2012). The investment had been planned in 2009 "when the quota was 1 million tons." Once the realized quota turned out to be much smaller than expected (370,000 tons), Nergard Sild closed down the processing facility, leading to substantial losses.

Staying in the domain of fish farming, another major shock in our sample is for the company Wilsgard Fiskeoppdrett. Wilsgard Fiskeoppdrett - a fish farming company specializing in salmon - experienced an idiosyncratic shock of -1.23 in 2015. According to national media, the reason for this drop was a massive outbreak of salmon lice (iLaks.no, 2015). The outbreak was so severe that the Norwegian Food Safety Authority threatened the company with a daily fine until the situation got under control, worrying that the outbreak would spread along the coast.

Subaru Norge AS - the lead importer of Subaru in Norway - had an idiosyncratic shock of -1.21 in 2007 according to our estimates. The drop was generated by a tax hike on gasoline-fueled cars, which changed the relative price on gasoline-fueled vs. diesel-fueled cars. While the tax was levied on all gasoline-fueled cars, Subaru was the only major brand without a viable diesel alternative (DN, 2007). As a consequence, the number of new cars sold for Subaru dropped from 3800 to 344 cars by August the following year.

The horticulture company F.Dalene Gartneri AS had an idiosyncratic shock of -1.17 in 2008 . According to local news media, the manager of the company was engaged in substantial fraud,

\footnotetext{
${ }^{7}$ The 1 st percentile of the idiosyncratic shock distribution is -.905 , while the 5 th percentile is -.459 .
} 
which culminated in arson on the main facility to recoup an insurance premium of approximately 5 million USD (pd.no, 2011).

Fraud is the reason for another one of the most negative shocks in our sample. FIBO an aluminum producer - experienced an idiosyncratic shock of -1.25 in 2007 according to our estimates, which ultimately lead to their subsequent bankruptcy in 2009. The bankruptcy trustee had substantial criticism towards the board of the company, going far in pointing to outright fraud and stating that the case was so severe that its "report would and should be sent to the Financial Supervisory Authority for further study" (jarlsbergavis.no, 2011).

Next, consider the case study of the furniture producer Ekornes, which in 2015 had an estimated idiosyncratic shock of -1.24 . The company blamed adverse conditions in the German consumer market, one of their largest client bases. Looking for the causes, the CEO of Ekornes pinpointed the uncertain economic environment and the conflict between Russia and Western Europe. "Germans are careful. They save in bad times. The conflict between Western Europe and Russia has affected Germans more than in Norway" (e24.no, 2014).

Other notable shocks in our sample include the shipping company Volstad Shipping, which in 2008 experienced an idiosyncratic shock of -1.28 due to misplaced foreign currency positions (smp.no, 2012), and the company Bergen Group Intech which in 2010 experienced an idiosyncratic shock of -1.33 due to under-performance of their investments in Iceland. Those assets were subsequently sold due to "not being within the core areas of the company" (Finansavisen, 2011).

Our estimated shocks also pick up less dramatic events. For instance, consider the firm GC Rieber Oils, a firm specializing in producing Omega 3-based products. In 2013, they recorded an $\epsilon_{\mathrm{j}, \mathrm{t}}$ of -0.24 . The incident which caused this, according to local newspapers, was an accidental spill of between 500 and 800 litres of raw material from the company's factories into the local harbor (Naeringsliv, 2013). The spill was eventually managed and dealt with thanks to the local municipality and fire services. The spill lead to "substantial economic losses" for the company, according to the CEO (Naeringsliv, 2013). 


\section{F Robustness Tests and Auxiliary Empirical Findings}

Figure 8: Granularity in Equity Portfolios of U.S. Institutional Investors

(a) All Investors

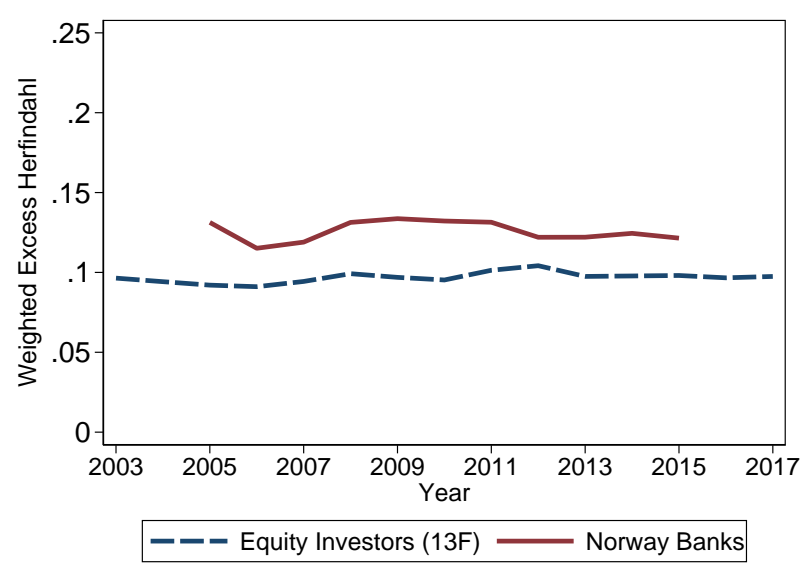

(b) Investor Types

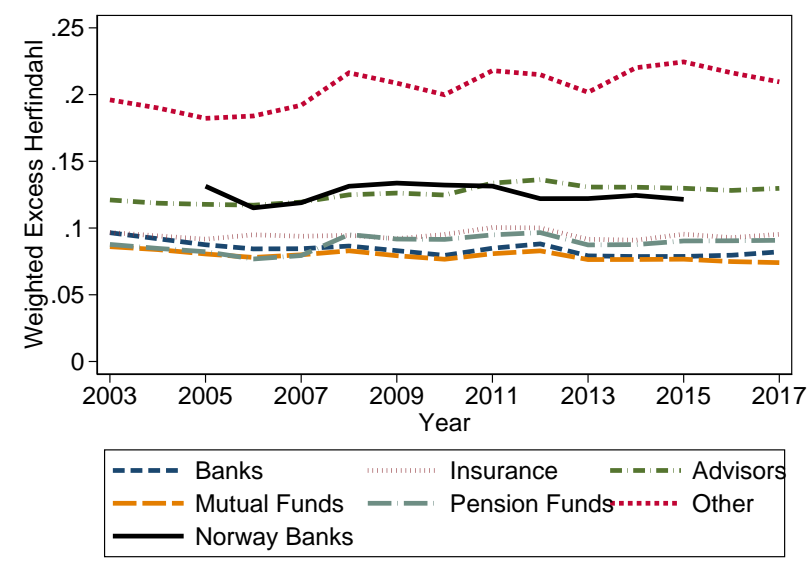

Notes: This figure plots weighted excess Herfindahl indices for equity portfolios of U.S. institutional investors and corporate loan portfolios of Norwegian banks. Institutional investor data comes from SEC Form 13F filings and was obtained from Thomson/Refinitiv. Investor types are from Koijen and Yogo (2018) and have been corrected for measurement and labelling errors. 
Figure 9: Pairwise Cross-Sectional Correlation of Firm Shocks

\section{Panel A: Histogram}

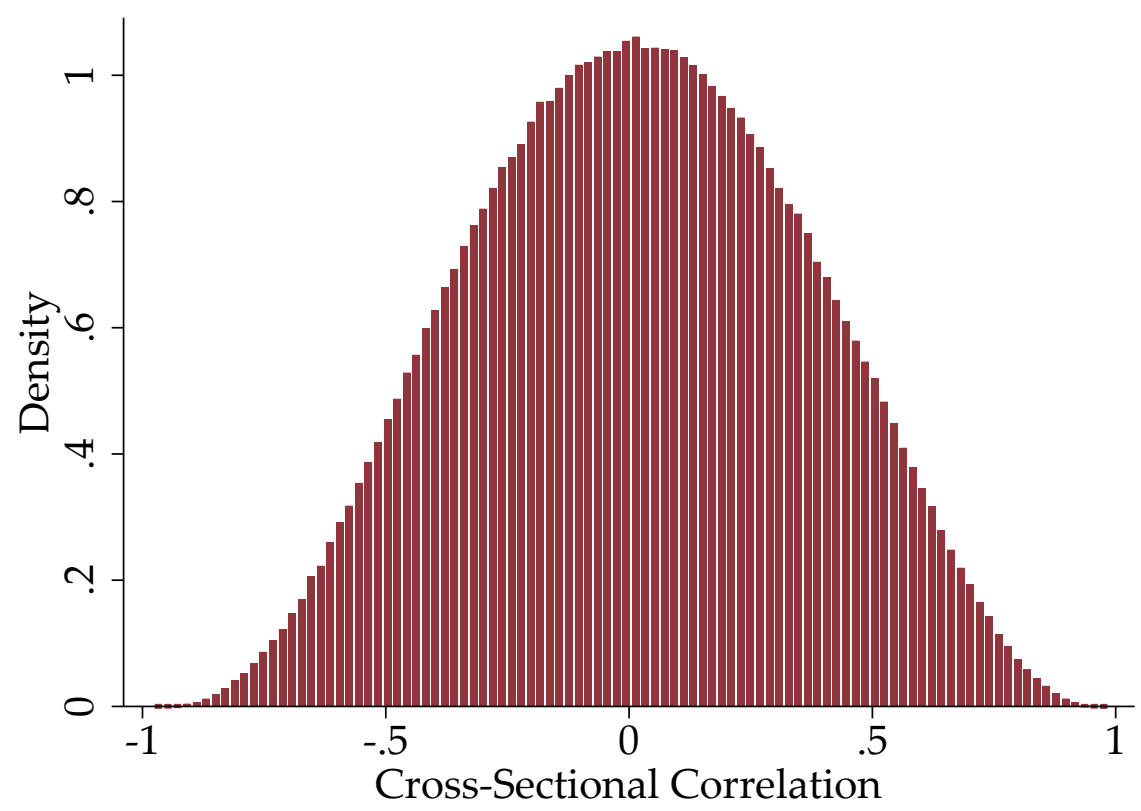

Panel B: Summary Statistics

\begin{tabular}{cccccc} 
& Number of Pairs & Mean & Std. Dev. & Min & Max \\
\hline Firm Shock & $1,861,485$ & 0.019 & 0.342 & -0.977 & 0.985 \\
\hline \hline
\end{tabular}

Notes: These figures report all pairwise cross-sectional correlation coefficients for idiosyncratic firm shocks. The sample includes a balanced panel of firms over 2003-2015. Panel A presents the histogram, and Panel B reports summary statistics. Firm shocks are extracted based on specification 1. 
Table 16: Robustness to the Great Financial Crisis

\begin{tabular}{lcccccc}
\hline \hline & $(1)$ & $(2)$ & $(3)$ & $(4)$ & $(5)$ & $(6)$ \\
\cline { 2 - 7 } Firm Shock & \multicolumn{3}{c}{ Loan-Level } & \multicolumn{3}{c}{ Bank-Level } \\
\cline { 2 - 7 } & 0.361 & 0.432 & 0.322 & 0.117 & 0.091 & 0.108 \\
& $(0.018)$ & $(0.032)$ & $(0.022)$ & $(0.029)$ & $(0.051)$ & $(0.037)$ \\
\hline All Fixed Effects & Yes & Yes & Yes & Yes & Yes & Yes \\
Bank Controls & & & & Yes & Yes & Yes \\
Observations & 292825 & 102879 & 189946 & 1211 & 472 & 737 \\
$\mathrm{R}^{2}$ & 0.167 & 0.158 & 0.172 & 0.101 & 0.066 & 0.127 \\
\hline \hline
\end{tabular}

Notes: This table reports timing robustness for baseline loan- and bank-level regressions from Tables 2 and 3, respectively. Columns (1)-(3) report results of loan and columns (4)-(6) of bank outcomes, respectively. Columns (1) and (4) are baseline estimates. Columns (2) and (5) include only the pre-2009 period. Columns (3) and (6) include only the post-2009 period. 
Table 17: Placebo Regressions - Permutation Tests

\begin{tabular}{lcccc}
\hline \hline & Simulations & True Coefficient & Event Frequency & Event P-value \\
\cline { 2 - 5 } & \multicolumn{4}{c}{ Loan Outcomes } \\
\hline Permuted Firm Shock & 1000 & 0.361 & 0 & 0.000 \\
\hline Permuted Firm Shook, Pooled & 1000 & 0.116 & 0 & 0.000 \\
Permuted Firm Shock, Positive Only & 1000 & 0.016 & 838 & 0.838 \\
Permuted Firm Shock, Negative Only & 1000 & 0.194 & 0 & 0.000 \\
\hline \hline
\end{tabular}

Notes: This table reports results from Monte Carlo permutation regressions where loan or bank return on loans are regressed on firm shocks that are randomly permuted. The last two rows report results when permuted shocks are positive or negative only, respectively. Columns report the number of simulations, the true coefficients based on Table 2 column (3) and Table 3 columns (3)-(5), the number of events where permutations produced estimates that are as large as the true estimate (in absolute value) by chance, and the associated p-values. 
Table 18: Placebo Regressions - Random Shocks

\begin{tabular}{lccccc}
\hline \hline & Number of Draws & Mean & Std. Dev. & Min & Max \\
\cline { 2 - 5 } & \multicolumn{5}{c}{ Loan Outcomes } \\
\hline Placebo Firm Shock & 1000 & 0.001 & 0.007 & -0.018 & 0.021 \\
\hline & 1000 & 0.000 & 0.005 & -0.016 & 0.018 \\
\hline Placebo Firm Shook, Pooled & 1000 & 0.001 & 0.018 & -0.053 & 0.049 \\
Placebo Firm Shock, Positive Only & 1000 & -0.000 & 0.014 & -0.041 & 0.046 \\
Placebo Firm Shock, Negative Only & \multicolumn{5}{c}{ Bank Outcomes } \\
\hline \hline
\end{tabular}

Notes: This table reports results from a placebo exercise where loan or bank outcomes are regressed on sequences of randomly generated numbers. In each row, placebo shocks are randomly drawn from the interval of the true shock. The last two rows report results when shocks are positive or negative only, respectively. Columns report the number of random draws and summary statistics of the regression coefficients: mean, standard deviation, minimum, and maximum. 
Table 19: Impact of Aggregate Shocks

\begin{tabular}{lccc}
\hline & $(1)$ & $(2)$ & $(3)$ \\
\hline Granular Credit Shock & 0.117 & & \\
& $(0.030)$ & & \\
Log (GDP) & & 0.348 & \\
& & $(0.075)$ & \\
Log (Oil Price) & & & 0.522 \\
& & & $(0.029)$ \\
Bank FE & Yes & Yes & Yes \\
Year FE & Yes & No & No \\
Bank Controls & Yes & Yes & Yes \\
Observations & 1211 & 1211 & 1211 \\
$\mathrm{R}^{2}$ & 0.627 & 0.152 & 0.242 \\
\hline \hline
\end{tabular}

Notes: this table presents results from bank-level regressions of bank-level returns on corporate loans on idiosyncratic and aggregate shocks. In column (1) the main regressor is the baseline GIV-instrumented idiosyncratic firm shock measure. In columns (2)-(3) the main regressors are the standardized logs of Norwegian real GDP and Brent oil prices, respectively. All specifications include the usual set of bank controls. Standard errors (in parentheses) are clustered at the bank level. 
Table 20: Estimating Fixed Effect Linear Models with AR(1) Disturbances

\begin{tabular}{lcccc}
\hline \hline & Borrower Level & Bank Level & Firm Industry Level & County Level \\
\hline Autoregressive Coef. & 0.318 & 0.122 & 0.241 & 0.223 \\
Standard Deviation & 0.267 & 0.107 & 0.254 & 0.251 \\
\hline \hline
\end{tabular}

Notes: This table reports parameter estimates of a linear unbalanced panel fixed effects model with a disturbance that follows an autoregressive process of order 1. Estimates for the autoregressive coefficient and the standard deviation of the error term are reported. Columns report results for various levels of aggregation. Idiosyncratic firm shocks are extracted based on specification 1 and then aggregated to different levels with loan shares as weights. 
Table 21: Theoretical Model Parameter Estimates

\begin{tabular}{ccccc}
\hline \hline Firm Size & \multicolumn{3}{c}{ Parameters } & Loan Distribution Variance \\
\hline \multirow{2}{*}{ Sales } & $\alpha$ & $\lambda$ & $\alpha \tau$ & \\
& 1.26 & 1.005 & 1.388 & Infinite \\
Assets & 1.321 & 0.923 & 1.587 & \\
& $(0.001)$ & $(0.361)$ & $(0.887)$ & Infinite \\
Equity & 1.495 & 1.086 & 1.641 & Infinite \\
& $(0.002)$ & $(0.467)$ & $(1.144)$ & \\
\hline \hline
\end{tabular}

Notes: This table reports estimates of key parameters of the model described in Section 7. $\alpha, \lambda$ and $\alpha \tau$ represent the Pareto power parameter of the firm size distribution, the firm's debt demand elasticity, and the sufficient statistic of the Singh-Maddala distribution, respectively. Standard errors (standard deviations for $\lambda$ and $\alpha \tau$ ) are in parentheses. 


\section{G Proof of Proposition 1}

The strategy of the proof follows closely Appendix 1 and Proposition 2 in Gabaix (2011). First, we show that L, which follows the Singh-Maddala distribution, satisfies Assumptions 1-2 below:

Assumption 1: $\lim _{1 \rightarrow \infty} \mathbb{P}\left(\mathrm{L}_{1}>\mathrm{x}\right) / \mathbb{P}\left(\left|\mathrm{L}_{1}\right|>\mathrm{x}\right)=\kappa \in[0,1]$

Assumption 2: $\mathbb{P}\left(\left|\mathrm{L}_{1}\right|>\mathrm{x}\right)=\mathrm{x}^{-\alpha} \mathrm{B}(\mathrm{x})$ with $\mathrm{B}(\mathrm{x})$ a slow-moving function.

Assumption 1 is verified trivially because $\mathrm{SM}$ is defined on the non-negative real line. Assumption 2 holds once we re-write: $\mathbb{P}\left(\left|\mathrm{L}_{1}\right|>\mathrm{x}\right)=\mathrm{x}^{-\alpha}\left(\frac{\mathrm{x}}{1+\mathrm{x}^{\tau}}\right)^{\alpha}$. So, $\mathrm{B}(\mathrm{x})=\left(\frac{\mathrm{x}}{1+\mathrm{x}^{\tau}}\right)^{\alpha}$. For $\tau=1$, the function is clearly slow-moving. Generally, for $\tau>0$ we must show that:

$$
\lim _{x \rightarrow \infty} B(t x) / B(x)=\frac{\lim B(t x)}{\lim B(x)}=1
$$

for any $\mathrm{t}>0$ and for as long as the denominator is $\neq 0$. $\lim _{\mathrm{x} \rightarrow \infty} \mathrm{B}(\mathrm{x})=\lim _{\mathrm{x} \rightarrow \infty}\left[\frac{\mathrm{x}}{1+\mathrm{x}^{\tau}}\right]^{\alpha}=$ $\lim _{\mathrm{x} \rightarrow \infty}\left[\frac{1}{1 / \mathrm{x}+\mathrm{x}^{\tau-1}}\right]^{\alpha}=1$. Similarly for $\mathrm{B}(\mathrm{tx})$.

Next, we construct three sequences $\left(a_{n}, b_{n}, s_{n}\right)$ that constitute the infinite sum across firms. $a_{n}=$ $\inf \left(\mathrm{x}: \mathbb{P}\left(\left|\mathrm{L}_{1}\right|>\mathrm{x}\right) \leq 1 / \mathrm{N}\right) \sim\left(\mathrm{N}^{1 / \alpha}-1\right)^{1 / \tau} \approx \mathrm{N}^{\frac{1}{\alpha \tau}} . \mathrm{b}_{\mathrm{n}}=\mathrm{n} \mathbb{E}\left(\mathrm{L}_{1} 1_{|\mathrm{L}| \leq \mathrm{a}_{\mathrm{n}}}\right)=0$. And $\mathrm{s}_{\mathrm{n}}=\sum_{\mathrm{i}}^{\mathrm{N}} \mathrm{L}_{\mathrm{i}}$. Thus:

$$
\lim _{\mathrm{N} \rightarrow \infty}\left(\mathrm{N}^{\frac{1}{\alpha \tau}}\right)^{-1} \sum_{\mathrm{i}}^{\mathrm{N}} \mathrm{L}_{\mathrm{i}} \stackrel{\mathrm{d}}{\rightarrow} \eta \sim \operatorname{Lévy}(\alpha \tau)
$$

In the remainder of the proof, we apply equation (25) to the case of constant $\sigma$, i.e. when firmliability volatility is constant over time and not correlated cross-sectionally. When $\alpha \tau>2$, standard Lindeberg-Lévy applies. When $1<\alpha \tau<2$, the loan portfolio Herfindahl decays according to:

$$
\mathrm{N}^{1-\frac{1}{\alpha \tau}} \frac{\left(\mathrm{N}^{\frac{-2}{\alpha \tau}} \sum_{\mathrm{i}}^{\mathrm{N}} \mathrm{L}_{\mathrm{i}}^{2}\right)^{1 / 2}}{\mathrm{~N}^{-1} \sum_{\mathrm{i}}^{\mathrm{N}} \mathrm{L}_{\mathrm{i}}} \stackrel{\mathrm{d}}{\rightarrow} \frac{\mathrm{Lévy}^{1 / 2}}{\mathbb{E}(\mathrm{L})}
$$

When $1<\alpha \tau<2$, the denominator (mean of Singh-Maddala) is finite. Since firm-level volatilities are constant, and Lévy is a stable random variable, the volatility of loan growth will be therefore decaying at the rate proportional to $\mathrm{N}^{1-\frac{1}{\alpha \tau}}$ :

$$
\sigma_{\mathrm{D}} \sim \frac{1}{\mathrm{~N}^{1-1 /(\alpha \tau)}} \text { Lévy }^{1 / 2} \sigma
$$

For $\tau=1$ we are in the special case of Singh-Maddala collapsing to the Pareto II distribution and 
standard results in Gabaix (2011) are obtained up to the slow-moving function $\mathrm{B}($.). For $\tau \neq 1$ but $\tau>0$, the sufficient statistic for the comparison of rates of convergence across finite and infinite variance cases is $\alpha \tau$. 


\section{References}

BAI, J. AND S. NG (2002): "Determining the number of factors in approximate factor models," Econometrica, 70, 191-221.

DN (2007): "Subaru salget stuper," https://www.dn.no/subaru-salget-stuper/1-1-982883.

E24.No (2014): "Ekornes sier de har sovet i timen," https://e24.no/boers-og-finans/ekornes-sierde-har-sovet-i-timen/23274867.

FinANSAVISEN (2011): "Bergen Group kvitter seg med to selskaper," https://finansavisen.no/nyheter/boers-finans/2011/07/bergen-group-kvitter-seg-med-toselskaper.

Gabaix, X. (2011): “The Granular Origins of Aggregate Fluctuations,” Econometrica, 79(3).

GABAIX, X. AND R. KoIJEN (2021): "In search of the origins of financial fluctuations: The inelastic markets hypothesis," NBER Wokring Paper 28967.

ILAKS.NO (2015): “Trues med dagmulkt,” https://ilaks.no/trues-med-dagmulkt/.

JARLSBERGAVIS.NO (2011): "Kritikk etter Fibo-konkursen," https://www.jarlsbergavis.no/nyheter/kritikk-etter-fibo-konkursen/s/1-67-5793472.

JuElsRud, R. E. AND E. G. WOLD (2020): "Risk-weighted capital requirements and portfolio rebalancing," Journal of Financial Intermediation, 41.

Koijen, R. And M. Yogo (2018): “A Demand System Approach to Asset Pricing,” Journal of Political Economy, Forthcoming.

NAERINGSLIV, D. (2013): “Bandak-konsernet overende,” https://www.tk.no/nyheter/slapp-ut-over500-liter-fiskeolje/s/1-113-6707592.

NRK.NO (2011): "Slutt for Hera Vekst," https://www.nrk.no/innlandet/slutt-for-hera-vekst1.7792540 .

— (2012): "Nergard legger ned i Bo," https://www.nrk.no/nordland/nergard-legger-ned-i-bo1.8834498 .

PD.NO (2011): “Gartnerens store tragedie,” https://www.pd.no/lokale-nyheter/gartnerens-storetragedie/s/1-89-5759714.

SMP.NO (2012): “Kjempear for Volstad Shipping," https://www.smp.no/nyheter/article240019.ece.

Stock, J. H. AND M. W. WATson (2016): "Dynamic factor models, factor-augmented vector autoregressions, and structural vector autoregressions in macroeconomics," in Handbook of macroeconomics, Elsevier, vol. 2, 415-525. 